UNIVERSIDADE DE SÃO PAULO

ESCOLA DE ENFERMAGEM

TATIANA YONEKURA

A OPERACIONALIZAÇÃO DO CONCEITO DE CLASSE SOCIAL NA EPIDEMIOLOGIA: UMA REVISÃO SISTEMÁTICA

SÃO PAULO

2011 


\title{
A OPERACIONALIZAÇÃO DO CONCEITO DE CLASSE SOCIAL NA EPIDEMIOLOGIA: UMA REVISÃO SISTEMÁTICA
}

\author{
Dissertação apresentada à Escola de \\ Enfermagem da Universidade de São Paulo \\ para obtenção do título de Mestre em \\ Ciências.
}

Área de concentração: Cuidado em Saúde

Orientadora: Prof ${ }^{\mathrm{a}}$. Dr ${ }^{\mathrm{a}}$. Cássia Baldini Soares

\section{SÃO PAULO}




\section{AUTORIZO A REPRODUÇÃO TOTAL OU PARCIAL DESTE TRABALHO, POR QUALQUER MEIO CONVENCIONAL OU ELETRÔNICO, PARA FINS DE ESTUDO E PESQUISA, DESDE QUE CITADA A FONTE.}

Assinatura:

Data:

Catalogação na Publicação (CIP)

Biblioteca "Wanda de Aguiar Horta"

Escola de Enfermagem da Universidade de São Paulo

Yonekura, Tatiana

A operacionalização do conceito de classe social na epidemiologia: uma revisão sistemática / Tatiana Yonekura. -São Paulo, 2011.

$167 \mathrm{p}$.

Dissertação (Mestrado) - Escola de Enfermagem da Universidade de São Paulo.

Orientadora: Prof ${ }^{\mathrm{a}}$ Dr $^{\mathrm{a}}$ Cássia Baldini Soares

1. Classes sociais 2. Epidemiologia 3. Processo saúde-doença 4. Saúde coletiva - Revisões 5. Desigualdades sociais I. Título. 


\section{Tatiana Yonekura}

A operacionalização do conceito de classe social na epidemiologia: uma revisão sistemática

Dissertação apresentada à Escola de Enfermagem da Universidade de São Paulo para a obtenção do título de Mestre em Ciências.

Área de concentração: Cuidado em Saúde.

Aprovado em:

Banca Examinadora

Prof. Dr.

Instituição:

Julgamento:

Assinatura:

Prof. Dr.

Instituição:

Julgamento:

Assinatura:

Prof. Dr.

Instituição:

Julgamento:

Assinatura: 


\section{AGRADECIMENTOS}

À professora Cássia Baldini Soares, pela orientação cuidadosa, admirável competência, paciência, sinceridade, confiança e rigor metodológico. Obrigada por acreditar neste projeto e pela parceria e companheirismo desde a graduação.

Aos pesquisadores do Joanna Briggs Institute Sarahlouise Jones, Craig Lockwood, Catalin Tufanaru e Dianne Gall, pelas revisões críticas, discussões e sugestões importantes que enriqueceram este trabalho.

Ao Centro Brasileiro para o Cuidado à Saúde Baseado em Evidências, principalmente à Prof ${ }^{a} D^{a}{ }^{a}$ Diná de Almeida Lopes Monteiro da Cruz, pelo interesse e acompanhamento de todo o processo.

À Prof ${ }^{a}$ Dra Célia Maria Sivalli Campos, pelo apoio, incentivo e influência desde a graduação.

Ao Prof. Dr. Reinaldo Jose Gianini e à Prof ${ }^{a} D^{a}$ Marilisa Berti de Azevedo Barros, pela participação e contribuição no Exame de Qualificação.

Aos trabalhadores da AD (enfermeiras, auxiliares de enfermagem, assistentes sociais, fisioterapeutas e oficiais administrativos), pelo acolhimento, apoio e compreensão. Em especial à Cidinha, Cintia, Cris, Edna, Edson, Eleir, Eliane, Eloísa, Fátima, Fernanda, Jorge, Mariana, Rosário e Tarcísio. À enfermeira Gislaine, pelos conselhos, apoio e discussões filosóficas vespertinas sobre a vida e trabalho, sempre muito bem-humoradas.

Aos trabalhadores da EEUSP, pelo acolhimento durante a graduação $e$ pós-graduação, principalmente à Terezinha, Nadir e Silvana da Pós, pelo apoio e simpatia.

Às amigas da graduação e pós-graduação (muitas já mestres e futuras grandes doutoras!). Especialmente à Adriana drika, Aline, Laiane, Márcia e Sayuri, companheiras do início ao fim desta jornada. Saudades da convivência diária, dos bons e não tão bons momentos... 
Aos queridos amigos de longa data e de todas as horas Olívia, Tiago e Raquel, pela convivência desde o colégio, alegres momentos desde então.

Aos companheiros de grupo de pesquisa Carla, Heitor, Miguel, Sheila $e$ Vilmar, pela convivência mensal e semanal em tempos passados, pelo aprendizado e discussões enriquecedoras. À Elaine, pelas ótimas aulas de estatística.

Aos meus pais, por tudo!

Ao Ricardo, Marcelo e Bia, pelo imprescindível companheirismo e carinho em todos os âmbitos da vida.

À minha família, pelo apoio incondicional e incentivo desde sempre.

À Fundação de Amparo à Pesquisa de São Paulo (FAPESP), pela concessão da bolsa de mestrado (Processo: 2008/08884-7).

Minha eterna gratidão! 
Desconfiai do mais trivial,

na aparência singelo.

E examinai, sobretudo, o que parece

habitual.

Suplicamos expressamente:

não aceiteis o que é de hábito como coisa

natural,

pois em tempo de desordem sangrenta,

de confusão organizada,

de arbitrariedade consciente,

de humanidade desumanizada,

nada deve parecer natural

nada deve parecer impossível de mudar

Nada é impossivel de mudar

Bertolt Brecht

Isso é tão vasto

que ultrapassa qualquer entender. Entender é sempre limitado.

Mas não entender pode não ter fronteiras.

sinto que sou muito mais completa quando não entendo.

Não entender, do modo como falo, é um dom. Não entender, mas não como um simples de espírito.

O bom é ser inteligente e não entender.

É uma benção estranha, como ter loucura sem ser doida.

É um desinteresse manso,

é uma doçura de burrice.

Só que de vez em quando vem a

inquietação:

quero entender um pouco.

Não demais:

mas pelo menos entender que não entendo.

Não entendo

Clarice Lispector 
Yonekura T. A operacionalização do conceito de classe social na epidemiologia: uma revisão sistemática [dissertação]. São Paulo: Escola de Enfermagem, Universidade de São Paulo; 2011.

\section{RESUMO}

Os objetivos deste estudo foram: descrever e analisar as produções científicas internacionais e nacionais que tratam da operacionalização do conceito de classe social na epidemiologia e da relação entre classe social e processo saúde-doença. Partiu-se dos fundamentos da Saúde Coletiva, como referencial teórico, que toma como sujeito a categoria classe social, entendendo que a utilização deste conceito na epidemiologia é importante e relevante para o estudo das desigualdades sociais. $\mathrm{O}$ estudo é uma revisão sistemática teórica e quantitativa, sendo que os procedimentos metodológicos seguem as recomendações do Joanna Briggs Institute (JBI). A revisão teórica foi utilizada para encontrar os modelos de classe social e a revisão quantitativa para evidenciar a relação classe social e processo saúde-doença. Foram selecionadas 16 bases de dados na área de ciências sociais, saúde e multidisciplinar para a busca bibliográfica, além de descritores e palavras para a seleção dos estudos. Era necessária a descrição de um modelo operacional de classe social para a inclusão do estudo teórico. Já na parte quantitativa, o critério era realização de estudo epidemiológica do tipo coorte ou caso-controle com a utilização de um modelo de classe. Após a elaboração de estratégias de busca, 22.314 estudos foram encontrados e 5.994 estudos foram pré-selecionados e armazenados em um gerenciador de bibliografia. Após a exclusão de 2.377 estudos duplicados e 49 não disponíveis online, 1890 estudos foram lidos na íntegra. Em relação à parte teórica, 28 trabalhos foram incluídos, sendo que nove latino-americanos, quatro americanos e 15 europeus. Mais da metade dos estudos foram publicados nas décadas de 70 e 80 . É possível identificar dois critérios que diferenciaram as classes e subsidiaram a elaboração dos modelos latino-americanos: a inclusão de variáveis relacionadas ao poder de consumo e outras relacionadas à inserção no processo de produção. Já os modelos teóricos americanos e europeus utilizaram predominantemente variáveis relacionadas à inserção no processo de produção. Em relação aos resultados quantitativos, 123 estudos foram incluídos, sendo 108 estudos de coorte $(87,8 \%)$ e 15 do tipo caso-controle $(12,2 \%)$. A maioria dos estudos epidemiológicos mostrou associações positivas entre classe social e saúde, além de problemas de saúde mais prevalentes entre as classes classificadas como aquelas com menor acesso à riqueza social. Considerando as dificuldades na identificação das desigualdades sociais na contemporaneidade, os modelos de classe social devem contemplar as características socioeconômicas nacionais e regionais de cada país, além das mudanças no mundo do trabalho e suas especificidades. Os estudos epidemiológicos devem considerar a utilização da categoria classe social para identificação das desigualdades sociais e assim dar respostas adequadas às necessidades de saúde, compreendidas, a partir das considerações teóricas da Saúde Coletiva, como necessidades sociais mais amplas.

Palavras-chave: Classe social; Epidemiologia; Processo Saúde-doença; Saúde Coletiva; Revisão sistemática; Desigualdade social. 
Yonekura T. The measurement of social class in epidemiology: a systematic review [dissertation] São Paulo: Escola de Enfermagem, Universidade de São Paulo; 2011.

\begin{abstract}
The objectives of this study were to describe and analyze the international scientific production dealing with the measurement of social class in epidemiology and the relationship between social class and health disease process. This essay had as theoretical framework the concepts underlying the field of Collective Health that takes social class as one essential analytical category. The study is a theoretical and quantitative systematic review, which follows the methodological recommendations of the Joanna Briggs Institute (JBI). Theoretical search was used to find models of social class and quantitative search was used to evidence the relation between social class and health disease process. Inclusion criteria were: description of a model of social class used in epidemiological studies and case-control and cohort studies that used a model of social class. We selected 16 databases in social sciences, health care and multidisciplinary for literature search, and multiple combinations of key words for the selection of studies. After the development of search strategies for each database, 22.314 studies were found and 5.994 studies were pre-selected and stored in a bibliography manager. After exclusion of 2.377 duplicate and 49 unavailable studies, 1.890 papers were read in full. In relation to theoretical results, 28 papers were included, of which nine were Latin American, four American and 15 European. More than half of the studies were published in the 70 's and 80's. It is possible to identify the main criteria that differentiate the classes and that support the development of the models: the inclusion of variables related to insertion in the production process. In relation to quantitative results, 123 studies were included, of which 108 were cohort studies $(87,8 \%)$ and 15 case-controls $(12,2 \%)$. Most studies showed positive associations between social class and health, as well as higher prevalence of health problems among the lower classes. There is a need to measure the concept of classes, considering changes in the contemporary world of work, overcoming the difficulties of this theoretical and methodological reference. Epidemiological studies should consider the use of social class category to identify health inequalities and thus provide answers that actually respond to health needs of the different social classes.
\end{abstract}

Keywords: Social Class; Epidemiology; Health Disease Process; Collective Health; Systematic Review. 


\section{LISTA DE SIGLAS}

\begin{tabular}{|c|c|c|}
\hline ANDI & - & Agência de Notícias dos Direitos da Infância \\
\hline AHRQ & - & Agency for Healthcare Research and Quality \\
\hline ASSIA & - & Applied Social Sciences Index and Abstracts \\
\hline $\mathrm{ABA}$ & - & Associação Brasileira de Anunciantes \\
\hline ABIPEME & - & Associação Brasileira de Institutos de Pesquisa de Mercado \\
\hline ABRASCO & - & Associação Brasileira de Pós-Graduação em Saúde Coletiva \\
\hline ASSIA & - & Applied Social Sciences Index and Abstracts \\
\hline CAPES & - & Coordenação de Aperfeiçoamento de Pessoal de Nível Superior \\
\hline CNDSS & - & Comissão Nacional Sobre Determinantes Sociais na Saúde \\
\hline CASP & - & Critical Appraisal Skills Programme \\
\hline CINAHL & - & Cumulative Index to Nursing and Allied Health Literature \\
\hline DARE & - & Database of Abstracts of Reviews of Effects \\
\hline DOAJ & - & Directory of Open Access Journals \\
\hline EBMR & - & Evidence-Based Medical Reviews \\
\hline EUA & - & Estados Unidos da América \\
\hline FTA & - & Formas de Trabalhar Adequadas \\
\hline FTI & - & Formas de Trabalhar Inadequadas \\
\hline FVA & - & Formas de Viver Adequadas \\
\hline FVI & - & Formas de Viver Inadequadas \\
\hline FAPESP & - & Fundação de Amparo à Pesquisa do Estado de São Paulo \\
\hline GSH & - & Grupo Social Homogêneo \\
\hline IBGE & - & Instituto Brasileiro de Geografia e Estatística \\
\hline JBI & - & Joanna Briggs Institute \\
\hline IBSS & - & International Bibliography of the Social Sciences \\
\hline MESH & - & Medical Subject Headings \\
\hline NICE & - & National Institute for Health and Clinical Excellence \\
\hline NIHRHTA & - & $\begin{array}{l}\text { National Institute for Health Research/Health Technology } \\
\text { Assessment Programme }\end{array}$ \\
\hline NBI & - & Necessidades Básicas Insatisfeitas \\
\hline NBS & - & Necessidades Básicas Satisfeitas \\
\hline NPF & - & Nível de Pobreza Federal \\
\hline
\end{tabular}




$\begin{array}{ll}\text { OMS } & - \text { Organização Mundial da Saúde } \\ \text { OPAS } & - \text { Organização Pan-Americana da Saúde } \\ \text { PEA } & - \text { População Economicamente Ativa } \\ \text { SEP } & - \text { Posição Socioeconômica } \\ \text { SM } & - \text { Salário Mínimo } \\ \text { AIDS } & - \text { Síndrome da Imunodeficiência Adquirida } \\ \text { SES } & - \text { Status Socioeconômico } \\ \text { TRIP } & - \text { Turning Research into Practice } \\ \text { WHO } & - \text { World Health Organization }\end{array}$




\section{LISTA DE QUADROS}

Quadro 1 - Características das Teorias da Unicausalidade e 28 Multicausalidade e da Tríade Ecológica de Leavell e Clark.

Quadro 2 - Diferenças conceituais da Epidemiologia Hegemônica e da 35 Epidemiologia Crítica.

Quadro 3 - Características da formação de castas segundo Marx e Weber, 38 descritas por Hirano (2006).

Quadro 4 - Diferenças entre estamento e classe segundo Marx Weber (1999).

Quadro 5 - Descrição das bases de dados secundárias incluídas.

Quadro 6 - Bases de dados incluídas na busca bibliográfica de acordo com a área de conhecimento que abrange.

Quadro 7 - Bases de dados incluídas na busca bibliográfica de acordo com a área de conhecimento, período de análise, número de registros e tipo de publicação.

Quadro 8 - MeSH e sinônimos selecionados para a busca bibliográfica.

Quadro 9 - Estratégias de busca utilizadas de acordo com as bases de dados.

Quadro 10 - Estudos não identificados em base de dados.

Quadro 11 - Caracterização dos estudos latino-americanos incluídos sobre a operacionalização do conceito de classe.

Quadro 12 - Definição das diferentes propostas latino-americanas de operacionalização do conceito de classe de acordo com a estrutura de classe, diferença entre classes e a inserção na produção.

Quadro 13 - Limites de adequação para a classificação das famílias.

Quadro 14 - Caracterização dos estudos incluídos sobre a operacionalização do conceito de classe.

Quadro 15 - Definição das diferentes propostas americanas e européias de operacionalização do conceito de classe de acordo com a estrutura de classe, diferença entre classes e a inserção na produção.

Quadro 16 - Caracterização dos estudos epidemiológicos incluídos quanto ao título, autor, ano de publicação e revista.

Quadro 17 - Estudos incluídos por periódico e origem do periódico.

Quadro 18 - Caracterização dos estudos incluídos sobre a relação classe social e saúde. 


\section{LISTA DE TABELAS}

Tabela 1 - Estratificação social de acordo com o enfoque das teorias e dos autores relevantes.

Tabela 2 - Número de estudos identificados e pré-selecionados de acordo com a base de dados.

Tabela 3 - Estudos quantitativos incluídos segundo a base de dados.

Tabela 4 - Estudos teóricos incluídos segundo a base de dados.

Tabela 5 - Número de estudos publicados sobre modelos operacionais latino-americanos de classe social por década de publicação.

Tabela 6 - Classificação dos estudos em Grupo 1 e Grupo 2 de acordo com o enfoque teórico.

Tabela 7 - Critérios isolados utilizados para identificar a divisão de classe nos modelos operacionais do conceito de classe social utilizados na epidemiologia.

Tabela 8 - Critérios isolados utilizados para identificar a divisão de classe nos modelos operacionais do conceito de classe social utilizados na epidemiologia, de acordo com a origem do estudo.

Tabela 9 - Critérios isolados utilizados para identificar a divisão de classe nos modelos operacionais do conceito de classe social utilizados na epidemiologia.

Tabela 10 - Número de critérios combinados utilizados para identificar as classes sociais de acordo com a origem dos modelos.

Tabela 11 - Variação do número de modelos de classe social em relação ao número de classes.

Tabela 12 - Estudos latino-americanos incluídos segundo referencial teórico.

Tabela 13 - Estudos norte-americanos e europeus incluídos segundo referencial teórico. 
Tabela 15 - Descrição dos estudos de coorte e caso-controle segundo população estudada, associação entre o objeto e classe social e maior risco de problemas de saúde por classe.

Tabela 16 - Estudos epidemiológicos incluídos segundo a análise da 122 categoria classe social. 


\section{LISTA DE GRÁFICOS}

Gráfico 1 - Número de estudos publicados sobre modelos operacionais do conceito de classe social por década de publicação.

Gráfico 2 - Número de modelos operacionais de classe e número de 106 estudos epidemiológicos por década de publicação. 


\section{LISTA DE FIGURAS}

Figura 1 - Modelo conceitual do Joanna Briggs Institute de saúde 51 baseada em evidências.

Figura 2 - Etapas do processo de seleção e inclusão dos estudos. 


\section{Sumário}

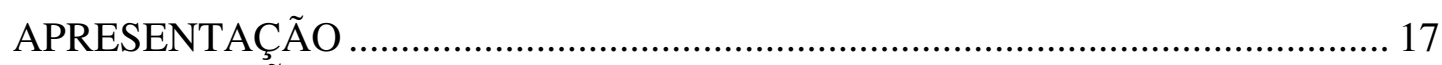

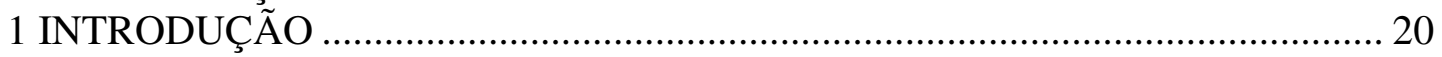

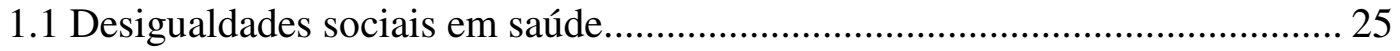

1.2 Desigualdades sociais e Epidemiologia …………………………………........ 27

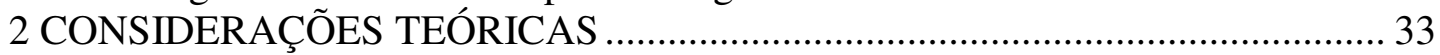

2.1 Processo saúde-doença na perspectiva da Saúde Coletiva................................... 33

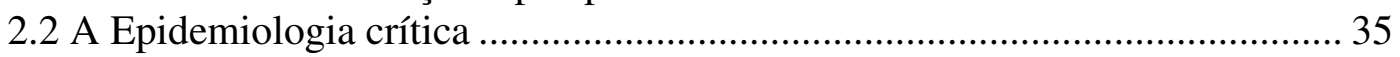

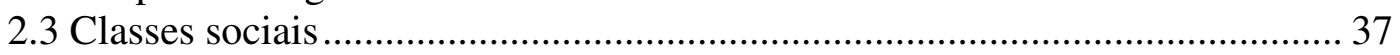

2.4 A operacionalização do conceito de classe social............................................. 42

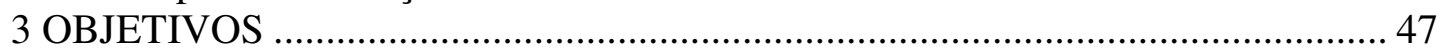

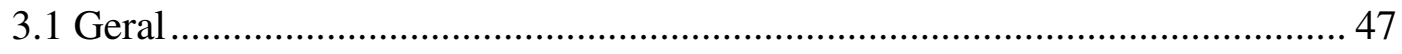

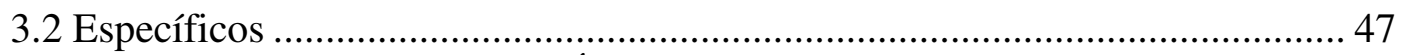

4 PROCEDIMENTOS METODOLÓGICOS .......................................................... 49

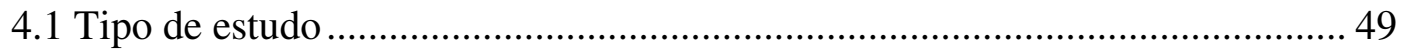

4.2 Etapas de uma revisão sistemática ............................................................ 52

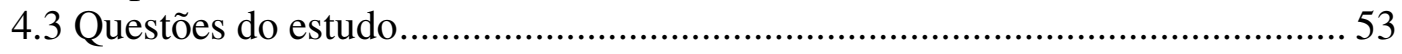

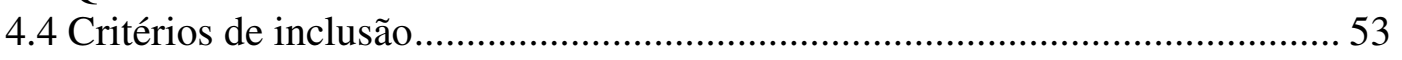

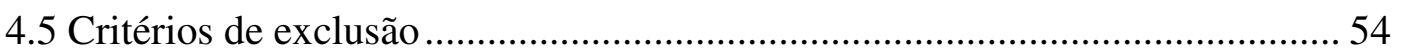

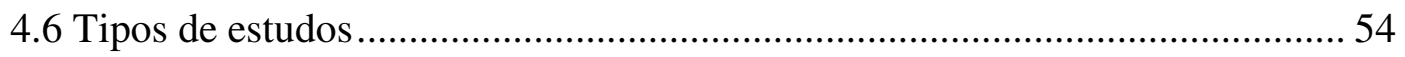

4.7 Tipos de participantes ................................................................................ 54

4.8 Tipos de intervenção/fenômeno de interesse …………………………………... 55

4.9 Estratégia de busca para identificação dos estudos............................................. 55

4.10 Seleção e avaliação da qualidade dos estudos...................................................... 64

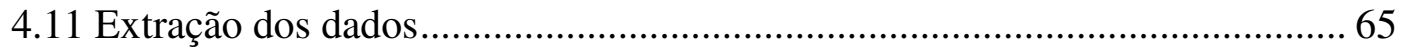

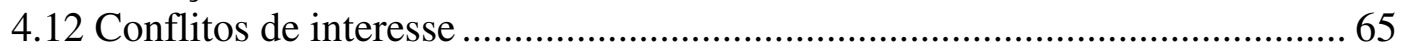

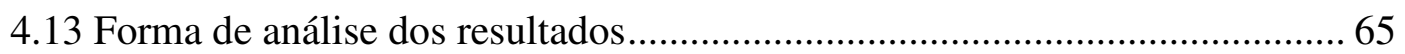

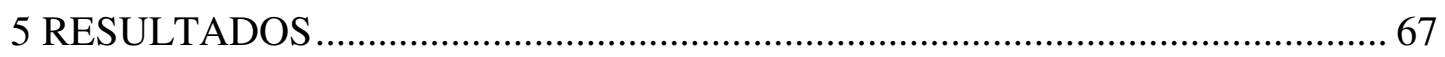

5.1 PARTE 1 - MODELOS OPERACIONAIS DO CONCEITO DE CLASSE

SOCIAL NA EPIDEMIOLOGIA ................................................................... 71

5.1.1 Modelos latino-americanos .......................................................................... 71

5.1.2 Modelos de operacionalização do conceito de classe na América do norte

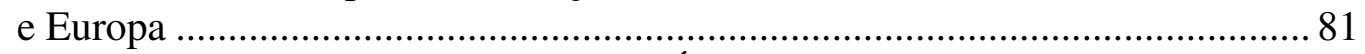

5.2 PARTE 2 - ESTUDOS EPIDEMIOLÓGICOS QUE UTILIZARAM UM MODELO DO CONCEITO DE CLASSE SOCIAL …………………………….... 93

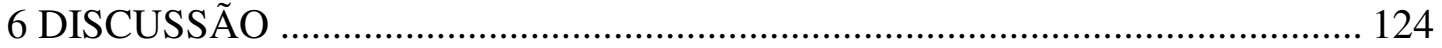

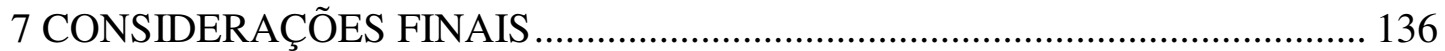

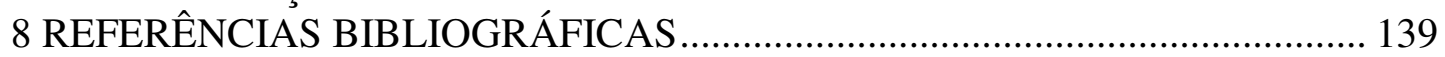

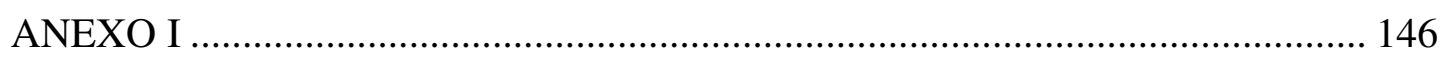

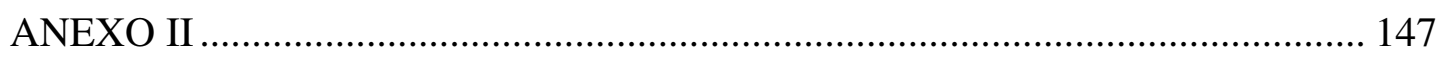

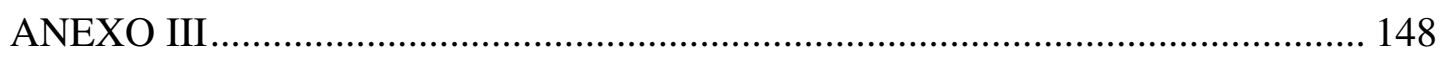

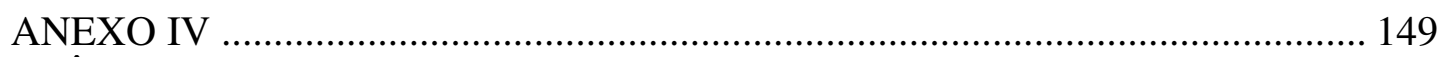

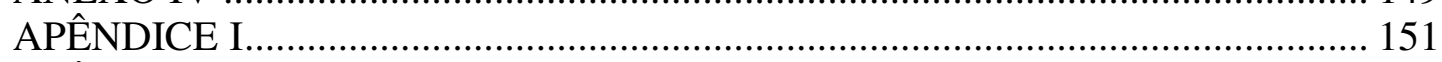

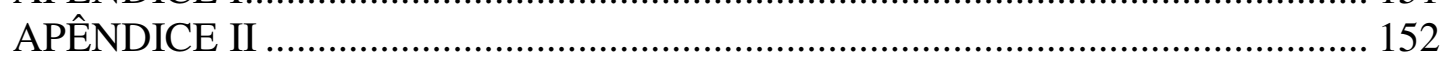

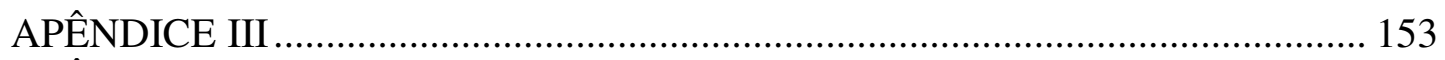

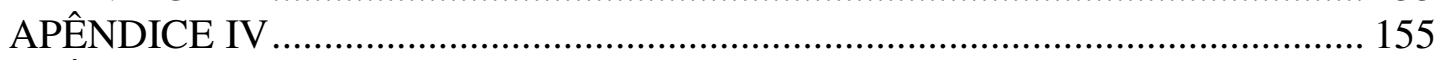

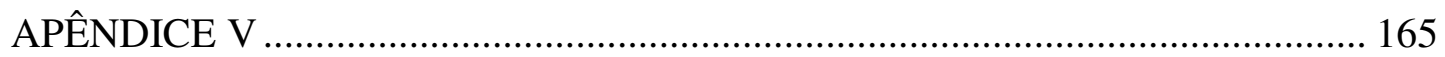




\section{APRESENTAÇÃO}

Durante a graduação, tive a oportunidade de estudar o núcleo conceitual do campo da Saúde Coletiva e trabalhar com os perfis epidemiológicos de grupos sociais de uma área de abrangência de uma unidade básica de saúde. Após esta primeira aproximação, comecei a frequentar o grupo de pesquisa "Fortalecimento e desgaste no trabalho e na vida: bases para a intervenção em saúde coletiva" em 2007. Além disso, iniciei um projeto de iniciação científica, denominado "Mapa da Juventude de Santo André", cujo objetivo era mapear a distribuição da desigualdade socioeconômica e demográfica de jovens de 15 a 24 anos do município de Santo André, a partir de dados secundários do Censo Demográfico de 2000.

Nesse projeto, foram selecionados 57 dados socioeconômicos e demográficos, relativos à reprodução social dos jovens, tomando-se por referência a construção teórica que reúne padrões de inserção na produção (condições de trabalho) e padrões de inserção no consumo (condições de vida) para servir de base à captação de dados empíricos, em diferentes realidades sociais.

Foram identificados quatro grupos sociais distribuídos pelo município, através de um método estatístico que selecionou 13 variáveis referentes às condições de trabalho e condições de vida. O mapeamento mostrou-se potente para revelar diferenças sociais entre os jovens.

No mestrado, o foco foi o aprofundamento dos estudos das desigualdades sociais, mais especificamente sobre a operacionalização do conceito de classe social na epidemiologia e a relação entre classes sociais e processo saúde-doença.

Foi elaborado um protocolo ${ }^{1}$ referente a este projeto de pesquisa de acordo com as orientações do Instituto Joanna Briggs (JBI), especializado em conduzir, avaliar e divulgar revisões sistemáticas. O protocolo foi submetido à apreciação crítica em junho de 2009, sendo aprovado em dezembro de 2009. Durante esse período, pesquisadores do JBI emitiram pareceres com críticas e sugestões para o aprimoramento desta revisão. A partir de maio de 2010, passei a ser membro do Centro Colaborador no Brasil na qualidade de Pesquisador Colaborador.

\footnotetext{
${ }^{1}$ Disponível no site: http://www.joannabriggs.edu.au/protocols/Protocol313.pdf
} 
Este trabalho ${ }^{2}$ congrega parcela da pesquisa intitulada Jovens, valores $e$ consumo de drogas: políticas públicas na perspectiva da saúde coletiva ${ }^{3}$, cujo objetivo geral é o de sistematizar um arcabouço teórico-metodológico e operacional para intervenção junto a jovens, baseado nos valores sociais e relativos ao consumo de drogas em diferentes classes sociais, sob o ponto de vista da Saúde Coletiva, com a finalidade de alicerçar o desenvolvimento de políticas públicas de prevenção na área.

\footnotetext{
${ }^{2}$ Financiado pela FAPESP, através de bolsa de mestrado (Processo 08/08884-7).

${ }^{3}$ Financiada pela FAPESP, através de auxílio pesquisa - edital de Pesquisa em Políticas Públicas (Processo 06/51671-9).
} 
1 INTRODUÇÃO 


\section{INTRODUÇÃO}

O objeto deste trabalho é a operacionalização do conceito de classe social na epidemiologia na perspectiva da Epidemiologia Crítica.

A utilização de modelos operacionais de classe social tem se configurado como proposta oportuna e pertinente no contexto internacional e principalmente no Brasil, em decorrência das graves e históricas desigualdades sociais regionais e intra-regionais.

A evolução demográfica brasileira foi marcada por profundas modificações sociais que impactaram nas condições de trabalho, de vida e de saúde da população e criaram enormes disparidades regionais. A transição demográfica é um processo social que condiciona as diversidades regionais e sociais, através de fenômenos históricos e estruturais. Particularmente, no Brasil, este fenômeno ocorreu de forma desorganizada no século passado, com a intensa urbanização e o significante crescimento populacional, acelerados nas últimas décadas, determinando principalmente mudanças na pirâmide populacional, com aumento de idosos e diminuição da fecundidade, e aumento vertiginoso da desigualdade social (Brito, 2008).

O êxodo rural que ocorreu no Brasil principalmente nas décadas de 60 e 70 estava relacionado ao processo de industrialização da região Sudeste, que atraiu muitos nordestinos, e às novas fronteiras agrícolas das regiões Centro-Oeste e Norte que atraíram trabalhadores do Sul e agricultores sem terra (Prata, 1994).

A introdução de novas técnicas de produção agrícola e a persistência das modalidades arcaicas de posse da terra obrigaram os trabalhadores a sair das áreas rurais mais valorizadas, impedindo o desenvolvimento das novas formas de produção no campo que contemplassem, além da acumulação, a produtividade, a justiça social e a preservação do meio ambiente (Sabroza, Toledo, Osani, 1992).

Prata (1994) refere que os migrantes eram "refugiados sociais" que se submeteram a piores condições de vida, já que a maioria foi morar nas periferias dos centros urbanos com precárias condições de subsistência. Um padrão particular de mortalidade por doenças infecciosas e causas externas entre os migrantes e o impacto nas condições de vida e de trabalho puderam ser observados. 
É importante ter em mente as implicações de todos estes fatores (históricos, políticos e econômicos) como determinantes das existentes desigualdades no bem-estar, na saúde e na mortalidade entre aqueles beneficiados pelo crescimento econômico e aqueles mantidos a sua margem (Prata, 1994, p.390).

O desenvolvimento das sociedades subdesenvolvidas gerou uma estrutura de segmentos pobres da população, compostos por desempregados, subempregados e trabalhadores pobres. Essa estrutura é consequência do desenvolvimento desigual no contexto capitalista (Berlinck, 1975).

A noção de marginalidade que por muito tempo foi relacionada com uma população excedente e inútil economicamente é enfatizada por Santos (1978) que indaga: "mas, pode-se porventura admitir que esses indivíduos são economicamente marginais, porque contribuem pouco para o crescimento econômico do qual também pouco se beneficiam?"

Marx, em O Capital, ressalta o papel do exército industrial de reserva que não está inserido economicamente, mas é uma força de trabalho excedente capaz de garantir a reprodução e acumulação do capital. As chamadas "massas marginais", decorrentes da migração rural-urbana, podem ser consideradas pouco marginais, pois desempenham uma das funções do exército industrial de reserva, o de diminuição da remuneração do trabalho (Berlinck, 1975).

Entretanto, muitos autores contestam a utilização do termo marginalidade, pela própria dificuldade de conceituação. Berlinck (1975) questiona o que são populações marginais, se são favelados, desempregados, subempregados, todos os pobres?

A problemática social na vertente marxista é discutida por Netto (1992) que analisa a "questão social" em uma perspectiva de classe que se expressa na contradição capital - trabalho no capitalismo.

A intervenção estatal sobre a "questão social" se realiza, com as características que já anotamos, fragmentando-a e parcializando-a. E não pode ser de outro modo: tornar a "questão social" como problemática configuradora de uma totalidade processual específica é remetê-la concretamente à relação capital/trabalho - o que significa, liminarmente, colocar em xeque a ordem burguesa (Netto, 1992, p.28).

O "pauperismo", fenômeno da "questão social", afetou a classe trabalhadora urbana, devido à perversa produção capitalista que apesar da 
crescente produção de bens e serviços, não permitia o acesso de um também crescente número de trabalhadores a essas riquezas (Netto, 1992).

Santos (1978) enfatiza o fenômeno da expansão da pobreza, considerando que este não seja um processo neutro e se diferencie de forma particular de acordo com as diversas realidades sociais, já que os processos não ocorrem uniformemente em uma sociedade de classes.

Pobreza é, sobretudo, um problema social que implica uma privação não só material, mas também de um modo de vida. Entretanto, a abordagem da pobreza, principalmente, nos países subdesenvolvidos, é dificultada pela falta de instrumentos de pesquisa eficientes e por problemas de interpretação das estatísticas públicas e pela heterogeneidade das informações (Santos, 1978).

Fundamentos conceituais importantes encontram-se na base das várias formas de avaliar diferenças sociais, sendo possível observar utilização bastante difundida das chamadas classificações socioeconômicas.

No Brasil, a classificação socioeconômica teve destaque primeiramente na área de marketing na década de 70, quando a Associação Brasileira de Anunciantes (ABA) propôs um sistema de estratificação que identificava quatro classes socioeconômicas (A, B, C e D), através da pontuação relativa à posse de bens (oito itens), presença de empregada e ao grau de instrução do chefe da família. Até então, não havia padronização nos critérios de estratificação para verificar o poder de consumo das famílias (Mattar, 1995).

Em 1976, após diversas críticas, as classes foram divididas em subclasses (A1, A2, B1, B2, C1, C2, D1 e D2) com a mudança dos pontos de corte das divisões. Já em 1978, a Associação Brasileira dos Institutos de Pesquisa de Mercado (Abipeme) introduziu o critério da ABA/Abipeme que adota cinco classes (A, B, C, D e E) com novos pontos de corte (Mattar, 1995).

A Abipeme define classe social através do poder aquisitivo das famílias e utiliza variáveis que discriminam os grupos sociais de acordo com sua capacidade de consumo. Mattar (1995) enfatiza a má utilização do conceito de classe social, já que, na sua avaliação, o conceito engloba outros importantes aspectos, além do econômico, e não inclui importantes variáveis para a discriminação de classes sociais, como ocupação do chefe de família, renda familiar e tipo de residência. 
Além disso, o autor ressalta a "necessidade de desenvolvimento de um novo método, compreendendo variáveis mais estáveis e precisas" (Mattar, 1995, p.67).

Diversos índices e indicadores têm sido elaborados nas últimas décadas com a finalidade de aperfeiçoar a leitura das desigualdades sociais brasileiras. Campos et al (2004) destacam os seguintes índices: de exclusão social, de pobreza, de desigualdade e de emprego. Estes índices foram construídos através dos dados do Censo demográfico do Instituto Brasileiro de Geografia e Estatística e apresentam faixas numéricas para indicar a realidade social (Campos et al, 2004).

A desigualdade social pode ser comparada internacionalmente através do coeficiente de Gini que utiliza a variável renda total familiar per capita para classificar as famílias de um país. Esse coeficiente varia de 0 a 1 e quanto menor o valor, menor a diferença de renda entre as famílias. Através desta classificação, é possível identificar a sensível diminuição da desigualdade social brasileira iniciada na década de 90, após a estabilização da economia. Entretanto, o coeficiente ainda é muito elevado e a evolução temporal revela uma tendência muito lenta na diminuição da desigualdade (Ferreira, 1999).

Viana (1999) ressalta que os estudos sobre a mensuração das desigualdades sociais enfatizam a distribuição de renda, já que o que se mede são os rendimentos do trabalho, deixando de fora a distribuição real da riqueza. Outro problema é que:

\footnotetext{
Privilegia-se o aspecto mensuração em detrimento das causas, e quando se retoma o debate sobre as causas, os aspectos estruturais, que antes eram muito mensurados, são substituídos por maior relevância às dimensões relacionadas com oportunidades individuais, com escolha, com dotações individuais. Pobreza e desigualdade voltam a se confundir, e a desigualdade acaba sendo "engolida" pela pobreza. O discurso privilegia a desigualdade, mas enfoca a pobreza. Esse é o viés. E tem o lado real, que é o fato de, no Brasil, pobreza e desigualdade serem fenômenos extremamente imbricados (Viana, 1999, p.17).
}

Lopes (2008) utilizou outra metodologia que classifica os domicílios e as pessoas em três níveis de pobreza: indigentes, pobres não indigentes e não pobres, de acordo com a renda domiciliar per capita. Em seu estudo, através dessa classificação, foi observado um alto índice de domicílios urbanos indigentes e pobres não indigentes nas regiões Norte, Nordeste e Centro-Oeste, além de um 
menor índice nas metrópoles, em relação às regiões urbanas de um mesmo município (Lopes, 2008).

$\mathrm{O}$ autor também classifica as necessidades básicas em satisfeitas e insatisfeitas para analisar a pobreza mais profundamente. As necessidades básicas estão relacionadas às características físicas da habitação - tipo de domicilio, abastecimento de água, esgotamento sanitário, vaso sanitário e densidade por dormitório - e condições sociais - frequência à escola por crianças de até 11 anos. Se o pesquisador considerar alguma variável inadequada, as necessidades são classificadas como insatisfeitas. Já o cruzamento de domicílios considerados pobres e não pobres com os índices de necessidade básica resulta em uma nova classificação social:

- pobres estruturais - famílias abaixo da linha de pobreza e com necessidades básicas insatisfeitas;

- pobres mais recentes - famílias abaixo da linha de pobreza e com necessidades básicas satisfeitas;

- pobres por NBI - famílias acima da linha de pobreza e com necessidades básicas insatisfeitas;

- não pobres stricto sensu - famílias acima da linha de pobreza e com necessidades básicas satisfeitas.

Segundo dados do Censo de $2000^{4}, 70 \%$ dos jovens $(22.772 .911$ de um total de 50.179.471) tinham renda domiciliar per capita inferior a um saláriomínimo (SM) e $45 \%$ destes tinham renda menor que 0,5 SM. O mesmo fenômeno ocorre com a população idosa e na análise da população geral. A descrição da distribuição de renda por região, Estado e município também revela dados alarmantes e a necessidade de considerar as diferenças sociais em estudos populacionais.

Cattani (2007) ressalta que os temas relacionados à pobreza e desigualdades estavam em menos de $2 \%$ na mídia impressa e $0,7 \%$ nas principais revistas do Brasil, segundo dados da ANDI de 2003, embora sejam temas extremamente pertinentes à realidade brasileira.

Mattar (1995) destaca as características importantes de um bom modelo de estratificação social: estabilidade no tempo - evita revisões periódicas constantes;

${ }^{4}$ Ver em: http://www.ibge.gov.br 
consistência e precisão - possibilita resultados idênticos entre entrevistadores diferentes; comparabilidade - permite comparar os resultados e identificar evoluções ao longo do tempo; validade - correspondência entre a realidade e os resultados obtidos do modelo; e facilidade de aplicação.

A análise das desigualdades sociais com a utilização do conceito de classe social principalmente, na área da saúde, tem se mostrado mais abrangente e capaz de explicar os determinantes sociais do processo saúde-doença (Lombardi et al, 1988).

Compreender e sistematizar as formas de operacionalização desse conceito pode contribuir para a discussão sobre as desigualdades sociais na área da saúde e potencializar o uso do conceito nas pesquisas epidemiológicas.

\subsection{Desigualdades sociais em saúde}

O campo das ciências sociais em saúde é estudado nos países latinoamericanos há menos de quatro décadas por iniciativa das faculdades de medicina. A origem da sociologia da saúde foi marcada pelo período pós-guerra, sendo produto da "pós-modernidade" e das conturbações sociais ocorridas no século passado (Nunes, 2003).

Silva e Barros (2002) chamam a atenção para os diferentes significados dos conceitos de desigualdade e iniquidade. Para Breilh (1989) desigualdades sociais em saúde são produzidas pela inserção social desigual dos indivíduos que gera diferentes repartições da propriedade e do poder. Na sociedade capitalista, a desigualdade "é resultado da divisão da sociedade em classes, sendo estas definidas, predominantemente, pelo tipo de relação de seus integrantes com os meios de produção". Já o conceito de iniquidade incorpora a idéia de injustiça e tem sido empregado em estudos sobre desigualdade social para mensurar a histórica injustiça social. (Silva e Barros, 2002, p.376).

Desde o século XIX, diversas investigações epidemiológicas abordam a relação entre desigualdade social e condições de saúde, demonstrando piores condições de saúde entre as camadas mais pobres da população. Os estudos clássicos de Engels sobre a classe trabalhadora inglesa, de Virchow sobre a epidemia de tifo na Silésia e de Snow sobre a epidemia de cólera em Londres comprovam essa complexa relação (Rosen, 1994). Apesar da associação causal 
entre doença e meio, descoberta no estudo, Snow também relacionou a doença a modos de vida e de trabalho e a políticas públicas da época (Rouquayrol, 1993).

A Inglaterra é reconhecida como o país que explora há mais tempo a temática e divulga dados sobre mortalidade desde o século XIX. O acompanhamento das desigualdades sociais é realizado com a classificação inglesa "Registrar-General's Social Class Categories" que permite conhecer padrões e tendências das desigualdades sociais em saúde e alocar recursos públicos mais satisfatoriamente (Rose, 1995).

A abordagem da temática é relevante para documentar, explicar e reduzir as desigualdades sociais em saúde, sendo necessárias pesquisas para validar medidas de classe social, posição socioeconômica ou status socioeconômico. Conforme chamamos a atenção acima, esses três diferentes termos são utilizados de acordo com marcos teóricos específicos do pesquisador.

Krieger, Williams e Moss (1997) sistematizam a importância do estudo das desigualdades sociais na área da saúde em três pontos:

1) o primeiro é a forte relação entre posição socioeconômica e mortalidade e morbidade. Diversos estudos enfatizam a relação entre as condições de vida e de trabalho e os índices de mortalidade adulta e infantil, doenças crônicas, infecciosas e psiquiátricas.

2) o segundo refere-se à crescente desigualdade de renda e riqueza internacional acompanhadas das desigualdades socioeconômicas em saúde. Como justificativa, a autora descreve a evolução dos índices de concentração de renda dos EUA desde a década de 20 até 1994.

3) outra evidência indica a relação inversa entre as taxas de mortalidade e os indicadores de desigualdade social em saúde. Mesmo com o declínio das taxas de mortalidade, as desigualdades socioeconômicas em saúde nos países industrializados continuam aumentando.

A desigualdade social também é evidenciada em outras estatísticas vitais e nos estudos longitudinais de base populacional, considerados fontes importantes e indispensáveis de dados descritivos sobre a distribuição social da mortalidade e morbidade e tendências ao longo do tempo (Krieger, Williams, Moss, 1997).

O mesmo estudo sugere três recomendações para novas investigações (Krieger, Williams, Moss, 1997): 
1) são necessárias investigações para identificar como a relação indivíduo, família, e bairro e classe social e outros aspectos da posição socioeconômica se relacionam entre si e se combinam para afetar a saúde.

2) os estudos devem focar na dimensão histórica da posição socioeconômica, já que a pobreza adquire características peculiares ao longo do tempo, e analisar as suas consequências para a saúde.

3) a pesquisa deve investigar outros aspectos da posição socioeconômica e o impacto na saúde, como a classe social do indivíduo na infância.

\subsection{Desigualdades sociais e Epidemiologia}

A desigualdade social é uma temática estudada há muito tempo por diversas áreas de conhecimento e, especialmente, na área da saúde, tem constituído objeto de interesse de estudos científicos de forma controversa.

Epidemiologia é a ciência que estuda os determinantes do processo saúdedoença e a distribuição dos problemas de saúde em coletividades, visando medidas de prevenção, controle e erradicação de doenças. O conhecimento epidemiológico é associado às transformações históricas da sociedade, adquirindo diferentes formas, dependendo da maneira em que as concepções de saúde e doença e os conhecimentos científicos são compreendidos (Rouquayrol, 1993).

Tem como disciplinas básicas as ciências biológicas, sociais e a estatística e diferencia-se da clínica que explica os problemas de saúde na dimensão biológica como processo individual, o que permite quantificar o problema e identificar fatores isolados que se relacionam com o risco (Granda e Breilh, 1989; Rouquayrol, 1993).

A partir do século XIX, com o crescimento populacional intenso e a consolidação rápida e caótica do capitalismo, a epidemiologia teve um papel importante para identificar as condições de saúde do coletivo, no momento em que as deteriorações das condições de vida, trabalho e saúde aumentavam (Rosen, 1994). Na América Latina, onde a maioria dos países tinha características de dependência e subdesenvolvimento, a crise do capitalismo na década de 70 revelou a heterogeneidade da região e grandes contrastes sociais (Breilh e Granda; 1989; Gianini, 1995). 
Ao longo da história, diversas teorias vêm tentando explicar o aparecimento das doenças. A Teoria da Unicausalidade, a História Natural da doença e a Teoria da multicausalidade com sua variação, a tríade ecológica de Leavell e Clark, foram as mais utilizadas, sendo que a Teoria da Multicausalidade é a que predomina nos estudos epidemiológicos atuais (Rouquayrol, 1993). As desigualdades sociais não eram abordadas ou eram pouco exploradas nessas concepções.

Quadro 1 - Características das Teorias da Unicausalidade e Multicausalidade e a Tríade Ecológica de Leavell e Clark.

\begin{tabular}{|c|c|c|}
\hline Teoria Unicausal & Teoria Multicausal & Tríade Ecológica \\
\hline $\begin{array}{c}\text { Causa única do efeito- } \\
\text { doença }\end{array}$ & $\begin{array}{c}\text { Coexistência de várias } \\
\text { causas }\end{array}$ & $\begin{array}{c}\text { Três fatores } \\
\text { interrelacionados: agente, } \\
\text { ambiente e hospedeiro }\end{array}$ \\
\hline $\begin{array}{c}\text { Doença como elemento } \\
\text { externo }\end{array}$ & $\begin{array}{c}\text { Relação simétrica entre } \\
\text { fatores e causas das } \\
\text { doenças }\end{array}$ & $\begin{array}{c}\text { A doença é o desequilíbrio } \\
\text { de um desses fatores }\end{array}$ \\
\hline "Era bacteriológica" & Conceito de risco & Os fatores estão equilibrados \\
\hline
\end{tabular}

Fonte: Rouquayrol (1993) e Granda e Breilh (1989).

No início dos anos 60, a epidemiologia estabeleceu indicadores típicos como a prevalência, a incidência e o conceito de risco nos estudos observacionais e descritivos para explicar o aparecimento, a ocorrência e a magnitude das doenças (Almeida-Filho e Rouquayrol, 1990). Esses indicadores são os conteúdos básicos da epidemiologia clássica ou tradicional.

A epidemiologia clássica baseia-se na Teoria da Multicausalidade da doença que descreve o conceito de risco como a probabilidade de um indivíduo desenvolver ou morrer de uma doença, considerando a doença como o resultado de uma variedade de fatores. Nessa teoria, são enfatizados os conceitos das ciências biológicas e da estatística (Almeida-Filho e Rouquayrol, 1990).

O modelo de Leavell e Clark, um dos aplicativos mais populares dessa teoria, propõe diferentes níveis de prevenção em qualquer fase do processo saúde- 
doença com base na história natural da doença. A complexidade da doença é reduzida às dimensões individual e biológica, transformando toda a sociedade, com múltiplas determinações, e a categoria social do homem, em uma relação entre variáveis, com ou sem associação estatística (Rouquayrol, 1993; Breilh, 2006).

A maioria dos estudos epidemiológicos se limita a descrever a desigualdade social e sua influência sobre a saúde. No entanto, não há uma discussão sobre a determinação social do processo saúde-doença, o que paralisa o aprofundamento teórico e o progresso metodológico dos estudos epidemiológicos (Barros, 1983).

Doenças como hanseníase, difteria e tuberculose são mais prevalentes em determinados grupos populacionais, em uma relação direta com condições de vida precárias. As políticas públicas focadas principalmente em campanhas de controle e prevenção não conseguem erradicar essas doenças que há séculos assolam o Brasil (Sabroza, Toledo, Osani, 1992).

Assim, as medidas de intervenção são provisórias, paliativas e não atacam as raízes dos problemas. Considera-se também a mudança de hábitos e condutas do indivíduo para a diminuição dos fatores de risco em um modelo normativo que acaba por culpabilizar o indivíduo (Castellanos, 1987).

As estratégias de controle baseadas na culpabilização do indivíduo relativizam as discussões sobre as responsabilidades do Estado, já que ressaltam as responsabilidades individuais para a prevenção de doenças em grupos populacionais mais expostos (Sabroza, Toledo, Osani, 1992). Campanhas amplamente divulgadas na mídia exemplificam essa questão: sobre a saúde do homem: "Homem que se cuida, não perde o melhor da vida", sobre a prevenção da AIDS: "Se você não se cuidar, a AIDS vai te pegar", sobre o diabetes: "Diabetes - seu corpo fala: evite o açúcar e controle a glicemia". Sabroza, Toledo e Osani (1992) assinalam que o foco das ações está na diminuição da letalidade e de incapacidades.

Stotz (2007) atualiza a discussão sobre os chamados comportamentos individuais de risco como causa dos problemas de saúde e a implicação para as práticas em saúde. As ações dos serviços de saúde como a de adesão ao tratamento e de orientação para prevenção de comportamento "de risco" não 
levam em consideração as condições sociais que permanecem ocultas nos serviços de saúde. A solução normativa "você tem isso, deve fazer aquilo" ainda domina as ações para a resolução de problemas (Stotz, 2007).

O problema é que as relações entre os problemas percebidos no nível individual e os de sua relação mais ampla e determinação ou condicionamento social não são facilmente percebidas e compreendidas pelos indivíduos [...] Daí a importância de se entender as dificuldades que as pessoas têm de andar sua própria vida, vinculando, por meio da escuta e do diálogo, as experiências com as formas de enfrentar o adoecimento a hipertensão arterial, o diabetes, os transtornos mentais leves em regra decorrentes da desorganização da vida em razão de desemprego, insuficiência de renda, violência social, perda de ou rupturas na relação com pessoas queridas (Stotz, 2007, p.49-50).

A Epidemiologia clássica busca identificar o complexo de fatores interrelacionados que permite a intervenção. Classe social, idade e gênero são exemplos de fatores. A associação estatística fornece uma causa componente de uma doença, mas que não pode ser uma conclusão absoluta (Almeida Filho, Rouquayrol, 1990; Lucas, McMichael, 2005).

Apesar da influência das condições sociais na saúde ter sido identificada há muito tempo, desde os estudos de William Farr, que analisou as diferenças de expectativa de vida entre os nobres e os trabalhadores e Snow, as desigualdades sociais têm sido exploradas de forma superficial e descontextualizada de categorias de análise (Rouquayrol, 1993).

Minayo et al (2003) relatam a dificuldade da aplicação dos conceitos das ciências sociais na epidemiologia, além de uma utilização distante de forma ideológica ou de senso comum e muitas vezes incorreta desses conceitos. $\mathrm{Na}$ década de 70 e 80, as raras aproximações das ciências sociais na área da saúde no Brasil utilizavam a teoria marxista, com ênfase na aproximação mais positivista, como o althusseriano (Minayo et al, 2003).

Muitos profissionais da área da saúde questionam a aplicação das ciências sociais, devido ao alto nível de abstração dos conceitos e à dificuldade metodológica de inclusão do conhecimento na prática, sem que haja o distanciamento dos problemas e a ausência da perspectiva de ação. Entretanto, deve-se reconhecer o papel fundamental das ciências sociais na apreensão de categorias e conceitos centrais em suas especificidades históricas, como os de população e desigualdade (Minayo et al, 2003). 
$\mathrm{Na}$ epidemiologia, as desigualdades sociais são geralmente medidas pela posição socioeconômica (SEP - do inglês socioeconomic position), principalmente na dimensão particular, indicadores ou uma composição de indicadores. As aplicações da teoria marxista de classe social que identificam o local que um grupo ocupa na produção são exceções. Os trabalhos de Wright e Lombardi et al foram pioneiros na aplicação dessa teoria à epidemiologia (Galobardes, Lynch, Smith, 2007).

Assim, a desigualdade social pode ser analisada segundo duas categorias principais: uma associando os fatores socioeconômicos definidos e metodologicamente quantificados aos diferenciais de morbidade e mortalidade; e a outra que se refere à utilização do conceito de classe social (Rouquayrol, 1993).

Os diversos estudos teóricos contemporâneos relacionados com a desigualdade social e o conceito de classe social são baseados principalmente nas teorias clássicas de Marx e Weber, Wright, Bourdieu e concepções funcionalistas. 


\section{CONSIDERAÇÕES TEÓRICAS}




\section{CONSIDERAÇÕES TEÓRICAS}

\subsection{Processo saúde-doença na perspectiva da Saúde Coletiva}

O conceito de saúde-doença varia de acordo com a categoria de análise e o momento histórico e social de uma sociedade. Desde a definição de saúde como ausência de doença e a da OMS que afirma que "saúde é um estado de completo bem-estar físico, mental e social”, vários autores questionam a análise individual do processo saúde-doença.

Laurell (1983) critica o modelo multifatorial que além de desconsiderar a historicidade do processo saúde-doença, reduz o social a "fatores de risco". O processo saúde-doença é determinado pelo modo de trabalho específico de cada grupo populacional, no qual ocorrem os processos de reprodução que podem ser potentes para o aparecimento de doenças (Laurell, 1983).

Breilh (1991) reforça que é necessário transformar a epidemiologia e redimensionar a clínica, de forma que o social não seja interpretado, sob o paradigma da saúde reducionista, como um fator individual estatisticamente significativo associado aos problemas de saúde.

Parte-se da crítica à epidemiologia clássica, embasada na Saúde Pública, para construir um quadro teórico com uma abordagem mais abrangente, visando entender como as formas de trabalhar e as condições de vida estão relacionadas com o processo saúde-doença. Laurell (1983, p.151) compreende que "o caráter social do processo saúde-doença manifesta-se empiricamente mais claro a nível da coletividade que do indivíduo".

Na década de 70, ocorreram diversos movimentos sociais na área da saúde nos países da América Latina, em uma época de profunda crise mundial do capitalismo, o que levou a uma distribuição regressiva da renda e da riqueza e ao aprofundamento dos problemas sociais e políticos, refletidos principalmente na população mais pobre. Esses movimentos questionavam o modo de atuar e pensar do "cientificismo positivista" que respondia às necessidades do capitalismo, deslocando a dimensão social dos problemas de saúde para a atenção aos processos biológicos, tendo em vista as condições de reprodução da força de trabalho (Breilh, Granda, 1989). A Saúde Coletiva nasce nesse contexto e redefine marcos conceitual e metodológico, a partir da potencialidade do materialismo histórico e dialético (Breilh, Granda; 1989; Gianini, 1995). 
Paim e Almeida Filho (1998) referem que a Saúde Coletiva pode ser considerada um campo interdisciplinar composto pelos conhecimentos da epidemiologia, do planejamento/administração de saúde e das ciências sociais em saúde. Breilh (1991) utilizou como categoria central a reprodução social sob as bases do marxismo, já que "permite analisar o processo produtivo em seu movimento, estudar a oposição dialética entre produção (...) e consumo individual" (Breilh, 1991, p.196).

As considerações de Soares (2007) sobre o campo da Saúde Coletiva na América Latina ajudam a compreender as dimensões teórica e prática desse campo, destacando que o processo saúde-doença é resultado de determinantes históricos e estruturais e é enfrentado de formas diversas, de acordo com as diferentes classes sociais. A Teoria da determinação social do processo saúdedoença é uma formulação desenvolvida nesse contexto.

A Teoria da Determinação Social do processo saúde-doença procura relacionar as formas de organização da sociedade com os determinantes sociais da saúde, captando as dimensões sociais e biológicas do processo (Breilh, Granda, 1989).

A abordagem da epidemiologia clássica do processo saúde-doença é discutida por Granda e Breilh (1989) que apontam as limitações ao não considerar a determinação histórico-social.

\begin{abstract}
Em lugar de interpretar os processos sociais (e entre eles a saúdedoença) como expressões de certos modos de produção, das classes em que se divide a sociedade, e em lugar de explicar as razões pelas quais cada classe social está exposta a diferentes riscos de adoecer e possibilidades de manter a saúde, se inventa um sistema ecológico equilibrado, no qual o equilíbrio (i.e. saúde), portanto, tudo o que rompe o equilíbrio é considerado patogênico ou anormal (i.e. doença) (Granda; Breilh, 1989, p.18-19).
\end{abstract}

Possas (1999) argumenta que a análise da estrutura social e da saúde na perspectiva da "determinação social da doença" precisa identificar as mediações envolvidas entre as classes sociais, padrões de morbidade e mortalidade e perfil epidemiológico da população, considerando as especificidades das formações sociais contemporâneas.

Granda e Breilh (1989) criticam a Epidemiologia Tradicional que fundamentalmente sustenta o projeto de dominação política das classes 
dominantes, por sua vez, dificultando uma compreensão estrutural do processo saúde-doença e as possibilidades de transformações mais amplas das formações sociais.

\subsection{A Epidemiologia crítica}

A Epidemiologia Crítica se constitui com o campo da Saúde Coletiva para designar uma nova forma de produzir conhecimento sobre as relações de trabalho, vida e saúde, em um movimento que tem início na década de 70 (Breilh, 1994; Granda, Breilh; 1989). O enorme potencial da Epidemiologia de explicar a situação de saúde de grupos específicos da população em uma forma não linear da relação causa-efeito é enfatizado por Castellanos (1987).

A Epidemiologia Crítica sugere que o processo saúde-doença é coletivo e que os perfis de reprodução social e de saúde-doença podem expor as contradições que ocorrem entre as dimensões da vida social que tem sua base na relação dialética entre produção e consumo (Breilh, 1994). Breilh (1991) esquematizou as principais diferenças entre a Epidemiologia Hegemônica e a Epidemiologia Crítica (Quadro 2):

Quadro 2: Diferenças conceituais da Epidemiologia Hegemônica e da Epidemiologia Crítica. São Paulo, 2010.

\begin{tabular}{|l|l|}
\hline \multicolumn{1}{|c|}{$\begin{array}{c}\text { Epidemiologia } \\
\text { Hegemônica }\end{array}$} & \multicolumn{1}{|c|}{ Epidemiologia Crítica } \\
\hline Empírico-positivista & $\begin{array}{l}\text { Contexto: urgencias sociosanitárias de povos } \\
\text { superexplorados }\end{array}$ \\
\hline $\begin{array}{l}\text { Falsacionista popperiana } \\
\text { (método hipotético- } \\
\text { dedutivo) }\end{array}$ & $\begin{array}{l}\text { Enfrenta postulados teóricos-metodológicos e } \\
\text { práticos da saúde pública oficial e da medicina } \\
\text { hegemónica }\end{array}$ \\
\hline $\begin{array}{l}\text { Define prioridade } \\
\text { probabilísticamente }\end{array}$ & $\begin{array}{l}\text { Não se reduz a uso "progresista" de conceitos, } \\
\text { técnicas e linhas de ação convencionais, } \\
\text { tampouco à adaptação terceiro-mundista de } \\
\text { modalidades simplificadas do saber dos } \\
\text { centros hegemónicos }\end{array}$ \\
\hline
\end{tabular}




\begin{tabular}{|l|l|}
\hline $\begin{array}{l}\text { Reduz necessidade ao } \\
\text { plano fenoménico }\end{array}$ & $\begin{array}{l}\text { Surge em torno do pensamento científico } \\
\text { emancipador como uma expressão particular } \\
\text { da luta autárquica que tem como respondente a } \\
\text { necessidade popular }\end{array}$ \\
\hline $\begin{array}{l}\text { Reidifica realidade em } \\
\text { "fatores de risco" }\end{array}$ & $\begin{array}{l}\text { Crescimento e aprofundamento especializados } \\
\text { de revolução filosófica que esteve na periferia } \\
\text { dos campos técnicos }\end{array}$ \\
\hline
\end{tabular}

Fonte: Breilh (1991, p. 130).

No conjunto da produção da Epidemiologia Crítica, os determinantes que operam a vida social devem necessariamente incluir: os processos estruturais da sociedade que permitem explicar as diferentes formas de trabalhar e de viver; os perfis de reprodução social (produção e consumo) dos diferentes grupos sociais com as correspondentes potencialidades e riscos de saúde e doença, assim como os processos de adoecimento e morrer e a compreensão integral dos fenômenos biológicos que configuram os padrões típicos de saúde-doença dos grupos e dos indivíduos que os compõem (Soares, 2007).

Granda e Breilh (1989, p. 37) ressaltam a importância da utilização da categoria processo que expressa o caráter dinâmico dos fatos vinculados à saúdedoença em todas as suas dimensões, já que a realidade objetiva encontra-se sempre se modificando.

As desigualdades sociais constituem um dos principais objetos da Epidemiologia Crítica. Nesse sentido, a importância da classe social como categoria de análise é justificada, já que tem a capacidade de representar as desigualdades na saúde e materializar a abstração da categoria de população (concebida como um grupo homogêneo de indivíduos sem referência à sua capacidade para ação) (Solla, 1992; Breilh, 2006; Soares, 2007).

Almeida Filho e Rouquayrol (1990) descrevem as diferentes interpretações que o conceito de população recebe nos estudos epidemiológicos. Os estudos ecológicos são aqueles que têm como unidade de análise não o indivíduo, mas sim, a população ou parte dela. Na perspectiva clássica, a população constitui um agregado de pessoas homogêneas que tem possibilidades aleatórias de contrair uma doença de acordo com variações individuais, como sexo, idade, renda, entre 
outros. A população torna-se um conceito abstrato sem a consideração de diferenças de classe.

Nas análises de Soares (2007), embasadas em contribuições de autores da epidemiologia crítica, é possível compreender como a classe social é essencial para determinar o processo saúde-doença. Perfis de reprodução social e de saúdedoença são caracterizados por condições de trabalho e de vida e representam os diferentes perfis epidemiológicos de uma sociedade, composta por diferentes classes sociais. Cada classe social e suas frações têm um perfil específico de reprodução social e um correspondente perfil saúde-doença, já que têm formas semelhantes de trabalho e de vida. Perfis de reprodução social, também determinam diferentes potenciais de fortalecimento e de desgaste, uma vez que estes são inerentes às formas de trabalho e vida dos grupos sociais.

Para articular o processo saúde-doença com as relações sociais de produção, a inserção de classe social nos estudos epidemiológicos exerce uma posição importante e determina o acesso diferenciado à infra-estrutura de saúde, à quantidade e à qualidade dos alimentos, à habitação e ao vestuário, entre outros (Barros, 1983; Lombardi et al, 1988).

\subsection{Classes sociais}

As formas de classificação e mobilidade sociais estão relacionadas com o processo dinâmico da divisão social do trabalho. Contudo, condições religiosas, raciais ou hereditárias podem predominar na divisão da sociedade, como é o caso das castas e estamentos. As forças que coexistem na sociedade como as sociais, políticas e econômicas geram transformações históricas, já que adquirem ao longo do tempo características revolucionárias, reformistas ou reacionárias (Ianni, 1972).

A maneira pela qual se estratifica uma sociedade depende da maneira pela qual os homens se reproduzem socialmente (...) ligada ao modo pelo qual eles organizam a produção econômica e o poder político (Ianni, 1972, p.11).

$\mathrm{Na}$ contemporaneidade, a estratificação social tem como objetivo identificar e descrever a distribuição da desigualdade social e os mecanismos de mobilidade (Grusky, 2000). Há diversos sistemas de estratificação, dentre os quais, destacam-se as castas, estamentos e classes sociais. 
As castas podem ser entendidas como uma das modalidades da formação pré-capitalista, incompatíveis com outras formações sociais, principalmente, o capitalismo, entretanto, há a possibilidade de coexistência de formas em uma mesma sociedade (Hirano, 2003). No caso da Índia, os sistemas de castas ainda persistem, mesmo com a expansão do sistema de classes e a promulgação da Constituição de 1949 que afirma a igualdade de todos os cidadãos hindus (Ianni, 1972).

Weber (1972) analisa casta como ação e ordem social direcionada pela "vontade divina" que acaba por impedir a liberdade de opção de cada indivíduo. Ressalta ainda que as castas podem ser divididas em diversas sub-castas com características semelhantes ou tão diferentes quanto as diversas castas. O processo de socialização é prescritivo e hierarquizado segundo normas de ordens sociais.

Já Marx, em O Capital, enfatiza a formação social das castas sob a perspectiva da divisão rudimentar do trabalho na sociedade. As "leis sociais" determinam privilégio imutável em uma hierarquia rígida histórica e social, determinada pela divisão social do trabalho por categoria de profissão.

Hirano (2006) descreve as abordagens marxista e weberiana de castas que foram assim sistematizadas no Quadro 3.

Quadro 3 - Características da formação de castas segundo Marx e Weber, descritas por Hirano (2006). São Paulo, 2010.

\begin{tabular}{|l|l|}
\hline \multicolumn{1}{|c|}{ Marx } & \multicolumn{1}{|c|}{ Weber } \\
\hline Fenômeno histórico e transitório & Elementos sagrados e religiosos \\
\hline $\begin{array}{l}\text { Refletem determinado desenvolvimento } \\
\text { da produção }\end{array}$ & $\begin{array}{l}\text { Vocação especifica de cada casta e } \\
\text { ética que valoriza o sagrado }\end{array}$ \\
\hline $\begin{array}{l}\text { Trabalho vitalício ou hereditário das } \\
\text { profissões }\end{array}$ & Elementos mágico-religiosos \\
\hline $\begin{array}{l}\text { Monopolização das atividades } \\
\text { profissionais }\end{array}$ & $\begin{array}{l}\text { Especialização e aperfeiçoamento } \\
\text { artesanal }\end{array}$ \\
\hline $\begin{array}{l}\text { Grupos sociais impermeáveis } \\
\text { "Destinos sociais" como produtos de } \\
\text { "leis sociais" }\end{array}$ & $\begin{array}{l}\text { Hereditariedade - define o destino } \\
\text { do homem }\end{array}$ \\
\hline
\end{tabular}


O desenvolvimento dos estamentos, também configurado como processo histórico-estrutural particular de uma sociedade, parte da época do feudalismo e se desenvolve até a monarquia absoluta. A divisão estamental, as relações hierárquicas e estruturas econômicas e políticas são definidas a partir de categorias socioculturais, como a tradição, linhagem, vassalagem, honra e cavalheirismo. Ao contrário das castas, o sistema de estamento possibilita a mobilidade social vertical, já que o que fundamenta a hierarquia dos estamentos é o sistema de direitos e deveres (Ianni, 1972).

Segundo Weber (1999), os estamentos compreendem aos grupos de "honra" e status sociais que se distribuem dentro da comunidade, sob a ordem social e jurídica. A situação estamental é um "componente típico do destino vital humano que está condicionado por uma específica avaliação social, positiva ou negativa, da honra, vinculado a determinada qualidade comum a muitas pessoas" (Weber, 1999: 180).

No estamento, a estrutura é convencional e hierárquica e os privilégios são jurídicos, o que leva a uma exclusividade de cargos para grupos limitados, à falta de necessidade de qualificação profissional, à monopolização dos bens e ao patrimonialismo que impede o livre desenvolvimento da economia (Weber, 1999).

Quadro 4 - Diferenças entre estamento e classe segundo Weber (1999). São Paulo, 2010.

\begin{tabular}{|l|l|}
\hline \multicolumn{1}{|c|}{ Estamento } & \multicolumn{1}{c|}{ Classe } \\
\hline Comunidade amorfa & Poder e dominação \\
\hline Honra social e dignidade, vantagens honoríficas & Posse de bens e propriedades \\
\hline Condução de vida & Oportunidades de vida \\
\hline Exclusivismo e Seletividade & Interesses econômicos \\
\hline $\begin{array}{l}\text { Monopolização de bens ou oportunidades } \\
\text { materiais e ideais }\end{array}$ & Determinação pelo mercado \\
\hline Consumo de bens & Produção e aquisição de bens \\
\hline
\end{tabular}


Para Marx, as fases de desenvolvimento da produção e do consumo estabelecem determinada divisão do trabalho social, o que consequentemente determina o tipo de estratificação social. A ocupação de cada indivíduo é determinada pelos modos de explorar o trabalho, sejam eles, escravista, patriarcal, estamental ou classista e cada etapa da divisão do trabalho "determina as relações dos indivíduos entre si” (Marx, 1985).

Os estamentos são relações sociais de produção também denominados propriedade feudal que refletem as condições de produção, materiais, instrumentos e relações de trabalho. A divisão do trabalho na organização feudal encontrava a contradição na relação cidade x campo e a separação entre nobreza, clero e camponeses, e mestres, oficiais, aprendizes e plebeus (Marx, 1985).

A monopolização das atividades profissionais também caracteriza os estamentos, ou seja, um camponês viverá como camponês sem a possibilidade de mobilidade ou ascensão social. Com a rápida expansão do comércio e a procura por mercadorias, ocorreu a transformação do estamento mercantil em modo de produção capitalista, já com uma classe dominante, a burguesia, defendendo seus interesses sob a retaguarda do Estado. Após o desenvolvimento dos estamentos, há a consolidação de duas classes sociais, a burguesia e o proletariado (Marx, 1985).

No Quadro 3, as diferenças entre os conceitos de estamento e classe são destacadas. As classes, para Weber, são caracterizadas pelo poder e pela dominação que se impõe umas as outras, como mecanismo de controle da sociedade. As características da situação de classe são definidas pelas oportunidades no mercado que é um "condicionador comum do destino dos indivíduos", com “interesses inequivocamente econômicos”, vinculados à existência de um mercado que cria a classe (Weber, 1999, p. 177).

Weber (1999) define alguns atributos fundamentais do conceito de classe: um componente causal específico que diferencia as pessoas de acordo com suas oportunidades de vida; esse componente está relacionado com os interesses econômicos e posse e aquisição de bens; e condicionados ao mercado de bens ou de trabalho.

O antagonismo de classe é caracterizado pela luta de preços ou de concorrência, esta última, define as situações de classe de acordo com a natureza 
da propriedade (aproveitáveis para fins aquisitivos e serviços que podem ser ofertados no mercado) (Weber, 1999).

Grusky (2000) agrupou as abordagens sobre estratificação social de acordo com o enfoque das teorias e dos autores relevantes (Tabela 1).

Tabela 1 - Estratificação social de acordo com o enfoque das teorias e dos autores relevantes. São Paulo, 2010.

\begin{tabular}{|c|c|c|}
\hline Asset Group & Selected Examples & Relevant Scholars \\
\hline 1. Economic & $\begin{array}{l}\text { Ownership of land, farms, factories, professional practices, } \\
\text { businesses, liquid assets, humans (i.e., slaves), labor power } \\
\text { (e.g., serfs) }\end{array}$ & Karl Marx; Erik Wright \\
\hline 2. Political & $\begin{array}{l}\text { Household authority (e.g., head of household); workplace } \\
\text { authority (e.g., manager); party and societal authority } \\
\text { (e.g., legislator); charismatic leader }\end{array}$ & Max Weber; Ralf Dahrendorf \\
\hline 3. Cultural & $\begin{array}{l}\text { High-status consumption practices; "good manners"; privileged } \\
\text { lifestyle }\end{array}$ & Pierre Bourdieu; Paul DiMaggio \\
\hline 4. Social & $\begin{array}{l}\text { Access to high-status social networks, social ties, associations } \\
\text { and clubs, union memberships }\end{array}$ & W. Lloyd Warner; James Coleman \\
\hline 5. Honorific & $\begin{array}{l}\text { Prestige; "good reputation"; fame; deference and derogation; } \\
\text { ethnic and religious purity }\end{array}$ & Edward Shils; Donald Treiman \\
\hline 6. Civil & $\begin{array}{l}\text { Rights of property, contract, franchise, and membership in } \\
\text { elective assemblies; freedom of association and speech }\end{array}$ & T. H. Marshall; Rogers Brubaker \\
\hline 7. Human & $\begin{array}{l}\text { Skills; expertise; on-the-job training; experience; formal } \\
\text { education; knowledge }\end{array}$ & Kaare Svalastoga; Gary Becker \\
\hline
\end{tabular}

Fonte: Grusky (2000): p.4

No sentido teórico, classe pode ser definida como: "conjuntos de agentes que ocupam posições semelhantes e que, colocados em condições semelhantes e sujeitos a condicionamentos semelhantes, têm (...) atitudes e interesses semelhantes". Entretanto, o conceito puramente teórico relativiza as diferenças sociais, além de não enfatizar o sentido de grupo, a ideia de luta e o espaço de relações (Bourdieu, 1998, p.136).

Em relação ao conceito marxista de classe social, não há uma definição precisa e única, já que o próprio Marx não elaborou uma análise sistemática sobre o conceito de classe, o que possibilitou diferentes leituras e interpretações (Barros, 1983). 
A classe social dentro do marxismo é definida a partir da relação com os meios de produção. Engels (1969) ${ }^{5}$ sustenta que a burguesia é a classe dos grandes capitalistas que detêm todos os meios de subsistência e instrumentos exclusivamente.

Em suas análises sobre o golpe do 18 Brumário de Luís Bonaparte na França, Marx identificou as seguintes frações de classe: burguesia, grande burguesia, aristocracia, pequena burguesia, campesinato, proletariado, lumpemproletariado e grandes proprietários (Marx, 2008).

Poulantzas (1976) sistematiza a teoria marxista de classes sociais em 17 pontos, assim resumidos: Classes sociais são compostas por agentes sociais, diferenciados, principalmente, mas não exclusivamente, por seu lugar no processo de produção, composto da unidade do processo de trabalho e das relações de produção. As relações econômicas detêm o papel principal na determinação das classes sociais, não sendo o salário determinante para a divisão de classe. Os lugares objetivos ocupados pelos agentes na divisão social do trabalho são designados a partir da determinação das classes e das relações políticas e ideológicas. As contradições e lutas de classes constituem o aspecto principal na análise, bem como os lugares dos agentes na luta de classes. Deve-se distinguir o modo de produção e a formação social, frações e camadas de classe, e determinação estrutural das classes e posição de classe na conjuntura. Os aparelhos de Estado não criam as divisões, mas influenciam para tal divisão e para a reprodução ampliada das classes sociais. A reprodução ampliada se refere ao campo ideológico-político.

\subsection{A operacionalização do conceito de classe social}

A relação entre o processo saúde-doença e classes sociais está bem estabelecida em vários estudos epidemiológicos. As taxas de mortalidade, expectativa de vida e de nutrição infantil são extremamente diferentes, quando a classe social é tomada em consideração (Barros, 1983; McFadden, Luben, Khaw, 2009).

\footnotetext{
5 Ver em: Engels F. The Principles of Communism. In: Marx K, Engels F. Selected Works. Moscow: Progress Publishers, 1969. Publicado no site: http://www.marxists.org/archive/marx/works/1847/11/prin-com.htm
} 
O emprego do conceito de classe social é necessário para relacionar os processos globais da sociedade ao processo saúde-doença. Apesar das evidências positivas, constata-se um declínio das investigações que utilizam o conceito de classe nas últimas décadas, o que pode estar relacionado com as limitações e os problemas na sua capacidade explicativa (Solla, 1992).

A partir da década de 70, diversos estudos analisaram a desigualdade social a partir do conceito marxista de classe social em contraposição aos estudos tradicionais de estratificação. Entretanto, a utilização do conceito de classe perdeu espaço nas pesquisas acadêmicas, devido à crise do pensamento marxista. Já na década de 90, a OPAS enfatizou o desenvolvimento de instrumentos metodológicos para aperfeiçoar a identificação, a análise e posterior superação das iniquidades (Silva, Barros, 2002).

Inúmeras dificuldades em utilizar o conceito de classe social na epidemiologia são relatadas na literatura, a respeito da definição do objeto de estudo e as diferentes interpretações que o mesmo tem recebido. Somente o conceito marxista de classe social gerou inúmeras interpretações diferentes (Barros, 1983; Lombardi et al, 1988).

A variedade de significados, que foram anexadas ao conceito de classe social, tem contribuído para a falta de clareza que caracteriza muitos debates contemporâneos sobre estratificação, incluindo debates sobre teoria social e a capacidade explicativa do conceito para explicar as desigualdades sociais (Crompton, 1998).

Os diversos conceitos também revelam a falta de consenso existente na área da Sociologia, o que gera questionamentos quanto à capacidade explicativa, as perspectivas na utilização desse conceito nos estudos epidemiológicos e a força do conceito na formulação de políticas públicas (Gianini, 1995).

Breilh (1991) afirma que é fundamental a definição de categorias explicativas para permitir a análise da desigualdade social. Instrumentos adequados são necessários para captar a realidade social adequadamente e propor intervenções coerentes com as necessidades da população. 
A carência de um instrumental idôneo é proporcional ao prolongamento das idéias e métodos comprovadamente ineficazes de uma epidemiologia empírica. Representa um vazio, uma solução de continuidade que se interpõe entre os problemas de saúde freqüentes e agudos das classes sociais majoritárias e a necessidade que existe de interpretar a realidade corretamente, formulando-a nos termos de seu verdadeiro interesse de classe (Breilh, 1991, p.43)

Ianni (1972, p. 287) ressalta a tentativa da sociologia contemporânea de tornar o conceito de classe social "mais operacional para a pesquisa empírica (...) ou de eliminar o conteúdo dialético da sua concepção clássica”. Sociólogos como Ralf Dahrendorf, W. Lloyd Warner e Talcott Parsons abriram novas perspectivas na análise de classe, mas não propuseram novos conceitos, nem resolveram suas próprias questões levantadas (Ianni, 1972).

Embora ocorra essa indefinição, o conceito de classe tem sido amplamente utilizado para descrever as desigualdades sociais nas sociedades contemporâneas e identificar a origem da identidade social e política, consciência e ação, como Marx definiu (Crompton, 1998).

O conceito sociológico de classe social se expressa em diferentes níveis e recortes da realidade, além de ser compreendido como um elemento interpretativo, relacionado a um evento, fenômeno percebido, ou a um processo compreendido. Assim, não existe somente um conceito certo, o que gera problemas relacionados à operacionalização, podendo ocasionar aproximações que podem não corresponder à realidade (Gianini, 1995).

Em uma revisão sobre a utilização do conceito de classe social e posição sócio-econômica nos Estados Unidos, as autoras chamam a atenção para a necessidade de superar a histórica falta de instrumentos adequados para identificar as desigualdades sociais em saúde (Krieger, Williams, Moss, 1997).

Outra dificuldade é relacionar os métodos de estudo com a amostra para identificar as diferentes classes e classificar cada pessoa. Há uma distância entre o conceito teórico de classe social e as formas de operacionalização, o que pode levar a uma distorção da realidade (Barros, 1983).

Solla (1992) ressalta a necessidade de superação de problemas da utilização do conceito, como considerar as peculiaridades de cada sociedade e os processos dinâmicos que nela ocorrem; a consideração que nem todos os conceitos podem ser reduzidos a variáveis na investigação empírica; e o 
aprofundamento de questões teórico-conceituais, como o ponto de corte de variáveis quantitativas, a quantidade de variáveis necessárias para compor um indicador, a inclusão da população não diretamente inserida na dimensão econômica como os estudantes e a classificação de indivíduos com mais de uma inserção na produção.

Este projeto leva em consideração dois estudos preliminares brasileiros que analisaram criticamente as propostas de medir o conceito de classe social, com foco em publicações latino-americanas (Gianini, 1995; Solla, 1992). No entanto, não eram revisões sistemáticas.

Portanto, parte-se do pressuposto em que o processo saúde-doença é determinado socialmente, a partir da realidade social concreta em que se encontram os diferentes grupos e classes sociais. Este processo está relacionado com os resultados advindos dos processos de integração do homem no trabalho e na vida (Laurel, 1989; Breilh, 1994).

Dessa forma, nesta investigação a análise será realizada a partir dos fundamentos da Saúde Coletiva, que toma como sujeito a classe social e a vem operacionalizando, nos estudos epidemiológicos críticos, especialmente a partir da categoria reprodução social. 
3 OBJETIVOS 


\section{OBJETIVOS}

\subsection{Geral}

Analisar criticamente as produções científicas nacionais e internacionais que tratam da operacionalização do conceito de classe social na área de epidemiologia.

\subsection{Específicos}

- Identificar as produções sobre os modelos de operacionalização do conceito de classe social.

- Caracterizar as produções, em relação ao país de origem, ano de publicação e tipo de pesquisa.

- Mapear temporal e espacialmente as tendências internacionais e nacionais na composição dos modelos.

- Analisar o quanto os modelos se aproximam ou se distanciam dos marcos da Epidemiologia Crítica e da Saúde Coletiva.

- Identificar como os estudos relacionam classe social e saúde. 
4 PROCEDIMENTOS METODOLÓGICOS 


\section{PROCEDIMENTOS METODOLÓGICOS}

\subsection{Tipo de estudo}

Trata-se de uma revisão sistemática teórica e quantitativa.

As revisões sistemáticas são estudos retrospectivos com abordagens quantitativas ou qualitativas que buscam direcionar as práticas através da síntese de conhecimentos de uma área específica. Utiliza métodos sistemáticos para identificar e avaliar criticamente os estudos primários (Booth, 2001; Pearson et al, 2005). São capazes de reunir os melhores resultados de pesquisas disponíveis sobre um dado objeto.

A revisão sistemática quantitativa busca responder à pergunta do estudo através da busca de estudos quantitativos. Deve ter uma pergunta bem definida e realizar uma busca abrangente de todos os trabalhos relevantes até a "saturação de dados" para a validade do estudo não ser comprometida. Quando os resultados da pesquisa derivam de procedimentos metodológicos semelhantes, é possível realizar uma análise estatística (metanálise) que compara os resultados de cada estudo, com o objetivo de obter um resultado final preciso. Os estudos considerados de baixa qualidade são excluídos da revisão (Booth, 2001).

$\mathrm{Na}$ revisão qualitativa, as regras devem seguir os critérios dos métodos quantitativos, entretanto alguns aspectos a diferenciam (Booth, 2001):

- a representatividade estatística não é uma exigência para a coleta de dados.

- preconiza-se uma avaliação do equilíbrio entre qualidade metodológica e peso do conteúdo do trabalho, em vez de rejeitar trabalhos abaixo de um determinado limiar de qualidade.

- o grau de concordância entre os investigadores não é realmente importante, pois o conteúdo das discordâncias e os conhecimentos que a discussão de interpretações alternativas pode fornecer, é também tomado em consideração.

A revisão sistemática qualitativa pode contribuir para a geração de modelos e teorias; validação e aferição de determinadas "escolas" de pensamento; traçar o desenvolvimento de conceitos na literatura longitudinalmente ao longo do tempo; complementar os resultados quantitativos e a interpretação de revisões sistemáticas; e identificar domínios e atributos importantes que permitam o desenvolvimento de instrumentos ou escalas (Booth, 2001). 
Já a revisão sistemática teórica busca evidenciar os fundamentos teóricos de um determinado objeto de estudo, além da superação de práticas em saúde através da articulação entre teoria e prática. Davies et al (2010) salientam que os trabalhos científicos devem explicitar melhor o uso da teoria que fundamenta as práticas de intervenção que estão sendo implementadas e que os pesquisadores desenvolvam com mais clareza a lógica de como a teoria proposta opera no estudo em questão.

Revisão sobre o uso de teorias em importante revista de saúde pública latino-americana mostrou que referências a teorias são infrequentes nas publicações, com uma minoria de trabalhos mencionando a teoria ou o modelo teórico que serviu de base para explicar o fenômeno que estava sendo investigado (Arana, 2007).

Este estudo segue as recomendações metodológicas do Instituto Joanna Briggs (JBI) ${ }^{6}$. O JBI foi criado em 1996, pela parceria do Royal Adelaide Hospital e da Universidade de Adelaide na Austrália com a missão de melhorar a saúde global por meio da geração, síntese e aplicação de práticas baseada em evidências. Tem como visão a utilização da prática baseada em evidências na prestação de cuidados como característica central dos serviços de saúde para melhoria da saúde da população global (JBI, 2008).

O JBI é uma organização internacional de pesquisa e desenvolvimento, sem fins lucrativos que atua em diversas áreas da saúde, promovendo e apoiando a disseminação das práticas baseada em evidências (JBI, 2008).

Iniciou suas atividades na área de enfermagem a atualmente envolve pesquisadores de diversas áreas da saúde como médicos, enfermeiros, pesquisadores, acadêmicos e gestores, atuando em 40 países ao redor do mundo através de centros colaboradoras. Estes centros estão geralmente localizados em universidades, serviços de saúde e organizações profissionais (JBI, 2008).

O Centro Brasileiro para o Cuidado à Saúde Baseado em Evidências: Centro Colaborador do Instituto Joanna Briggs (JBI - Brasil) ${ }^{7}$ é a primeira entidade colaboradora do JBI no Brasil. Através da iniciativa conjunta da Escola de Enfermagem, da Faculdade de Saúde Pública e do Hospital Universitário da Universidade de São Paulo, o Centro Brasileiro iniciou suas atividades em 2009 e

\footnotetext{
${ }^{6}$ Ver em: http://www.joannabriggs.edu.au

${ }^{7}$ Ver em: http://www.ee.usp.br/pesq/nucleo/jbi/
} 
visa promover e disseminar o cuidado à saúde baseado em evidências em todo o território brasileiro.

As recomendações do JBI fundamentam-se no modelo de saúde baseada em evidências (Figura 1) que segue as seguintes etapas (Pearson et al, 2005):

- geração de evidência na área de saúde

- síntese da evidência

- transferência de conhecimento

- utilização da evidência

Cada etapa é representada em um processo cíclico, que deve ter como finalidade a busca por práticas que levam ao aprimoramento da saúde em âmbito mundial (Pearson et al, 2005).

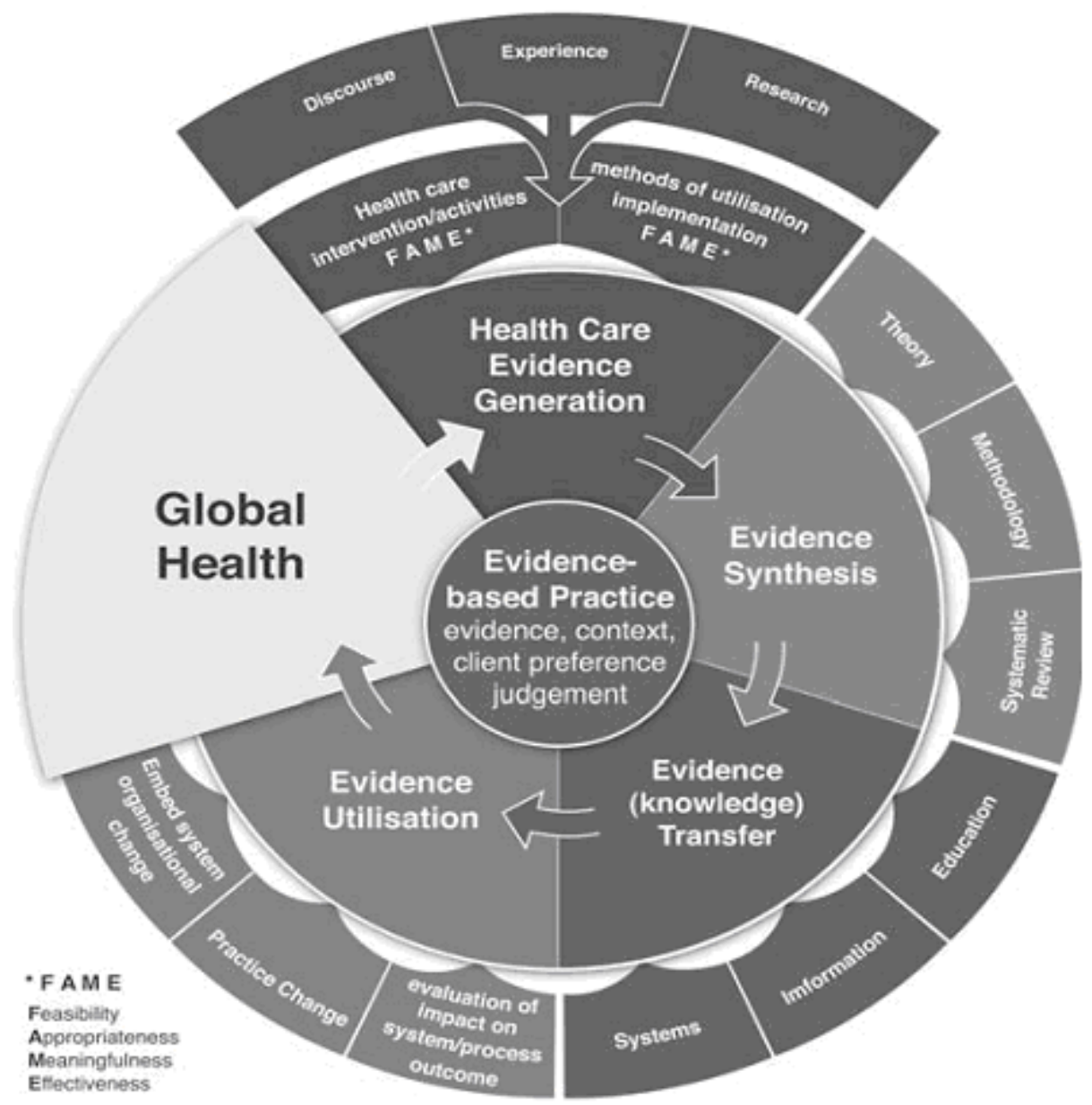

Figura 1 - Modelo conceitual do Joanna Briggs Institute de saúde baseada em evidências. 
O Instituto trabalha em estreita cooperação com a Colaboração Cochrane, especializada em revisões sistemáticas quantitativas com metanálise, e a Colaboração Campbell, instituição inglesa que trabalha principalmente com estudos sistemáticos qualitativos. O JBI é um líder na realização de revisões sistemáticas que utilizam outras abordagens, em especial a investigação qualitativa, a quantitativa e a econômica. Essas abordagens permitem identificar e considerar a importante relação entre saúde e condições sociais (JBI, 2008).

\subsection{Etapas de uma revisão sistemática}

O desenvolvimento desta revisão sistemática seguiu as seguintes etapas:

1) Formulação de uma pergunta de estudo;

1) Busca nas bases de dados secundárias para verificar se existe uma revisão sistemática em andamento ou já finalizada com a mesma pergunta de seu estudo;

3) Identificação dos critérios de inclusão e exclusão;

4) Identificação dos tipos de estudos, tipos de participantes/problema e tipos de intervenção/fenômeno de interesse;

5) Detalhamento da estratégia de busca para a seleção dos estudos. Inclui as bases de dados e os termos;

6) Forma de seleção dos estudos e utilização de um instrumento para incluir ou não o estudo;

7) Avaliação da qualidade do estudo através de um instrumento;

8) Forma de extração dos dados através de um instrumento;

9) Análise e síntese dos estudos relevantes;

10) Apresentação dos resultados;

11) Interpretação dos resultados/determinação da aplicabilidade dos resultados.

O JBI recomenda o desenvolvimento de um protocolo, contemplando todos os passos da revisão sistemática, que deve ser encaminhado para um pesquisador do instituto que irá submetê-lo a dois pareceristas para avaliação e aprovação. Esta etapa pode ser realizada através do JBI-CReMS, um software projetado para elaborar protocolos, realizar revisões sistemáticas, armazenar dados sobre os estudos e acessar os módulos específicos para avaliação crítica de cada tipo de revisão sistemática (JBI-QARI para estudos qualitativos, JBI- 
MAStARI para estudos quantitativos, JBI-MAStARI para estudos de custos e JBINOTARI para textos narrativos ou de opinião) (JBI, 2008).

O protocolo desta revisão foi submetido à apreciação crítica e aprovado, conforme comentado anteriormente.

\subsection{Questões do estudo}

As questões de uma revisão sistemática podem ser elaboradas através da estratégia PICo para estudos qualitativos ( $\mathrm{P}$ de população/problema, I de fenômeno de interesse e Co de contexto) e da estratégia PICO para revisões quantitativas (P significa paciente, população ou problema, I de intervenção ou indicador, $\mathrm{C}$ de comparação e $\mathrm{O}$ de resultado ou desfecho, relativo à palavra outcome).

Nesta investigação definiu-se os seguintes parâmetros:

PICo (Parte teórica):

Problema: processo complexo de identificação de diferenças

Interesse: modelos para operacionalizar o conceito de classe social

Contexto: estudos na área de epidemiologia

PICO (Parte quantitativa):

Problema: diferentes classes sociais na sociedade

Intervenção: classe social

Comparação/Contexto: relação entre classe social e saúde

Outcome/Resultado/: diferenças da classe social na saúde

Assim, para o delineamento do estudo, foram definidas duas perguntas:

- Como a classe social vem sendo medida na epidemiologia?

- Qual a relação entre classe social e processo saúde-doença?

\subsection{Critérios de inclusão}

Para serem incluídos na primeira busca, os estudos deveriam apresentar resumo em inglês e estar escritos em português, inglês ou espanhol. Nos casos em que o título e o resumo não fossem suficientes para definir a primeira seleção, a publicação na íntegra foi buscada. Não houve restrição quanto ao ano de publicação. 
Em relação à parte teórica, os estudos deveriam abordar um modelo do conceito de classe social em contexto predominantemente urbano que seja utilizado na epidemiologia.

Em relação à parte quantitativa, os estudos epidemiológicos deveriam ser do tipo coorte ou caso-controle (que encontram-se mais bem avaliados na hierarquia de evidência), utilizar um modelo de classe social, relacionar um problema de saúde, de âmbito da atenção básica, e classe social e terem o adulto como população do estudo.

\subsection{Critérios de exclusão}

- estudos sobre validação de escalas, acesso a serviços de saúde, mortalidade, câncer e análise de gênero;

- utilização de diferentes conceitos de classe, SES e SEP nos métodos do estudo;

- utilização do descritor classe social, mas no resumo há a descrição da utilização de SES ou SEP.

\subsection{Tipos de estudos}

Para a identificação dos modelos operacionais do conceito de classe social, foram considerados todos os tipos de estudo nacionais ou internacionais, incluindo os estudos teórico-metodológicos qualitativos, discursivos, de opinião, cartas e editoriais, entre outros, que descrevem, analisam ou propõem um modelo de classe.

Para identificar aos estudos que relacionaram classe social e saúde, foram incluídos estudos quantitativos epidemiológicos do tipo coorte ou caso-controle.

\subsection{Tipos de participantes}

Esta revisão não teve como foco um grupo particular de participantes, e sim, os modelos de operacionalização do conceito de classe social no campo da epidemiologia. Já nos estudos que relacionaram a classe social e a saúde o foco era a população adulta. 


\subsection{Tipos de intervenção/fenômeno de interesse}

Os fenômenos de interesse são os modelos operacionais do conceito de classe social na epidemiologia para a captação empírica da desigualdade social e a relação entre classe social e saúde, descrita nos resultados dos estudos epidemiológicos.

\subsection{Estratégia de busca para identificação dos estudos}

Antes da busca bibliográfica propriamente dita, foi necessário realizar uma busca inicial nas bases secundárias que cadastram e divulgam revisões sistemáticas em andamento ou já finalizadas. Esta etapa é recomendada para verificar se uma revisão sistemática está sendo conduzida ou já foi realizada por outros pesquisadores.

As bases de dados foram selecionadas de acordo com o objeto de estudo, pois potencialmente poderiam ter em seu cadastro revisão semelhante. Foram procuradas e não encontradas revisões semelhantes nas bases relacionadas no Quadro 5.

Quadro 5 - Descrição das bases de dados secundárias incluídas. São Paulo, 2010.

\begin{tabular}{|l|l|}
\hline \multicolumn{1}{|c|}{ Base de dados } & \multicolumn{1}{|c|}{ Descrição } \\
\hline Bandolier & $\begin{array}{l}\text { A primeira edição do Bandolier, uma revista } \\
\text { independente sobre saúde baseada em evidências, } \\
\text { escrita por cientistas de Oxford, (RAM e HJM) foi } \\
\text { impressa em fevereiro de 1994. Tornou-se a principal } \\
\text { fonte de evidências de informações de saúde no } \\
\text { Reino Unido e em todo o mundo para os } \\
\text { profissionais de saúde. }\end{array}$ \\
\hline Campbell Collaboration & $\begin{array}{l}\text { É uma rede internacional de pesquisa que produz } \\
\text { revisões sistemáticas relacionadas a efeitos das } \\
\text { intervenções sociais. Campbell tem atualmente cinco } \\
\text { grupos de coordenação: Bem-Estar Social, Crime e } \\
\text { Justiça, Educação, Métodos e do grupo Usuários. }\end{array}$ \\
\hline$\underline{\text { org }}$ & $\begin{array}{l}\text { É uma fonte internacional das melhores evidências } \\
\text { disponíveis sobre os efeitos de intervenções clínicas. }\end{array}$ \\
\hline$\underline{\text { Clinical Evidence }}$ & \\
\hline
\end{tabular}




\begin{tabular}{|c|c|}
\hline Cochrane Library & $\begin{array}{l}\text { Contém evidências de alta qualidade, para embasar a } \\
\text { tomada de decisões. Inclui revisões sistemáticas, } \\
\text { ensaios clínicos, e muito mais. As revisões Cochrane } \\
\text { trazem o resultado combinado dos melhores } \\
\text { evidências do mundo e são reconhecidas como o } \\
\text { padrão-ouro nos cuidados de saúde baseada em } \\
\text { evidências. }\end{array}$ \\
\hline $\begin{array}{l}\text { Critical Appraisal Skills } \\
\text { Programme (CASP) } \\
\text { http://www.phru.nhs.uk/pag } \\
\text { es/PHD/CASP.htm }\end{array}$ & $\begin{array}{l}\text { Tem ajudado a desenvolver uma abordagem baseada } \\
\text { em evidências na saúde e assistência social, } \\
\text { trabalhando com grupos locais, nacionais e } \\
\text { internacionais. }\end{array}$ \\
\hline $\begin{array}{l}\text { DARE } \\
\underline{\text { www.crd }}\end{array}$ & $\begin{array}{l}\text { DARE contém } 15.000 \text { resumos de revisões } \\
\text { sistemáticas, incluindo mais de } 6.000 \text { comentários de } \\
\text { qualidade avaliado e detalhes de todas as revisões } \\
\text { Cochrane e protocolos. }\end{array}$ \\
\hline $\begin{array}{l}\text { Dopher } \\
\text { eppi.ioe.ac.uk/ } \\
\text { /Intro.aspx?ID }\end{array}$ & $\begin{array}{l}\text { Registra revisão sistemática e não sistemática de } \\
\text { eficácia na promoção da saúde e da saúde pública no } \\
\text { mundo. Atualmente contém mais de } 2.500 \text { revisões } \\
\text { sobre promoção da saúde e da efetividade da saúde } \\
\text { pública. }\end{array}$ \\
\hline $\begin{array}{l}\text { Evidence-Based Medical } \\
\text { Reviews (EBMR) } \\
\text { http://www.ovid.com/site/c } \\
\text { atalog/DataBase/904.jsp }\end{array}$ & $\begin{array}{l}\text { Divulga revisões sistemáticas, artigos de revisão e } \\
\text { acesso aos ensaios clínicos. Atualmente contém mais } \\
\text { de } 360000 \text { trabalhos. }\end{array}$ \\
\hline $\begin{array}{l}\text { Joanna Briggs Institute } \\
\underline{\text { www.joannabriggs.edu.au }} \\
\end{array}$ & $\begin{array}{l}\text { É uma organização internacional sem fins lucrativos } \\
\text { de pesquisa especializada em recursos com base em } \\
\text { evidências para profissionais de saúde em } \\
\text { enfermagem, obstetrícia, medicina e outros } \\
\text { profissionais da saúde. }\end{array}$ \\
\hline $\begin{array}{l}\text { National Institute for } \\
\text { Health and Clinical } \\
\text { Excellence (Nice) } \\
\text { www.nice.org.uk/ }\end{array}$ & $\begin{array}{l}\text { É uma organização independente responsável por } \\
\text { fornecer as diretrizes para a promoção da boa saúde e } \\
\text { à prevenção e tratamento da doença. NICE atua em } \\
\text { três áreas de saúde: saúde pública - orientação sobre } \\
\text { a promoção da saúde e da prevenção da saúde, } \\
\text { autoridades locais e do setor público em geral e } \\
\text { voluntária; tecnologias em saúde - orientação sobre o } \\
\text { uso de novos e existentes, medicamentos, } \\
\text { tratamentos e prática clínica - orientação sobre o } \\
\text { tratamento adequado e cuidados de pessoas com } \\
\text { doenças e condições específicas. }\end{array}$ \\
\hline $\begin{array}{l}\text { echnology } \\
\text { gramme } \\
\text { ute for }\end{array}$ & $\begin{array}{l}\text { Produz investigação independente sobre a eficácia de } \\
\text { tratamentos de saúde, custos e impacto mais amplo } \\
\text { dos tratamentos de saúde e testes para aqueles que }\end{array}$ \\
\hline
\end{tabular}




\begin{tabular}{|l|l|}
\hline $\begin{array}{l}\text { Health Research } \\
\text { (NIHRHTA) }\end{array}$ & planejam, prestam ou recebem cuidados. \\
\hline http://www.ncchta.org/ & $\begin{array}{l}\text { Fonte internacional sobre teorias de enfermagem e } \\
\text { enfermagem clínica }\end{array}$ \\
\hline$\underline{\text { enursescribe.doereport.com }}$ & $\begin{array}{l}\text { É uma ferramenta de pesquisa clínica projetada para } \\
\text { Practice (TRIP) } \\
\text { permitir que os profissionais de saúde identifiquem } \\
\text { rapidamente as evidências clínicas de alta qualidade } \\
\text { para a prática clínica. }\end{array}$ \\
\hline$\underline{\text { www.tripdatabase.com/inde }}$ & $\underline{\text { x.html }}$
\end{tabular}

A busca bibliográfica propriamente dita tem como objetivo encontrar estudos publicados e não publicados. O primeiro passo foi a busca nas bases primárias que concentram artigos originais, teses, dissertações, resumos de eventos, entre outros, incluindo-se 16 bases/bancos relacionados às áreas da saúde, ciências sociais e multidisciplinares (Quadros 6 e 7). A seleção destas bases foi orientada por duas bibliotecárias, uma da Escola de Enfermagem e outra do JBI.

Quadro 6 - Bases de dados incluídas na busca bibliográfica de acordo com a área de conhecimento que abrange. São Paulo, 2010.

\begin{tabular}{|l|l|l|}
\hline \multicolumn{1}{|c|}{ Ciências Sociais } & \multicolumn{1}{|c|}{ Saúde } & \multicolumn{1}{c|}{ Interdisciplinar } \\
\hline $\begin{array}{l}\text { Applied Social Sciences } \\
\text { Index and Abstracts (ASSIA) }\end{array}$ & CINAHL & $\begin{array}{l}\text { Banco de dissertações e teses da } \\
\text { CAPES }\end{array}$ \\
\hline MUSE & Current Contents & $\begin{array}{l}\text { Directory of Open Access } \\
\text { Journals (DOAJ) }\end{array}$ \\
\hline Social Service abstracts & EMBASE & DEDALUS/USP \\
\hline Sociological Abstracts & LILACS & $\begin{array}{l}\text { Dissertation Abstracts } \\
\text { International }\end{array}$ \\
\hline & MEDLINE/ PubMed & PsycINFO \\
\hline & SCOPUS & Web of Science \\
\hline
\end{tabular}


Quadro 7 - Bases de dados incluídas na busca bibliográfica de acordo com a área de conhecimento, período de análise, número de registros e tipo de publicação.

São Paulo, 2010.

\begin{tabular}{|c|c|}
\hline Base de dados & Descrição \\
\hline $\begin{array}{l}\text { Applied Social Sciences Index } \\
\text { and Abstracts (ASSIA) } \\
\text { csaweb116v.csa.com }\end{array}$ & $\begin{array}{l}\text { Áreas: Saúde, serviços sociais, psicologia, } \\
\text { sociologia, economia, política, relações raciais e } \\
\text { educação. } \\
\text { Período de análise: } 1987 \text { - atual. } \\
\text { Número de registros: } 453.720 \text { registros em junho } \\
\text { de } 2009 \text {. Mais de } 500 \text { periódicos publicados em } 16 \\
\text { países diferentes, incluindo o Reino Unido e dos } \\
\text { EUA. } \\
\text { Tipo de publicação: Artigos. }\end{array}$ \\
\hline $\begin{array}{l}\text { Banco de Teses da CAPES } \\
\text { servicos.capes.gov.br/capesdw/ }\end{array}$ & $\begin{array}{l}\text { Áreas: Multidisciplinar. } \\
\text { Período de análise: } 1987 \text { - } 2006 . \\
\text { Número de registros: mais de } 280.000 \text { resumos. } \\
\text { Tipo de publicação: dissertações e teses }\end{array}$ \\
\hline $\begin{array}{l}\text { CINAHL } \\
\text { www.cinahl.com } \\
\end{array}$ & $\begin{array}{l}\text { Áreas: Enfermagem e saúde. } \\
\text { Período de análise: } 1981 \text { - atual. } \\
\text { Número de registros: } 2,928 \text { periódicos e mais de } \\
1,000,000 \text { publicações } \\
\text { Tipo de publicação: Artigos, livros, material } \\
\text { audiovisual, panfletos, softwares, dissertações e } \\
\text { instrumentos de pesquisa. }\end{array}$ \\
\hline $\begin{array}{l}\text { Current Contents Connect } \\
\text { www.scientific.thomson.com } \\
\end{array}$ & $\begin{array}{l}\text { Áreas: Multidisciplinar (agricultura, medicina, } \\
\text { biologia e outros). } \\
\text { Período de análise: } 1988 \text { - atual. } \\
\text { Número de registros: Mais de } 8.000 \text { registros, } \\
\text { sites, } 1900 \text { livros. } \\
\text { Tipo de publicação: Artigos, resumos e } \\
\text { informações bibliográficas completas de alguns } \\
\text { jornais eletrônicos antes de serem publicados. }\end{array}$ \\
\hline $\begin{array}{l}\text { Dissertation Abstracts } \\
\text { International/Digital } \\
\text { Dissertations } \\
\text { Www.umi.com/enUS/products/d } \\
\text { issertations/ }\end{array}$ & $\begin{array}{l}\text { Áreas: Multidisciplinar. } \\
\text { Período de análise: } 1861 \text { - atual. } \\
\text { Número de registros: } 2 \text { milhões de dissertações. } \\
\text { Mais de } 700 \text { universidades parceiras. } \\
\text { Tipo de publicação: Resumos de tese e } \\
\text { dissertações digitais. Texto integral de títulos } \\
\text { publicados desde 1997. }\end{array}$ \\
\hline $\begin{array}{l}\text { DOAJ } \\
\text { www.doaj.org/ } \\
\end{array}$ & $\begin{array}{l}\text { Áreas: Multidisciplinar. } \\
\text { Período de análise: não descrito. } \\
\text { Número de registros: } 127 \text { revistas. } \\
\text { Tipo de publicação: Resumos e artigos na íntegra. }\end{array}$ \\
\hline
\end{tabular}




\begin{tabular}{|c|c|}
\hline $\begin{array}{l}\text { EMBASE } \\
\underline{\text { www.embase.com }}\end{array}$ & $\begin{array}{l}\text { Áreas: Biomédica com ênfase em Farmacologia. } \\
\text { Período de análise: } 1947 \text { - atual. } \\
\text { Número de registros: } 19.000 \text { mil registros } \\
\text { indexados com mais de } 600 \text { mil adições anuais de } \\
\text { mais de } 7.000 \text { revistas especializadas. } \\
\text { Tipo de publicação: Artigos. }\end{array}$ \\
\hline $\begin{array}{l}\text { LILACS } \\
\text { www.bireme.br } \\
\end{array}$ & $\begin{array}{l}\text { Áreas: Ciências da saúde latino-americana e do } \\
\text { Caribe } \\
\text { Período de análise: } 1982 \text { - atual. } \\
\text { Número de registros: } 1300 \text { revistas e } 400000 \\
\text { registros. } \\
\text { Tipo de publicação: teses, capítulos de teses, } \\
\text { livros, capítulos de livros, anais de congressos ou } \\
\text { conferências, relatórios técnico-científicos e } \\
\text { publicações governamentais. }\end{array}$ \\
\hline $\begin{array}{l}\text { MEDLINE/Pubmed } \\
\text { www.pubmed.gov }\end{array}$ & $\begin{array}{l}\text { Áreas: Ciências da vida. } \\
\text { Período de análise: } 1948 \text { - atual. } \\
\text { Número de registros: Mais de } 18 \text { milhões de } \\
\text { citações. } \\
\text { Tipo de publicação: Artigos. }\end{array}$ \\
\hline $\begin{array}{l}\text { MUSE } \\
\underline{\text { muse.jhu.edu }}\end{array}$ & $\begin{array}{l}\text { Áreas: Ciências Sociais - Economia, Educação, } \\
\text { Linguística, Ética, Ciência e Teoria Política, } \\
\text { Sociologia, Filosofia, Artes e outros. } \\
\text { Período de análise: } 1993 \text { - atual. } \\
\text { Número de registros: Mais de } 400 \text { títulos. } \\
\text { Tipo de publicação: Artigos na íntegra. }\end{array}$ \\
\hline $\begin{array}{l}\text { PsycINFO } \\
\text { psyinfo.apa.org }\end{array}$ & $\begin{array}{l}\text { Áreas: Psicologia, Ciências da saúde e social. } 22 \\
\text { grandes categorias e } 135 \text { subcategorias. } \\
\text { Período de análise: } 1806 \text { - atual. } \\
\text { Número de registros: Mais de } 2 \text { milhões de } \\
\text { registros. } \\
\text { Tipo de publicação: Artigos com resumos, artigos } \\
\text { na íntegra, livros, teses e dissertações. }\end{array}$ \\
\hline $\begin{array}{l}\text { ScienceDirect } \\
\text { www.sciencedirect.com }\end{array}$ & $\begin{array}{l}\text { Áreas: Ciências físicas e engenharia, biológicas, da } \\
\text { saúde, sociais e humanas. } \\
\text { Período de análise: não descrito. } \\
\text { Número de registros: mais de } 2500 \text { revistas e mais } \\
\text { de } 6000 \text { livros. } \\
\text { Tipo de publicação: não descrito. }\end{array}$ \\
\hline
\end{tabular}




\begin{tabular}{|c|c|}
\hline $\begin{array}{l}\text { SCOPUS } \\
\text { www.scopus.com } \\
\end{array}$ & $\begin{array}{l}\text { Áreas: Medicina e Ciências sociais, incluindo artes } \\
\text { e humanidades. A origem de mais da metade do } \\
\text { conteúdo é da Europa, América Latina e Ásia. } \\
\text { Período de análise: Desde } 1996.70 \% \text { dos registros } \\
\text { desde } 1823 \text { possuem resumo. } \\
\text { Número de registros: Mais de } 16.500 \text { jornais, } 575 \\
\text { publicações de negócios, } 315 \text { séries de livros, } \\
\text { extensa cobertura da conferência ( } 3,6 \text { milhões de } \\
\text { artigos em conferências), } 37 \text { milhões de registros, } \\
\text { dos quais, } 18 \text { milhões incluem referências a partir } \\
\text { de } 1996 \text { (75\% incluem referências), } 19 \text { milhões de } \\
\text { registros publicados desde } 1823 \text { até } 1996 \text {. } \\
\text { Tipo de publicação: Artigos, livros e anais de } \\
\text { congressos. }\end{array}$ \\
\hline $\begin{array}{l}\text { Social Service abstracts } \\
\text { http://csaweb111v.csa.com/ids7 } \\
\text { 0/quick_search.php?SID=60qb5 } \\
\text { majikhsbhks00q219can6 }\end{array}$ & $\begin{array}{l}\text { Áreas: Serviço social, serviços humanos, e áreas } \\
\text { afins, incluindo o bem-estar social, política social e } \\
\text { desenvolvimento comunitário. } \\
\text { Período de análise: } 1979 \text { - atual. } \\
\text { Número de registros: Mais de } 151.744 \text { registros. } \\
\text { Tipo de Publicação: resumos e índices de mais de } \\
\text { 1.300 publicações seriadas, resumos de dissertações } \\
\text { e citações de resenhas de livros. }\end{array}$ \\
\hline $\begin{array}{l}\text { Sociological Abstracts } \\
\text { www.csa.com }\end{array}$ & $\begin{array}{l}\text { Áreas: Sociologia e disciplinas afins no campo das } \\
\text { ciências sociais e comportamentais. } \\
\text { Período de análise: } 1952 \text { - atual. } \\
\text { Número de registros: Mais de } 1800 \text { publicações. } \\
\text { Tipo de publicação: Resumos e capítulos de livros, } \\
\text { livros, dissertações e trabalhos apresentados em } \\
\text { congressos. }\end{array}$ \\
\hline $\begin{array}{l}\text { Web of Science } \\
\text { www.scientific.thomson.com }\end{array}$ & $\begin{array}{l}\text { Áreas: Multidisciplinar com } 256 \text { disciplinas. } \\
\text { Período de análise: } 1900 \text { - atual. } \\
\text { Número de registros: Mais de } 16 \text { milhões de } \\
\text { publicações, } 8700 \text { revistas, } 110000 \text { anais de } \\
\text { congressos. } \\
\text { Tipo de publicação: Artigos e anais de congressos. }\end{array}$ \\
\hline
\end{tabular}

A busca por estudos não publicados ou não indexados na literatura (literatura cinzenta) incluiu os seguintes sites: Agency for Healthcare Research and Quality (AHRQ), GoogleScholar, Grey Literature Report from New York Academy of Medicine, Scirus.com website e WHO.

Outro passo do estudo foi a identificação das referências relevantes nos estudos selecionados.

Além da seleção das bases de dados, foi necessário selecionar descritores adequados para abranger todos os estudos relevantes das áreas. A estratégia 
consistiu na utilização dos descritores em Ciências da Saúde, baseado no MeSH (Medical Subject Headings of U.S. National Library of Medicine) ou sinônimos de acordo com as diferentes bases de dados. Diferentes combinações dos descritores escolhidos e dos conectores OR e AND foram utilizadas nas bases selecionadas (Quadro 8). O estudo deve conter pelo menos um descritor ou sinônimo relacionado à classe social e outro relacionado à área da saúde, no título ou resumo. Houve adaptações de acordo com a forma de busca das diversas bases.

Quadro 8 - MeSH e sinônimos selecionados para a busca bibliográfica. São Paulo, 2010.

\begin{tabular}{|l|l|}
\hline \multicolumn{1}{|c|}{ MeSH } & \multicolumn{1}{c|}{ Sinônimos } \\
\hline Classe social & Desigualdade em saúde \\
\hline Condição social & Desigualdade social \\
\hline Epidemiologia & Estratificação social \\
\hline Estudos epidemiológicos & Indicadores demográficos \\
\hline Fatores demográficos & Pobreza \\
\hline Fatores socioeconômicos & Posição socioeconômica \\
\hline Indicadores de saúde & Processo saúde-doença \\
\hline Mobilidade social & Status socioeconômico \\
\hline
\end{tabular}

O Quadro 9 descreve as estratégias de busca utilizadas em cada base de dados.

Quadro 9 - Estratégias de busca utilizadas de acordo com as bases de dados. São Paulo, 2010. 


\begin{tabular}{|c|c|}
\hline Base de dados & Estratégia de busca \\
\hline ASSIA & $\begin{array}{l}\mathrm{AB}=(\text { "social class" OR "social classes" OR "class position" } \\
\text { OR "class factors" OR "Social Stratification") AND AB=( } \\
\text { epidemiology OR "epidemiologic study" OR "epidemiologic } \\
\text { method" OR "epidemiologic research design" OR "health- } \\
\text { disease process" OR "Health Inequalities" OR } \\
\text { "Epidemiologic Factors" OR "Health Status Indicators" OR } \\
\text { "case-control" OR "cohort" OR "Primary care") }\end{array}$ \\
\hline CAPES & $\begin{array}{l}\text { (all fields)= Classe social), }(\text { all fields })=\text { classes sociais }) \text { ou } \\
(\text { all fields })=\text { Epidemiologia })\end{array}$ \\
\hline CINAHL & $\begin{array}{l}\mathrm{AB}=(\text { (social class" OR "social classes" OR "class position" } \\
\mathrm{OR} \text { "class factors" OR "Social Stratification") AND } \mathrm{AB}=( \\
\text { epidemiology OR "epidemiologic study" OR "epidemiologic } \\
\text { method" OR "epidemiologic research design" OR "health- } \\
\text { disease process" OR "Health Inequalities" OR } \\
\text { "Epidemiologic Factors" OR "Health Status Indicators") }\end{array}$ \\
\hline Current Contents & $\begin{array}{l}\text { AB=("social class" OR "social classes" OR "socioeconomic } \\
\text { position" OR "socioeconomic status" OR "class position" } \\
\text { OR "class factors" OR "Social Stratification") AND } \\
\text { Topic=(epidemiology OR "epidemiologic study" OR } \\
\text { "epidemiologic method" OR "epidemiologic research } \\
\text { design" OR "health-disease process" OR "Health } \\
\text { Inequalities" OR "Epidemiologic Factors" OR "Health } \\
\text { Status Indicators" OR "Primary care") NOT Topic=(child* } \\
\text { OR bab* OR infant* OR neonate* OR Newborn OR elderly } \\
\text { OR old-aged OR ancient) }\end{array}$ \\
\hline Dedalus & $\begin{array}{l}\text { (all fields)=("classe social" or "classes sociais" or "posição } \\
\text { socioeconômica" or "status socioeconômi) AND (Todos os } \\
\text { Campos (all fields) =(epidemiologia or "estudo } \\
\text { epidemiológico" or saúde or desigualdade) }\end{array}$ \\
\hline $\begin{array}{l}\text { Dissertation } \\
\text { Abstracts } \\
\text { International }\end{array}$ & 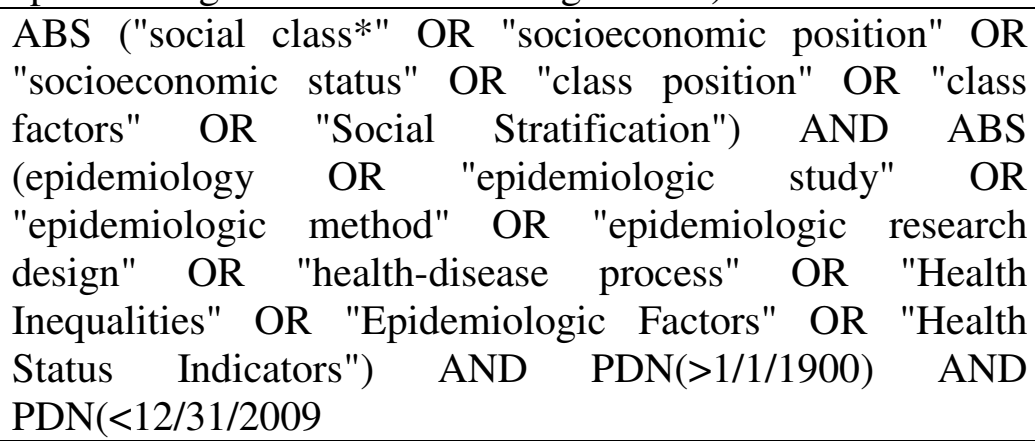 \\
\hline DOAJ & Abstract=social class or epidemiology \\
\hline EMBASE & 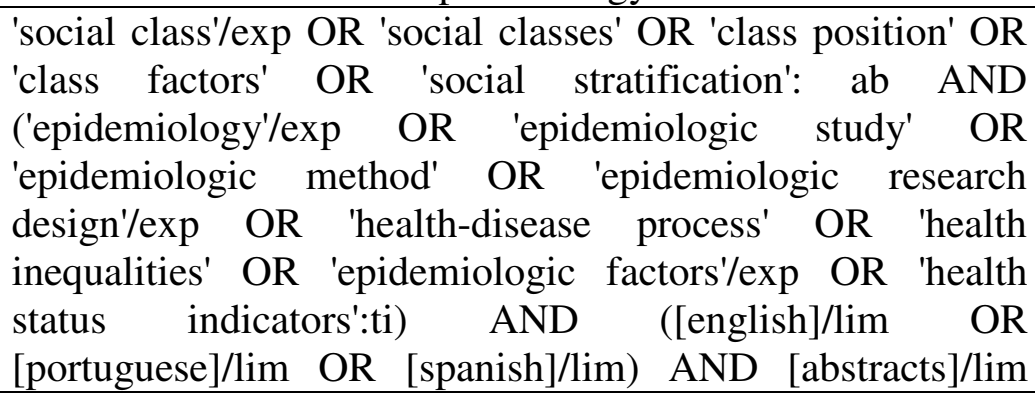 \\
\hline
\end{tabular}




\begin{tabular}{|c|c|}
\hline & AND [embase]/lim AND [1966-2009]/py \\
\hline LILACS & $\begin{array}{l}\text { "classe social" or "classes sociais" [words] or "posição } \\
\text { socioeconomica" or "posição socio-economica" [words]or } \\
\text { "status socioeconomico" or "status socio-econômico" } \\
\text { [words] }\end{array}$ \\
\hline MEDLINE/PUBMED & $\begin{array}{l}\text { ("social class" OR "social classes" OR "class position" OR } \\
\text { "class factors" OR "Social Stratification"[Title/Abstract]) } \\
\text { AND (epidemiology OR "epidemiologic study" OR } \\
\text { "epidemiologic method" OR "epidemiologic } \\
\text { design" OR "hearch } \\
\text { Inequalities" OR "Epidemiologic Factors" OR "Health } \\
\text { Status Indicators"[Title/Abstract]) }\end{array}$ \\
\hline MUSE & $\begin{array}{l}\text { "social class" OR "social classes" OR "socioeconomic } \\
\text { position" OR "socioeconomic status" OR "class position" } \\
\text { OR "class factors" OR "Social Stratification" in All Fields } \\
\text { w/Text AND epidemiology OR "epidemiologic study" OR } \\
\text { "epidemiologic method" OR "epidemiologic research } \\
\text { design" OR "health-disease process" OR "Health } \\
\text { Inequalities" OR "Epidemiologic Factors" OR "Health } \\
\text { Status Indicators" in All Fields w/Text (limited by year) }\end{array}$ \\
\hline PsyInfo & $\begin{array}{l}\text { (social class" OR "social classes" OR "socioeconomic } \\
\text { position" OR "socioeconomic status" OR "class position" } \\
\text { OR "class factors" OR "Social Stratification" AND } \\
\text { epidemiology OR "epidemiologic study" OR "epidemiologic } \\
\text { method" OR "epidemiologic research design" OR "health- } \\
\text { disease process" OR "Health Inequalities" OR } \\
\text { "Epidemiologic Factors" OR "Health Status Indicators" OR } \\
\text { health OR cohort OR "case-control"):Any Field and [1806 } \\
\text { TO 2009]:PublicationYear }\end{array}$ \\
\hline SCC & $\begin{array}{l}\text { (TITLE-ABS-KEY("social class" OR "social classes" OR } \\
\text { "class position" OR "class factors" OR "Social } \\
\text { Stratification") AND TITLE-ABS-KEY(epidemiology OR } \\
\text { "epidemiologic study" OR "epidemiologic method" OR } \\
\text { "epidemiologic research design" OR "health-disease } \\
\text { process" OR "Health Inequalities" OR "Epidemiologic } \\
\text { Factors" OR "Health Status Indicators") AND PUBYEAR } \\
\text { BEF 2010 }\end{array}$ \\
\hline $\begin{array}{l}\text { Soci } \\
\text { abst }\end{array}$ & $\begin{array}{l}\mathrm{AB}=\text { ("social class" OR "social classes" OR "class position" } \\
\text { OR "class factors" OR "Social Stratification") AND ( } \\
\text { epidemiology OR "epidemiologic study" OR "epidemiologic } \\
\text { method" OR "epidemiologic research design" OR "health- } \\
\text { disease process" OR "Health Inequalities" OR } \\
\text { "Epidemiologic Factors" OR "Health Status Indicators" OR } \\
\text { "case-control" OR "cohort" OR "Primary care") }\end{array}$ \\
\hline Sociological abstracts & $\begin{array}{l}\mathrm{AB}=\text { ("social class" OR "social classes" OR "class position" } \\
\text { OR "class factors" OR "Social Stratification") AND ( } \\
\text { epidemiology OR "epidemiologic study" OR "epidemiologic } \\
\text { method" OR "epidemiologic research design" OR "health- } \\
\text { disease process" OR "Health Inequalities" OR }\end{array}$ \\
\hline
\end{tabular}




\begin{tabular}{|l|l|}
\hline & "Epidemiologic Factors" OR "Health Status Indicators" OR \\
& "case-control" OR "cohort" OR "Primary care") \\
\hline Web of Science & Topic=("social class" OR "social classes" OR "class \\
position" OR "class factors" OR "Social Stratification") \\
AND Topic=(epidemiology OR "epidemiologic study" OR \\
"epidemiologic method" OR "epidemiologic research \\
design" OR "health-disease process" OR "Health \\
Inequalities" OR "Epidemiologic Factors" OR "Health \\
Status Indicators" OR "case-control" OR "cohort" OR \\
"Primary care")
\end{tabular}

\subsection{Seleção e avaliação da qualidade dos estudos}

O estudo contou com dois revisores para a seleção e avaliação dos estudos encontrados que utilizaram diferentes instrumentos, de acordo com o tipo de estudo encontrado. Um revisor ficou responsável pela seleção e avaliação da qualidade dos estudos e o outro pela checagem destas tarefas.

Para facilitar a seleção dos estudos, foi utilizado um instrumento do programa JBI-NOTARI (Anexo 1) para os estudos qualitativos e outro instrumento do programa JBI-MAStARI (Anexo 2) para os quantitativos. O JBINOTARI possui sete perguntas para avaliar os estudos e foi acordado entre os revisores que o estudo seria incluído se obtivesse cinco ou mais respostas positivas. Além deste instrumento, foi elaborado um instrumento adaptado do JBINOTARI (Apêndice 1), com a finalidade de incorporar a captação e análise das teorias que fundamentam as pesquisas. Neste caso, o estudo foi incluído se obtivesse todas (duas) as respostas positivas.

No caso do JBI-MAStARI, o estudo foi selecionado se obtivesse sete ou mais respostas positivas, num total de nove perguntas. Caso não houvesse concordância entre os dois revisores, foi acordado que um terceiro revisor seria chamado.

Os estudos com resumos inconclusivos e que não se mostraram suficientes para a definição da seleção, mas dentro dos critérios de inclusão, foram também incluídos para uma busca da publicação na íntegra.

Os estudos incluídos na revisão foram inicialmente armazenados no programa EndNote e nos programas do JBI. 


\subsection{Extração dos dados}

Foram utilizados outros instrumentos do formulário do JBI para a extração dos dados dos estudos incluídos: JBI-NOTARI (Anexo 3), para os estudos qualitativos e JBI-MAStARI (Anexo 4), para os estudos quantitativos.

\subsection{Conflitos de interesse}

Não há conflitos de interesse.

\subsection{Forma de análise dos resultados}

A sistematização dos dados resultantes foi quantitativa e qualitativa. Em primeiro lugar, os estudos foram classificados por ano, procedência, tema/objeto específico analisado, natureza, tipo de estudo, resultados obtidos, país de publicação, entre outros.

Em segundo lugar, levantados os modelos teóricos, analisou-se os conteúdos de acordo com categorias teóricas pré-estabelecidas, como classe social propriamente dita e reprodução social. Levou-se em consideração a orientação de Bardin (1977) para análise de conteúdo de forma que a sistematização dos dados seguiu três etapas: pré-análise; descrição analítica e interpretação referencial. $\mathrm{Na}$ pré-análise o material foi organizado; na etapa de descrição analítica a comunicação foi analisada com profundidade, a partir dos fundamentos teóricos da pesquisa, que predefiniram os temas. A terceira etapa consistiu de uma interpretação referencial que estabeleceu relações entre os dados coletados e o objeto de análise e seu contexto mais amplo.

A sistematização dos dados quantitativos foi realizada no programa Excel, sendo seus resultados apresentados em forma de tabelas e gráficos, em números absolutos e índices percentuais (relativos). Da mesma forma, os conteúdos atinentes às categorias teóricas pré-definidas foram organizadas em quadros e tabelas. 


\section{RESULTADOS}




\section{RESULTADOS}

Cada estratégia de busca identificou um número de estudos nas 16 bases de dados, em um total de 22.314 ${ }^{8}$. Pubmed, SCOPUS e Web of Science foram as bases que mais identificaram estudos. Foi realizada uma pré-seleção, levando-se em consideração apenas o título e o resumo (Tabela 2). Os resultados desta primeira busca foram exportados para o programa EndNote ${ }^{\circledR}$ (142 estudos não foram exportados, pela dificuldade ou impossibilidade de exportação - bases CAPES, DEDALUS, Dissertation Abstracts International e LILACS - sendo analisados na própria base).

Tabela 2 - Número de estudos identificados e pré-selecionados de acordo com a base de dados. São Paulo, 2010.

\begin{tabular}{lcc}
\hline Bases de dados & \multicolumn{2}{c}{ Estudos } \\
\hline & Identificados & Pré-selecionados \\
ASSIA & 205 & 174 \\
CAPES & 875 & 51 \\
CINAHL & 37 & 28 \\
Current Contents & 630 & 246 \\
Dedalus & 131 & 17 \\
Dissertation Abstracts International & 71 & 1 \\
DOAJ & 138 & 32 \\
EMBASE & 2.666 & 189 \\
LILACS & 499 & 73 \\
MEDLINE/PUBMED & 9.097 & 2.764 \\
MUSE & 405 & 25 \\
PsyInfo & 220 & 113 \\
Scopus & 4.701 & 1.020 \\
Social service abstracts & 62 & 49 \\
Sociological abstracts & 356 & 214 \\
Web of science & 2.292 & 998 \\
\hline Total & $\mathbf{2 2 . 3 1 4}$ & $\mathbf{5 . 9 9 4}$ \\
\hline
\end{tabular}

Dos 22.314 estudos identificados pelas estratégias de busca bibliográfica, 5.994 foram pré-selecionados através do título e do resumo. Após a exclusão dos estudos duplicados e a avaliação inicial através de instrumento padronizado com os critérios de inclusão (JBI-MAStARI), 1.890 estudos foram considerados

\footnotetext{
${ }^{8}$ Foram excluídas as teses, dissertações e livros não disponíveis on-line
} 
potencialmente importantes e foram verificados na íntegra. Destes, 1.767 foram excluídos pelas seguintes razões: discussões teóricas acerca da relação entre classe social e saúde $(\mathrm{N}=137)$, utilização de variáveis socioeconômicas e demográficas isoladas, sem conotação de uso de modelo $(\mathrm{N}=544)$ e estudos fora do âmbito da atenção básica e/ou que utilizaram dados ou controles hospitalares $(\mathrm{N}=79)$, tipos de estudos epidemiológicos diferentes dos que preenchiam os critérios de inclusão e que não diziam respeito à população adulta $(\mathrm{N}=1.007)$.

Assim, 123 estudos epidemiológicos foram incluídos para atender ao segundo objetivo da revisão. A maioria dos estudos incluídos estava localizada na base Pubmed (Tabela 3).

Tabela 3 - Estudos quantitativos incluídos segundo a base de dados. São Paulo, 2010.

\begin{tabular}{lcc}
\hline Base de dados & \multicolumn{2}{c}{ Estudos } \\
\hline & $\mathbf{N}$ & $\%$ \\
Pubmed & 120 & 97,5 \\
SCOPUS & 3 & 2,5 \\
Total & $\mathbf{1 2 3}$ & $\mathbf{1 0 0}$ \\
\hline
\end{tabular}

Através dos estudos selecionados para leitura na íntegra $(\mathrm{N}=1890)$ e da procura na literatura cinzenta, foi possível identificar 34 modelos operacionais do conceito de classe social, dos quais 28 foram incluídos (Tabela 4) de acordo com os critérios do instrumento JBI-NOTARI, quatro excluídos e dois não analisados (Quadro 10), pois não foram encontrados na íntegra.

Os 28 estudos foram encontrados nas seguintes bases de dados: 
Tabela 4 - Estudos teóricos incluídos segundo base de dados. São Paulo, 2010.

\begin{tabular}{lcc}
\hline Base de dados & Estudos \\
\hline & N & $\%$ \\
Pubmed & 7 & 25,0 \\
Lilacs & 4 & 14,3 \\
Dedalus & 2 & 7,1 \\
Literatura cinzenta & 15 & 53,6 \\
Total & 28 & 100 \\
\hline
\end{tabular}

Quadro 10 - Estudos não identificados em base de dados. São Paulo, 2010.

\begin{tabular}{|c|c|c|c|c|}
\hline Autor & Título & Origem & Fonte & Ano \\
\hline $\begin{array}{l}\text { Botta AM } \\
\text { et al }\end{array}$ & $\begin{array}{l}\text { Proyecto de formulación } \\
\text { de um índice de } \\
\text { estratificación social para } \\
\text { el sistema de estadísticas } \\
\text { sociodemográficas }\end{array}$ & Argentina & INEC & 1989 \\
\hline $\begin{array}{l}\text { León A, } \\
\text { Martínez } \\
\text { JB }\end{array}$ & $\begin{array}{c}\text { La estratificación social } \\
\text { chilena hacia fines del } \\
\text { siglo XX }\end{array}$ & Chile & Livro & 2001 \\
\hline
\end{tabular}

As etapas do processo de seleção e inclusão dos estudos foram sintetizadas na Figura 2.

Figura 2 - Etapas do processo de seleção e inclusão dos estudos. São Paulo, 2010. 
Estudos identificados pela busca eletrônica

$\mathrm{N}=22.314$

Estudos pré-selecionados

através do título e resumo

$\mathrm{N}=5.994$ Estudos duplicados
$N=1.678$
Estudos excluídos a partir dos critérios de inclusăo $\mathrm{N}=2.377$

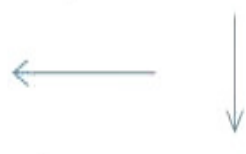

Estudos pré-selecionados únicos

$N=4.316$

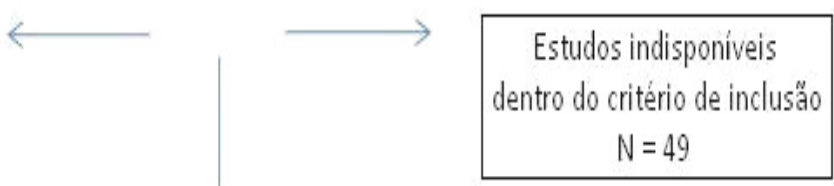

Estudos analisados na íntegra

$N=1890$

Literatura cinzenta

Estudos excluídos

$N=1767$
Estudos epidemiológicos incluídos $N=123$
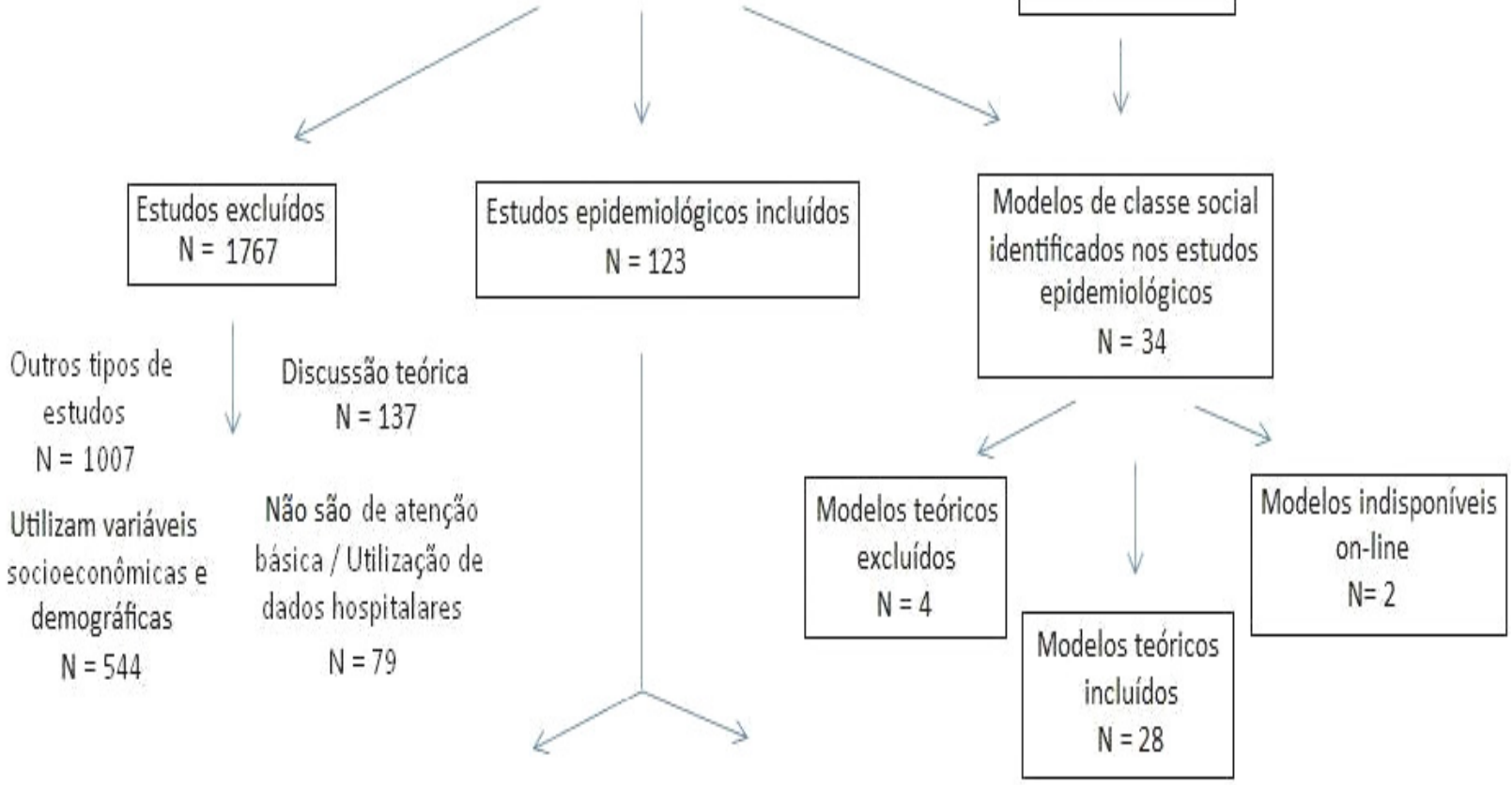

Estudo de caso-controle

$N=15$ 


\subsection{PARTE 1 - MODELOS OPERACIONAIS DO CONCEITO DE CLASSE SOCIAL NA EPIDEMIOLOGIA}

Os resultados estão apresentados em duas partes. A primeira descreve os modelos de classe social utilizados em estudos epidemiológicos. A segunda é referente aos estudos epidemiológicos que utilizaram um modelo de classe social.

\subsubsection{Modelos latino-americanos}

Do total de 32 trabalhos encontrados através da busca bibliográfica, 14 são latino-americanos, conforme o Quadro 11. Devido à peculiaridade da América Latina, optou-se por analisar os estudos separadamente ${ }^{9}$.

Quadro 11 - Caracterização dos estudos latino-americanos incluídos sobre a operacionalização do conceito de classe. São Paulo, 2010.

\begin{tabular}{|c|c|c|c|c|c|}
\hline Código & Autor (es) & Título & Origem & Fonte & Ano \\
\hline E1 & $\begin{array}{l}\text { Associação } \\
\text { Brasileira de } \\
\text { Empresas de } \\
\text { Pesquisa }\end{array}$ & $\mathrm{O}$ critério ABA/ABIPEME & Brasil & $\begin{array}{l}\text { Revista } \\
\text { Mercado } \\
\text { Global }\end{array}$ & 1984 \\
\hline E2 & $\begin{array}{l}\text { Associação } \\
\text { Nacional de } \\
\text { Empresas de } \\
\text { Pesquisa }\end{array}$ & $\begin{array}{l}\text { Critério de Classificação } \\
\text { Econômica Brasil }\end{array}$ & Brasil & ANEP & 2007 \\
\hline E3 & Barros MBA & $\begin{array}{l}\text { A utilização do conceito de } \\
\text { classe social nos estudos dos } \\
\text { perfis epidemiológicos: uma } \\
\text { proposta }\end{array}$ & Brasil & $\begin{array}{c}\text { Revista de } \\
\text { Saúde Pública }\end{array}$ & 1986 \\
\hline E4 & Behm H & $\begin{array}{c}\text { Determinantes económicas y } \\
\text { socials de la mortalidad en } \\
\text { América Latina }\end{array}$ & Costa Rica & $\begin{array}{c}\text { Revista } \\
\text { Cubana de } \\
\text { Adm.de Salud }\end{array}$ & 1980 \\
\hline E5 & Breilh $\mathrm{J}$ et al & $\begin{array}{l}\text { Clase social y desigualdad ante } \\
\text { la muerte en Quito }\end{array}$ & Equador & CEAS & 1983 \\
\hline E6 & $\begin{array}{l}\text { Bronfman M, } \\
\text { Tuirán R }\end{array}$ & $\begin{array}{l}\text { La desigualdad ante la muerte: } \\
\text { clases sociales y mortalidad en } \\
\text { La niñez }\end{array}$ & México & $\begin{array}{l}\text { Cuadernos } \\
\text { Médico } \\
\text { Sociales }\end{array}$ & 1984 \\
\hline E7 & $\begin{array}{l}\text { Carvalheiro } \\
\text { JR }\end{array}$ & $\begin{array}{c}\text { Processo migratório e } \\
\text { disseminação de doenças }\end{array}$ & Brasil & ABRASCO & 1986 \\
\hline
\end{tabular}

${ }^{9}$ Gianini (1995) relata que a América Latina foi caracterizada por enormes conflitos e crises políticas e se apresenta como um campo específico com enorme contraste social e de perfis de saúde entre os grupos sociais. 
Resultados

\begin{tabular}{|c|c|c|c|c|c|}
\hline E8 & $\begin{array}{l}\text { Graciano } \\
\text { MIG, } \\
\text { Lehfeld } \\
\text { NAS, Neves } \\
\text { A Filho }\end{array}$ & $\begin{array}{c}\text { Critérios para classificação } \\
\text { sócio-econômica: elementos } \\
\text { de atualização }\end{array}$ & Brasil & $\begin{array}{l}\text { Serviço Soc } \\
\text { Realidade }\end{array}$ & 1999 \\
\hline E9 & $\begin{array}{l}\text { La } \\
\text { Associación } \\
\text { de Institutos } \\
\text { de Estudios } \\
\text { de Mercado } \\
\text { y Opinión }\end{array}$ & $\begin{array}{l}\text { Descripcion Grupos } \\
\text { socioeconomicos }\end{array}$ & Chile & AIM Chile & 2008 \\
\hline E10 & $\begin{array}{l}\text { Lombardi C } \\
\text { et al }\end{array}$ & $\begin{array}{l}\text { Operacionalização do conceito } \\
\text { de classe social em estudos } \\
\text { epidemiológicos }\end{array}$ & Brasil & $\begin{array}{c}\text { Revista de } \\
\text { Saúde Pública }\end{array}$ & 1988 \\
\hline E11 & $\begin{array}{l}\text { Méndez- } \\
\text { Castellano H, } \\
\text { Méndez MC }\end{array}$ & $\begin{array}{l}\text { Estratificación social y } \\
\text { biologia humana: método } \\
\text { Graffar modificado }\end{array}$ & Venezuela & $\begin{array}{c}\text { Archivos } \\
\text { venezolanos } \\
\text { de } \\
\text { puericultura y } \\
\text { pediatría }\end{array}$ & 1986 \\
\hline E12 & $\begin{array}{l}\text { Queiroz VM, } \\
\text { Salum MJL }\end{array}$ & $\begin{array}{l}\text { A construção de perfis } \\
\text { epidemiológicos e a } \\
\text { responsabilidade da } \\
\text { universidade pública na luta } \\
\text { pela saúde como direito social }\end{array}$ & Brasil & $\begin{array}{l}\text { Congresso de } \\
\text { Medicina } \\
\text { Social }\end{array}$ & 2000 \\
\hline E13 & Silva GB & $\begin{array}{c}\text { Critérios de estratificação } \\
\text { social }\end{array}$ & Brasil & $\begin{array}{c}\text { Revista de } \\
\text { Saúde Pública }\end{array}$ & 1981 \\
\hline E14 & Solla JJSP & $\begin{array}{l}\text { Classe Social e Saúde: um } \\
\text { Estudo sobre a Utilização } \\
\text { deste Conceito na Investigação } \\
\text { Epidemiológica }\end{array}$ & Brasil & $\begin{array}{l}\text { Dissertação de } \\
\text { mestrado }\end{array}$ & 1992 \\
\hline
\end{tabular}

A origem da maioria dos estudos $(64,3 \%)$ é brasileira, no entanto também foram encontrados estudos do Equador, México, Chile, Costa Rica e Venezuela. O período de publicação foi de 1981 a 2009, sendo que a década de 80 concentrou a publicação dos estudos (Tabela 5).

Tabela 5 - Número de estudos publicados sobre modelos operacionais latino-americanos de classe social por década de publicação. São Paulo, 2010.

\begin{tabular}{lcc}
\hline Década de publicação & N & \% \\
\hline $\mathbf{8 0}$ & 9 & 64,3 \\
$\mathbf{9 0}$ & 2 & 14,3 \\
$\mathbf{2 0 0 0}$ & 3 & 21,4 \\
Total & 14 & 100,0 \\
\hline
\end{tabular}


Conforme o conceito de classe utilizado para a operacionalização, os estudos incluídos foram categorizados em dois grupos: grupo 1 que utilizou o conceito de classe focado no poder de consumo da família e grupo 2 que utilizou um conceito de classe social operacionalizado a partir da inserção da família no processo de produção (Tabela 6).

Tabela 6 - Classificação dos estudos em Grupo 1 e Grupo 2 de acordo com o enfoque teórico. São Paulo, 2010.

\begin{tabular}{lcc}
\hline Grupo & $\mathbf{N}$ & $\mathbf{\%}$ \\
\hline 1 & $\mathbf{5}$ & 35,7 \\
& $(\mathrm{E} 1, \mathrm{E} 2, \mathrm{E} 8, \mathrm{E} 9, \mathrm{E} 11)$ & \\
2 & $\mathbf{9}$ & 64,3 \\
& $(\mathrm{E} 3, \mathrm{E} 4, \mathrm{E} 5, \mathrm{E} 6, \mathrm{E} 7, \mathrm{E} 10, \mathrm{E} 12, \mathrm{E} 13, \mathrm{E} 14)$ & \\
Total & $\mathbf{1 4}$ & $\mathbf{1 0 0}$ \\
\hline
\end{tabular}

Os estudos do grupo 1 não foram incluídos nesta revisão, devido à definição teórica inadequada do conceito de classe social. Entretanto, diversos estudos epidemiológicos brasileiros utilizam estes modelos para mensurar a desigualdade social, motivo pelo qual foram descritos neste estudo.

O E1 define classe social através do poder aquisitivo das famílias e utiliza variáveis que discriminam os estratos sociais de acordo com seu poder de consumo. Apesar da denominação de classe social nos modelos operacionais dos estudos do grupo 1 e da existência de diversos estudos epidemiológicos que também denominam essas classificações de classe social, todos os estudos deste grupo foram classificados como formas de operacionalização do conceito de classe socioeconômica ${ }^{10}$, ao invés de classe social.

Duas classificações empregaram variáveis de consumo e posse de bens duráveis (televisão, rádio, banheiro, automóvel, máquina de lavar, videocassete e/ou DVD, geladeira, freezer), presença de empregada mensalista e grau de instrução do chefe da família, para decompor as classes. Um estudo (E2) incluiu

\footnotetext{
${ }^{10}$ Segundo Mattar (1995), classes socioeconômicas são definidas no Brasil a partir dos processos de consumo familiar, sem a preocupação de incluir os processos sociais das classes. Já na Europa o conceito é operacionalizado segundo estilo de vida.
} 
também a posse de aspirador de pó. Os estudos E8 e E11 se diferenciaram dos outros, pois utilizaram variáveis não estritamente econômicas como número de membros da família, escolaridade, habitação e ocupação, além da renda familiar (E8) e ocupação do chefe de família, escolaridade da mãe, principal fonte de renda familiar (ex. fortuna herdada, doações, salário mensal, subsídios públicos) e condição de moradia (E11).

Cada proposta utiliza um intervalo de pontos para cada classe ou estrato, baseado na quantidade de itens para classificar uma família.

$$
\begin{aligned}
& \mathrm{E} 1=5 \text { classes }-\mathrm{A}, \mathrm{B}, \mathrm{C}, \mathrm{D}, \mathrm{E} . \\
& \mathrm{E} 2=8 \text { estratos }-\mathrm{A} 1, \mathrm{~A} 2, \mathrm{~B} 1, \mathrm{~B} 2, \mathrm{C} 1, \mathrm{C} 2, \mathrm{D}, \mathrm{E} . \\
& \mathrm{E} 8=6 \text { classes }- \text { alta, média superior, média, média inferior, baixa }
\end{aligned}
$$
superior, baixa inferior.

E11 = 5 estratos - I, II, III, IV, V.

O E9 considerou as variáveis: ocupação, escolaridade e renda para identificar sete frações de classe: (A, B, C1, C2, C3, D, E). Estas classes foram agrupadas em três classes, assim denominadas: classe alta (A, B, C1), classe média (C2), classe média baixa (C3), classe baixa (D) e classe muito baixa (E).

Dos cinco modelos incluídos no grupo 1, três $(60 \%)$ foram propostos por associações de pesquisa e mercado.

Em relação ao grupo 2, algumas diferenças entre os modelos operacionais de classe social estão descritas no Quadro 12 (O Apêndice 2 descreve as referências completas dos estudos). As dimensões de análise estão relacionadas ao lugar que o sujeito ocupa no sistema de produção capitalista.

Quadro 12 - Definição das diferentes propostas latino-americanas de operacionalização do conceito de classe de acordo com a estrutura de classe e diferença entre classes e a inserção na produção. São Paulo, 2010.

\begin{tabular}{|l|l|l|}
\hline Estudo & \multicolumn{1}{|c|}{ Divisão da classe } & Diferença entre as classes \\
\hline E3 Barros & $\begin{array}{l}\text { Burguesia empresarial, pequena } \\
\text { burguesia, burguesia gerencial, } \\
\text { proletariado, subproletariado. }\end{array}$ & $\begin{array}{l}\text { Posição na ocupação, tipo de } \\
\text { ocupação, propriedade, } \\
\text { renda e número de } \\
\text { empregados. }\end{array}$ \\
\hline E4 Behm & Burguesia, grupos médios, & Posição na ocupação e tipo \\
\hline
\end{tabular}




\begin{tabular}{|c|c|c|}
\hline & proletariado e trabalhadores agrícolas & de ocupação, escolaridade.. \\
\hline E5 Breilh & $\begin{array}{l}\text { Grupo } 1-\text { grupo social ligado à } \\
\text { indústria pecuária, mineração e } \\
\text { agricultura de subsistência. Grupo } 2- \\
\text { vinculado à produção de mercadorias. } \\
\text { Grupo } 3-\text { ligado diretamente à } \\
\text { produção capitalista. } \\
\text { Grupo } 4 \text { - subproletariado ("exército } \\
\text { de reserva"). Grupo } 5 \text { - setor da } \\
\text { população de classe média ligado ao } \\
\text { Estado. Grupo } 6 \text { - classe dominante }\end{array}$ & $\begin{array}{l}\text { Posição na ocupação, tipo de } \\
\text { ocupação. }\end{array}$ \\
\hline E6 Bronfman & $\begin{array}{l}\text { Burguesia, nova burguesia, pequena } \\
\text { burguesia tradicional, proletariado } \\
\text { típico ou atípico, força de trabalho } \\
\text { livre. }\end{array}$ & $\begin{array}{l}\text { Posição na ocupação, tipo de } \\
\text { ocupação, setor de atividade, } \\
\text { número de empregados, } \\
\text { propriedade dos meios de } \\
\text { produção, grau de controle } \\
\text { do processo de trabalho, } \\
\text { escolaridade, forma em que } \\
\text { recebem a parte da riqueza } \\
\text { social. }\end{array}$ \\
\hline E7 Carvalheiro & $\begin{array}{l}\text { Burguesia, proletariado e } \\
\text { subproletariado. }\end{array}$ & $\begin{array}{l}\text { Posição na ocupação, tipo de } \\
\text { ocupação, renda, } \\
\text { característica da moradia. }\end{array}$ \\
\hline E10 Lombardi & $\begin{array}{l}\text { Burguesia, nova pequena burguesia, } \\
\text { pequena burguesia tradicional, } \\
\text { proletariado não típico, proletariado } \\
\text { típico, subproletariado. }\end{array}$ & $\begin{array}{l}\text { Posição na ocupação, tipo de } \\
\text { ocupação, papel na } \\
\text { organização social do } \\
\text { trabalho, escolaridade, } \\
\text { forma em que recebem a } \\
\text { parte da riqueza social. }\end{array}$ \\
\hline E12 Queiroz & $\begin{array}{l}\text { - GSH1*: famílias com Formas de } \\
\text { Trabalhar Adequadas (FTA) e Formas } \\
\text { de Viver Adequadas (FVA). } \\
\text { - GSH2: famílias com Formas de } \\
\text { Trabalhar Adequadas (FTA) e Formas } \\
\text { de Viver Inadequadas (FVI) ou com } \\
\text { Formas de Trabalhar Inadequadas } \\
\text { (FTI) e Formas de Viver Adequadas } \\
\text { (FVA). } \\
\text { - GSH3: famílias com Formas de } \\
\text { Trabalhar Inadequadas (FTI) e } \\
\text { Formas de Viver Inadequadas (FVI). }\end{array}$ & $\begin{array}{l}2 \text { conjuntos de variáveis: FT } \\
\text { - renda familiar per capita } \\
\text { (em salários mínimos, } \\
\text { considerando o salário, } \\
\text { outros rendimentos ou } \\
\text { atividades informais para } \\
\text { complementação de renda), } \\
\text { usufruto de benefícios e } \\
\text { registro formal no trabalho. } \\
\text { FV: propriedade da } \\
\text { habitação e o grau de } \\
\text { agregação social (vida } \\
\text { associativa) e o usufruto de } \\
\text { alguma atividade de lazer. }\end{array}$ \\
\hline E13 Silva & $\begin{array}{l}\text { A. Posição de classe: Atividades não } \\
\text { assalariadas manuais ou não-manuais } \\
\text { - empregador, trabalhador autônomo } \\
\text { - e Atividades assalariadas - manuais } \\
\text { ou não-manuais. } \\
\text { B. Situação de classe: menos de um }\end{array}$ & $\begin{array}{l}\text { Posição na ocupação, } \\
\text { relação no sistema de } \\
\text { produção, situação de classe } \\
\text { e renda. }\end{array}$ \\
\hline
\end{tabular}




\begin{tabular}{|c|c|c|}
\hline & $\begin{array}{l}\text { SM, de } 1 \text { a } 2 \text { SM, de } 3 \text { a } 7 \text { SM, de } 7 \text { a } \\
10 \text { SM, mais de } 10 \text { SM. }\end{array}$ & \\
\hline E14 Solla & $\begin{array}{l}\text { Burguesia, pequena burguesia } \\
\text { tradicional, nova pequena burguesia, } \\
\text { proletariado típico ou atípico, força de } \\
\text { trabalho livre. }\end{array}$ & $\begin{array}{l}\text { Posição na ocupação, tipo de } \\
\text { ocupação, quantidade de } \\
\text { empregados, escolaridade, }\end{array}$ \\
\hline
\end{tabular}

*GSH: Grupo social homogêneo

O E3 (Barros) propõe um modelo operacional que distingue três classes sociais: burguesia, pequena burguesia e proletariado, além de quatro frações de classe: burguesia gerencial e empresarial, proletariado propriamente dito e subproletariado. A burguesia foi fracionada em burguesia empresarial (proprietários dos meios de produção com renda maior ou igual a nove SM ou cinco ou mais empregados) e gerencial (composta pelos técnicos, administradores e dirigentes assalariados das empresas); a pequena burguesia é definida como a classe intermediária proprietária de seus meios de produção com renda menor a nove SM ou até quatro empregados; o proletariado propriamente dito que vende sua força de trabalho em troca de salário (exemplo: vendedores, bancários e escriturários); e o subproletariado, constituído dos trabalhadores com inserção precária no mercado de trabalho (construção civil, empregados domésticos e trabalhadores agrícolas) e dos trabalhadores fora da PEA (do lar, afastados e doentes). Os autônomos sem a propriedade do negócio também foram classificados como subproletariado. Já aqueles com a propriedade do negócio entraram na classificação como pequena burguesia.

O E4 (Behm) propõe um esquema de quatro classes: burguesia (proprietários agrícolas, do setor industrial ou comercial, gerentes e diretores de alto status), grupos médios (assalariados ligados ao processo de produção e que trabalham em setores de prestação de serviços e comércio, onde desempenham trabalho não manual, têm níveis altos de escolaridade - mais de 7 anos), proletariado (trabalhadores do setor secundário e terciário, níveis baixos de escolaridade) e trabalhadores agrícolas (assalariados com educação menor que o proletariado urbano). 
O E5 (Breilh) sugere a divisão social em seis $\operatorname{grupos}^{11}$ : o grupo 1 é composto de trabalhadores rurais e de mineração com jornada de trabalho excessiva, capacidade rudimentar de organizar o trabalho, sem o uso de tecnologia e acesso ao âmbito do consumo para sobrevivência. O grupo 2 está vinculado aos pequenos produtores de mercadorias (autônomos) que: empregam poucos funcionários, possuem longas horas de trabalho, capacidade limitada de organizar o trabalho, empresa com pouca competitividade, e acesso limitado no âmbito do consumo. O grupo 3 está ligado diretamente à produção capitalista: trabalhadores que vendem sua força de trabalho e possuem escasso acesso ao consumo. $\mathrm{O}$ grupo 4 está relacionado ao subproletariado, mais especificamente à força de trabalho subempregada ou desempregada (exército de reserva). O padrão de consumo é incerto. O grupo 5 é composto por trabalhadores ligados diretamente ou não ao Estado. O trabalho é intelectual, planejado, organizado e autônomo que permite um amplo acesso ao consumo (exemplo: gerentes, médicos, arquitetos e engenheiros). Já o grupo 6 é composto pelas classes sociais dominantes. O padrão de consumo é suntuoso.

O esquema do E6 (Bronfman) é composto pela burguesia (classe proprietária dos meios de produção), pequena burguesia tradicional (proprietária dos meios de produção sem a contratação de força de trabalho assalariado), nova pequena burguesia (trabalhadores assalariados de alto nível hierárquico), proletariado (vendem sua força de trabalho) típico (vínculo direto com a produção e transporte de mercadorias. Exemplo: pedreiros e operários) ou atípico (vínculo indireto com a produção. Exemplo: bancários e trabalhadores de escritório). Este esquema é baseado em quatro dimensões do conceito de classe: lugar que ocupa em um sistema de produção historicamente determinado, relação com os meios de

\footnotetext{
${ }^{11}$ Em seu estudo sobre mortalidade, Breilh utilizou a seguinte classificação abreviada, devido à precariedade dos sistemas de informação: alta (empresários e industriais - trabalhadores da classe dominante), média (trabalhadores técnicos, profissionais, militares e policiais com qualificação alta e média, agricultores qualificados, empregados e trabalhadores altamente qualificados) e baixa (trabalhadores e empregados de baixa qualificação, comerciantes e agricultores de baixa qualificação). Estudos que utilizaram a classificação completa: Wulf LMB. La dinamica socio-historica en el area metropolitana y su impacto en las condiciones de vida de la familia y el perfil saludenfermedad bucal del escolar. Caracas 1997. Acta odontol. Venez. 1999; 37(3):177-187. Rugeles AO. Condiciones de vida y de salud bucal del escolarizado y su familia: municipio Caroni, Estado Bolivar, 1992. Acta odontol. Venez. 2000; 38(1):18-36.Montiel D. Condiciones de vida y vih-sida. Servicio de atención a pacientes con enfermedades infecto contagiosas "elsa la corte". Facultad de odontología de la ucv. Caracas.2002. Acta odontol. Venez. 2003; 41(3): 4-11.
} 
produção, papel na organização social do trabalho e magnitude e forma de recebimento da riqueza social.

O E7 (Carvalheiro), baseado em Paul Singer ${ }^{12}$, propõe uma divisão em três classes: burguesia, proletariado e subproletariado. A burguesia é a classe composta por empregadores urbanos e agrícolas com renda superior a $10 \mathrm{SM}$ e cinco SM, respectivamente, além dos empregados com posição de comando na burocracia estatal ou com funções de direção em grandes empresas com renda superior a cinco SM. O poder de consumo é alto, sendo que as moradias são espaçosas e ventiladas. Os assalariados sem poder de decisão com renda de um (1) a dois SM são os proletariados. Realizam trabalhos manuais e têm condições de participação em lutas reivindicatórias, atividade sindical e partidária. As moradias são modestas e originam gastos entre 25 e $30 \%$ do total. O subproletariado é a classe composta pelos empregados domésticos e assalariados de pequenos produtores diretos. Não há condições de participação na luta de classes, possuem renda pessoal inferior a um (1) SM, baixo poder de consumo e moradia pequena e precária em regiões desprovidos de serviços públicos.

O E10 (Lombardi) define a burguesia como a classe proprietária dos meios de produção que emprega cinco ou mais pessoas e/ou tem renda superior a $15 \mathrm{SM}$; a nova pequena burguesia que são os trabalhadores assalariados de alto nível hierárquico; a pequena burguesia tradicional, composta por trabalhadores, sem ensino superior, que dispõem de meios de produção próprios e empregam menos de 5 pessoas e/ou contam com renda inferior a 15 SM. O proletariado é classificado em típico e não típico, conforme a descrição do E5. Já o subproletariado é a classe dos trabalhadores não assalariados, instáveis e sem qualificação.

Os critérios de classificação do E12 (Queiroz) são baseados no conceito de Reprodução Social que subsidiou a construção de perfis de reprodução social do coletivo. Quatro classificações foram consideradas: Formas de Trabalhar Adequadas (FTA): famílias que apresentaram pelo menos duas variáveis de corte relacionadas às formas de trabalhar dentro dos limites de adequação propostos;

\footnotetext{
${ }^{12}$ Singer (1981) considera em seu trabalho "Dominação e Desigualdade" a existência de três classe sociais: a burguesia, dividida em empresarial e gerencial; a pequena burguesia, composta pelos trabalhadores e também proprietários dos meios de produção; e o subproletariado que reúne os desempregados, trabalhadores com ocupações irregulares e trabalhadores agrícolas.
} 
Formas de Viver Adequadas (FVA): famílias que apresentaram pelo menos duas variáveis de corte relacionadas às formas de viver. Formas de Trabalhar Inadequadas (FTI) e/ou Formas de Viver Inadequadas (FVI): famílias que apresentaram para essas variáveis valores fora dos limites de adequação (Quadro 13).

Quadro 13 - Limites de adequação para a classificação das famílias.

\begin{tabular}{|c|c|c|}
\hline VARIÁVEIS & \multicolumn{2}{|c|}{ PONTOS DE CORTE } \\
\hline \begin{tabular}{|l} 
FORMAS DE \\
TRABALHAR (FT)
\end{tabular} & Adequadas (FTA) & Inadequadas (FTI) \\
\hline Renda familiar per capita & $\geq 1,8 \mathrm{SM}$ & $<1,8 \mathrm{SM}$ \\
\hline Registro formal no Trabalho & $\begin{array}{l}\text { Pelo menos um dos membros } \\
\text { trabalhadores com registro em } \\
\text { carteira profissional }\end{array}$ & $\begin{array}{l}\text { Nenhum dos membros } \\
\text { trabalhadores com registro } \\
\text { em carteira profissional }\end{array}$ \\
\hline $\begin{array}{l}\text { Benefícios oriundos do } \\
\text { trabalho }\end{array}$ & $\begin{array}{l}\geq 2 \text { benefícios oriundos do } \\
\text { trabalho, sendo pelo menos um } \\
\text { deles relacionado à assistência } \\
\text { a saúde }\end{array}$ & $\begin{array}{l}<2 \text { benefícios oriundos do } \\
\text { trabalho, desde que não } \\
\text { relacionados à assistência a } \\
\text { saúde }\end{array}$ \\
\hline FORMAS DE VIVER (FV) & Adequadas (FVA) & Inadequadas (FVI) \\
\hline Propriedade da habitação & Casa própria & $\begin{array}{l}\text { Casa alugada, cedida ou } \\
\text { invadida }\end{array}$ \\
\hline Atividades de lazer & $\begin{array}{l}\text { Pelo menos um dos membros } \\
\text { com alguma atividade de lazer, } \\
\text { não relacionada à TV ou vídeo }\end{array}$ & $\begin{array}{l}\text { Nenhum dos membros com } \\
\text { atividade de lazer não } \\
\text { relacionada à TV ou vídeo }\end{array}$ \\
\hline Agregação social & $\begin{array}{l}\text { Participação de pelo menos um } \\
\text { dos membros da família em } \\
\text { associações ou grupos de } \\
\text { natureza diversa }\end{array}$ & $\begin{array}{l}\text { Não participação de nenhum } \\
\text { membro da família em } \\
\text { associações ou grupos de } \\
\text { natureza diversa }\end{array}$ \\
\hline
\end{tabular}

Fonte: Queiroz e Salum (2000).

De acordo com o E12, as formações de GSH's estavam relacionadas com as formas de viver e trabalhar, assim classificadas e designadas: GSH1: famílias com FTA e FVA; GSH2: famílias com FTA e FVI ou com FTI e FVA; e GSH3: famílias com FTI e FVI.

O E13 (Silva) sugere um modelo de classificação baseado na posição de classe e na situação de classe. Em relação à posição, os trabalhadores são divididos em atividades não assalariadas (subdivididos em empregador ou 
trabalhador autônomo e a forma do trabalho, manual ou não manual) e atividades assalariadas, subdivididas em manuais ou não manuais. Para operacionalizar a situação de classe, o estudo propõe cinco faixas de SM (menos de 1SM, de 1 a 2 SM, de 3 a 7 SM e mais de 10 SM). A definição da classe do indivíduo é realizada a partir da combinação de posição e situação de classe.

O último modelo (E14 Solla) propõe as seguintes classes: a burguesia (proprietários do meio de produção que empregam mais de cinco empregados), pequena burguesia tradicional (proprietários do meio de produção que empregam menos de 5 empregados), nova pequena burguesia (trabalhadores assalariados de alto nível hierárquico), proletariado típico ou atípico, assim como define o E6, e força de trabalho livre (chefe da família não inserido no PEA como os estudantes, donas de casa e aposentados).

A maioria dos autores dos modelos latino-americanos utilizou dados de estudos epidemiológicos populacionais para verificar se o modelo era aplicável na prática epidemiológica.

E3: amostra da população urbana do município de Ribeirão Preto em 1978.

E4: dados do censo e de pesquisas sobre mortalidade infantil.

E5: dados de classificações estatísticas de registros oficiais.

E6: dados da pesquisa demográfica nacional do México em 1982.

E7: dados de uma pesquisa sobre incidência de meningite meningocócica no município de São Paulo.

E10: dados de famílias de um estudo longitudinal do município de Pelotas.

E12: dados da população da área de abrangência de um hospital universitário no município de São Paulo.

E13: sem informações.

E14: dados do Projeto Morbi-mortalidade Materno-Infantil realizado no município de Salvador. 


\subsubsection{Modelos de operacionalização do conceito de classe na América do} Norte e Europa

Foram incluídos 19 estudos que descreveram, propuseram ou analisaram modelos operacionais do conceito de classe social (Quadro 14). As referências completas estão descritas no Apêndice 3.

Quadro 14 - Caracterização dos estudos incluídos sobre a operacionalização do conceito de classe. São Paulo, 2010.

\begin{tabular}{|c|c|c|c|c|c|}
\hline Código & Autor (es) & Título & Origem & Fonte & Ano \\
\hline E15 & Alonso & $\begin{array}{l}\text { Validez de la ocupación } \\
\text { como indicador de la } \\
\text { clase social, según La } \\
\text { clasificación del British } \\
\text { Registrar General }\end{array}$ & Espanha & $\begin{array}{l}\text { Gaceta } \\
\text { Sanitaria }\end{array}$ & 1997 \\
\hline E16 & $\begin{array}{l}\text { Central Statistics } \\
\text { Office }\end{array}$ & $\begin{array}{l}\text { Census } 2006 \text { - Principal } \\
\text { socio-economic results }\end{array}$ & Irlanda & $\begin{array}{l}\text { Stationery } \\
\text { Office }\end{array}$ & 2007 \\
\hline E17 & $\begin{array}{l}\text { Erikson- } \\
\text { Goldthorpe }\end{array}$ & $\begin{array}{l}\text { Intergenerational class } \\
\text { mobility in three western } \\
\text { countries: England, } \\
\text { France and Sweden }\end{array}$ & Suécia & $\begin{array}{l}\text { The British } \\
\text { Journal of } \\
\text { Sociology }\end{array}$ & 1979 \\
\hline E18 & $\begin{array}{l}\text { French national } \\
\text { job classification }\end{array}$ & $\begin{array}{l}\text { Institute of Statistics and } \\
\text { Economic Studies }\end{array}$ & França & $\begin{array}{l}\text { Portrait } \\
\text { Social }\end{array}$ & 2002 \\
\hline E19 & Hansen & $\begin{array}{l}\text { Social groups in } \\
\text { Denmark }\end{array}$ & Dinamarca & $\begin{array}{l}\text { Institute of } \\
\text { Social } \\
\text { Science }\end{array}$ & 1984 \\
\hline E20 & Hollingshead & $\begin{array}{l}\text { Social class and mental } \\
\text { illness: a community } \\
\text { study }\end{array}$ & $\begin{array}{l}\text { Estados } \\
\text { Unidos }\end{array}$ & $\begin{array}{l}\text { John Wiley } \\
\text { \& Sons }\end{array}$ & 1958 \\
\hline E21 & Corcoran & $\begin{array}{l}\text { Effect of socioeconomic } \\
\text { status and parents' } \\
\text { education at birth on risk } \\
\text { of schizophrenia in } \\
\text { offspring }\end{array}$ & $\begin{array}{l}\text { Estados } \\
\text { Unidos/ } \\
\text { Israel }\end{array}$ & $\begin{array}{l}\text { Social } \\
\text { Psychiatry } \\
\text { and } \\
\text { Psychiatric } \\
\text { Epidemiology }\end{array}$ & 2009 \\
\hline E22 & Navarro & $\begin{array}{l}\text { Desigualdades sociales en } \\
\text { salud en España, Madrid }\end{array}$ & Espanha & $\begin{array}{l}\text { The Johns } \\
\text { Hopkins } \\
\text { University }\end{array}$ & 1996 \\
\hline
\end{tabular}


Resultados

\begin{tabular}{|c|c|c|c|c|c|}
\hline E23 & Regidor & $\begin{array}{l}\text { Obesity and } \\
\text { socioeconomic position } \\
\text { measured at three stages } \\
\text { of the life course in the } \\
\text { elderly }\end{array}$ & Espanha & $\begin{array}{l}\text { European } \\
\text { Journal of } \\
\text { Clinical } \\
\text { Nutrition }\end{array}$ & 2004 \\
\hline E24 & $\begin{array}{l}\text { Registrar } \\
\text { General's } \\
\text { Classification }\end{array}$ & $\begin{array}{l}\text { Office of Population } \\
\text { Censuses and Surveys. }\end{array}$ & Inglaterra & HMSO & 1980 \\
\hline E25 & Salvany & $\begin{array}{l}\text { Propuesta de un indicador } \\
\text { de clase social basado en } \\
\text { la ocupación. }\end{array}$ & Espanha & $\begin{array}{l}\text { Gaceta } \\
\text { Sanitaria }\end{array}$ & 1989 \\
\hline E26 & $\begin{array}{l}\text { Spanish Society } \\
\text { of Epidemiology }\end{array}$ & $\begin{array}{l}\text { Una propuesta de medida } \\
\text { de classe social }\end{array}$ & Espanha & $\begin{array}{l}\text { Atención } \\
\text { Primaria }\end{array}$ & 2000 \\
\hline E27 & Starfield & $\begin{array}{l}\text { Social Class Gradients } \\
\text { and Health in Childhood }\end{array}$ & $\begin{array}{l}\text { Estados } \\
\text { Unidos }\end{array}$ & $\begin{array}{l}\text { Ambulatory } \\
\text { pediatrics }\end{array}$ & 1989 \\
\hline E28 & $\begin{array}{l}\text { Starfield } \\
\text { adaptado } \\
\text { (Stevens) }\end{array}$ & $\begin{array}{l}\text { Gradients in the Health } \\
\text { Status and } \\
\text { Developmental Risks of } \\
\text { Young Children: The } \\
\text { Combined Influences of } \\
\text { Multiple Social Risk } \\
\text { Factors }\end{array}$ & $\begin{array}{l}\text { Estados } \\
\text { Unidos }\end{array}$ & $\begin{array}{l}\text { Maternal and } \\
\text { Children } \\
\text { Health } \\
\text { Journal }\end{array}$ & 2006 \\
\hline E29 & $\begin{array}{l}\text { Statistics } \\
\text { Finland }\end{array}$ & $\begin{array}{l}\text { Socio-economic } \\
\text { classification }\end{array}$ & Finlândia & Handbooks & 1989 \\
\hline E30 & $\begin{array}{l}\text { Statistics } \\
\text { Sweden }\end{array}$ & $\begin{array}{l}\text { Swedish sócio-economic } \\
\text { classification }\end{array}$ & Suécia & $\begin{array}{l}\text { Statistics } \\
\text { Sweden }\end{array}$ & 1995 \\
\hline E31 & $\begin{array}{l}\text { European socio- } \\
\text { economic } \\
\text { classification }\end{array}$ & $\begin{array}{l}\text { European Socio- } \\
\text { economic Classification } \\
(\mathrm{ESeC})\end{array}$ & $\begin{array}{l}9 \\
\text { instituições }\end{array}$ & $\begin{array}{l}\text { Institute for } \\
\text { social \& } \\
\text { economic } \\
\text { research }\end{array}$ & 2004 \\
\hline E32 & $\begin{array}{l}\text { The National } \\
\text { Statistics Socio- } \\
\text { economic } \\
\text { classification }\end{array}$ & $\begin{array}{l}\text { The National Statistics } \\
\text { Socio-economic } \\
\text { Classification User } \\
\text { Manual }\end{array}$ & Inglaterra & $\begin{array}{l}\text { National } \\
\text { Statistics }\end{array}$ & 2008 \\
\hline E33 & Wright & Class, Crisis and the State & $\begin{array}{l}\text { Estados } \\
\text { Unidos }\end{array}$ & $\begin{array}{l}\text { New Left } \\
\text { Books }\end{array}$ & 1978 \\
\hline
\end{tabular}

Em relação ao país de publicação, 15 (78,9\%) trabalhos são europeus e quatro $(21,1 \%)$ são americanos. O período de publicação deste grupo de estudos também ficou concentrado em maior proporção nas décadas de 70 e 80 (47,3\%) 
(Gráfico 1). Diferente dos estudos latino-americanos houve uma produção significativa após o ano 2000.

Gráfico 1 - Número de estudos publicados sobre modelos operacionais americanos e europeus de classe social por década de publicação. São Paulo, 2010 .

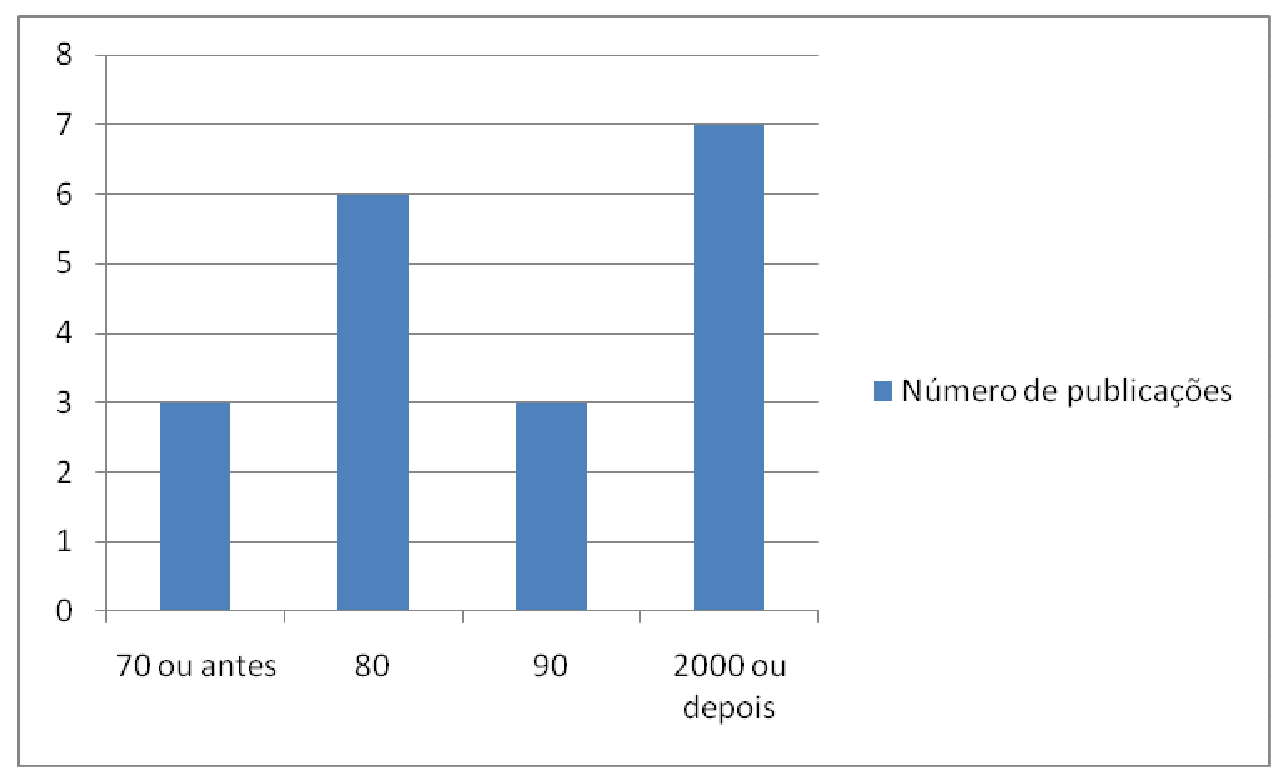

O Quadro 15 descreve as divisões de classe social de cada esquema, assim como os critérios que diferenciam cada classe.

Quadro 15 - Definição das diferentes propostas americanas e européias de operacionalização do conceito de classe de acordo com a estrutura de classe, diferença entre classes e a inserção na produção. São Paulo, 2010.

\begin{tabular}{|lll|}
\hline Estudo & Divisão da classe & $\begin{array}{l}\text { Diferença entre as } \\
\text { classes }\end{array}$ \\
\hline E15 & - Classe I: profissionais, diretores e & $\begin{array}{l}\text { Posição na ocupação, } \\
\text { tipo de ocupação }\end{array}$ \\
& técnicos superiores & \\
& - Classe II: outras ocupações de direção, \\
& técnicos médios, comércio \\
& - Classe III: ocupações intermediárias \\
& administrativas \\
& - Classe IVa: trabalhadores manuais \\
& qualificados \\
& - Classe IVb: trabalhadores manuais semi- \\
\hline
\end{tabular}




\begin{tabular}{|c|c|c|}
\hline & $\begin{array}{l}\text { qualificados } \\
\text { - Classe V: trabalhadores não qualificados } \\
\text { - Não classificáveis: forças armadas, sem } \\
\text { profissão, profissão mal declarada }\end{array}$ & \\
\hline $\begin{array}{l}\text { E16 } \\
\text { Central } \\
\text { Statistics } \\
\text { Office }\end{array}$ & $\begin{array}{l}\text { - Classe I: Trabalhadores profissionais } \\
\text { - Classe II: gerencial e técnico } \\
\text { - Classe III: não-manuais } \\
\text { - Classe IV: manual qualificados } \\
\text { - Classe V: Semi-qualificados } \\
\text { - Classe VI: não qualificados } \\
\text { - Classe VII: outras ocupações e sem } \\
\text { informação }\end{array}$ & $\begin{array}{l}\text { Posição na ocupação, } \\
\text { tipo de ocupação }\end{array}$ \\
\hline $\begin{array}{l}\text { E17 } \\
\text { Erikson- } \\
\text { Goldthorpe }\end{array}$ & $\begin{array}{l}\text { - Classe I: grandes empregadores, } \\
\text { administradores e gerentes } \\
\text { - Classe II: pequenos empregadores, } \\
\text { administradores e gerentes, trabalhadores } \\
\text { de alto nível técnico } \\
\text { - Classe III: trabalhadores intermediários, } \\
\text { não-manual (altos - IIIa, baixos - IIIb) } \\
\text { - Classe IV: Pequenos empregadores da } \\
\text { indústria e agricultura (IVa,c) e } \\
\text { autônomos da indústria e agricultura } \\
\text { (IVb,c) } \\
\text { - Classe V: Trabalhadores manuais } \\
\text { qualificados } \\
\text { - Classe VI: Trabalhadores manuais da } \\
\text { indústria } \\
\text { - Classe VII: Trabalhadores da indústria } \\
\text { não-qualificado e agricultores (VIIa,b) }\end{array}$ & $\begin{array}{l}\text { Posição na ocupação, } \\
\text { autonomia, número } \\
\text { de empregados }\end{array}$ \\
\hline $\begin{array}{l}\text { E18 } \\
\text { French } \\
\text { national job } \\
\text { classification }\end{array}$ & $\begin{array}{l}\text { - Classe alta: ocupações de alta } \\
\text { qualificação - gestores } \\
\text { - Classe intermediária: ocupações níveis } \\
\text { intermediários - técnicos } \\
\text { - Classe baixa: ocupações de baixa } \\
\text { qualificação - manuais }\end{array}$ & $\begin{array}{l}\text { Posição na ocupação, } \\
\text { tipo de ocupação }\end{array}$ \\
\hline $\begin{array}{l}\text { E19 } \\
\text { Hansen }\end{array}$ & $\begin{array}{l}\text { - Classe I - empregadores com nível } \\
\text { universitário e com mais de } 20 \\
\text { empregados e assalariados com mais de } \\
50 \text { subordinados } \\
\text { - Classe II - empregadores com } 6 \text { a } 20 \\
\text { empregados e trabalhadores assalariados } \\
\text { com } 11-50 \text { subordinados } \\
\text { - Classe III - empregadores com menos de } \\
6 \text { empregados e assalariados com 1-10 } \\
\text { subordinados } \\
\text { - Classe IV - os assalariados sem } \\
\text { subordinados e operários qualificados; } \\
\text { - Classe V - operários não qualificados, } \\
\text { desempregados e pensionistas }\end{array}$ & $\begin{array}{l}\text { Posição na ocupação, } \\
\text { tipo de ocupação, } \\
\text { número de } \\
\text { empregados, } \\
\text { propriedade dos } \\
\text { meios de produção, }\end{array}$ \\
\hline
\end{tabular}




\begin{tabular}{|c|c|c|}
\hline Igshead & $\begin{array}{l}\text { - Classe I: lideranças na administração e } \\
\text { indústria e profissionais da comunidade, } \\
\text { com rendas altas; homens com ensino } \\
\text { superior e mulheres com educação } \\
\text { secundária variável de um a quatro anos; } \\
\text { famílias tradicionais } \\
\text { - Classe II: membros possuem educação } \\
\text { secundária e muitas vezes superior; os } \\
\text { homens ocupam posições administrativas } \\
\text { e profissões classificadas em nível mais } \\
\text { baixo. } \\
\text { - Classe III: pequenos proprietários, } \\
\text { empregados, operários qualificados; os } \\
\text { filhos dessas famílias estudam nos } \\
\text { colégios técnicos e, às vezes, em } \\
\text { universidades; vivem em boas áreas } \\
\text { residenciais, mais homens e mulheres } \\
\text { estão insatisfeitos com suas condições } \\
\text { atuais de vida e menos otimistas sobre o } \\
\text { futuro } \\
\text { - Classe IV: operários semiqualificados, } \\
\text { que só frequentaram a escola primária; } \\
\text { sentem-se seguros com sua situação } \\
\text { econômica, mas não totalmente satisfeitos } \\
\text { com suas condições de vida; os filhos } \\
\text { estão insatisfeitos; não pertencem a } \\
\text { clubes, e as atividades de lazer limitam-se } \\
\text { a ver televisão, ouvir rádio, ir ao cinema e } \\
\text { fazer passeios; os homens participam dos } \\
\text { sindicatos; vivem em áreas menos } \\
\text { valorizadas; } \\
\text { - Classe V: operários não qualificados, } \\
\text { cuja maioria não completou a escola } \\
\text { primária; moram em áreas menos } \\
\text { valorizadas, incluindo cortiços; vida social } \\
\text { limitada à família, à vizinhança, à rua ou a } \\
\text { agências sociais da comunidade; adultos } \\
\text { ressentem-se das formas como são } \\
\text { tratados por patrões e outros membros da } \\
\text { comunidade }\end{array}$ & $\begin{array}{l}\text { Posição na ocupação, } \\
\text { tipo de ocupação, } \\
\text { propriedade, renda, } \\
\text { escolaridade, status }\end{array}$ \\
\hline $\begin{array}{l}\text { E21 } \\
\text { Corcoran }\end{array}$ & $\begin{array}{l}\text { - Classe I: } 15 \text { ou mais anos de } \\
\text { escolaridade e ocupações intelectuais } \\
\text { - Classe II: } 13 \text { a } 14 \text { e ocupações de } \\
\text { administração } \\
\text { - Classe III: } 12 \text { e ocupações de } \\
\text { administração } \\
\text { - Classe IV: } 9 \text { a11 e ocupações } \\
\text { qualificadas } \\
\text { - Classe V: } 7 \text { a } 8 \text { e ocupações qualificadas } \\
\text { - Classe VI: menos que } 7 \text { e ocupações não }\end{array}$ & $\begin{array}{l}\text { Posição na ocupação } \\
\text { e escolaridade }\end{array}$ \\
\hline
\end{tabular}




\begin{tabular}{|c|c|c|}
\hline & qualificadas & \\
\hline $\begin{array}{l}\text { E22 } \\
\text { Navarro }\end{array}$ & $\begin{array}{l}\text { - Trabalhadores não-manuais de nível } \\
\text { superior: empresários, agricultores ou } \\
\text { gerentes com seis ou mais empregados } \\
\text { - Trabalhadores não-manuais de nível } \\
\text { baixo: autônomos, empregadores, } \\
\text { agricultores e administradores com cinco } \\
\text { ou menos empregados } \\
\text { - Trabalhadores manuais qualificados } \\
\text { - Trabalhadores manuais não-qualificado }\end{array}$ & $\begin{array}{l}\text { Posição na ocupação, } \\
\text { tipo de ocupação, } \\
\text { propriedade, } \\
\text { escolaridade }\end{array}$ \\
\hline $\begin{array}{l}\text { E23 } \\
\text { Regidor }\end{array}$ & $\begin{array}{l}\text { - Classe I: profissionais, gerentes, } \\
\text { proprietários } \\
\text { - Classe II: proprietários de terra; } \\
\text { - Classe III: trabalhadores qualificados e } \\
\text { não qualificados de colarinho azul; } \\
\text { - Classe IV: trabalhadores agrícolas } \\
\text { assalariados }\end{array}$ & $\begin{array}{l}\text { Posição na ocupação, } \\
\text { tipo de ocupação, } \\
\text { propriedade }\end{array}$ \\
\hline $\begin{array}{l}\text { E24 } \\
\text { Registrar }\end{array}$ & $\begin{array}{l}\text { - Classe I: Ocupações profissionais de alto } \\
\text { nível } \\
\text { - Classe II: Ocupações profissionais de } \\
\text { médio nível } \\
\text { - Classe IIIN: Ocupações qualificadas } \\
\text { não-manuais } \\
\text { - Classe IIIM: Ocupações qualificadas } \\
\text { manuais } \\
\text { - Classe IV: Ocupações semi-qualificadas } \\
\text { - Classe V: Ocupações não qualificadas }\end{array}$ & $\begin{array}{l}\text { Posição na ocupação, } \\
\text { tipo de ocupação }\end{array}$ \\
\hline $\begin{array}{l}\text { E25 } \\
\text { Salvany }\end{array}$ & $\begin{array}{l}\text { - Classe I: Direção, administração de } \\
\text { empresas, altos funcionários, profissionais } \\
\text { liberais e técnicos superiores } \\
\text { - Classe II: Direção e propriedade de } \\
\text { comércios e serviços, técnicos não } \\
\text { superiores, artistas e esportistas } \\
\text { - Classe III: Direção intermediária, } \\
\text { administrativos e trabalhadores de serviço } \\
\text { de proteção e seguridade } \\
\text { - Classe IV: Trabalhadores manuais } \\
\text { qualificados e semi-qualificados da } \\
\text { indústria } \\
\text { - Classe V: Trabalhadores não } \\
\text { qualificados }\end{array}$ & $\begin{array}{l}\text { Posição na ocupação, } \\
\text { tipo de ocupação, } \\
\text { propriedade }\end{array}$ \\
\hline $\begin{array}{l}\text { E26 } \\
\text { Spanish } \\
\text { Society of } \\
\text { Epidemiology }\end{array}$ & $\begin{array}{l}\text { - Classe I: Direção e cargos superiores } \\
\text { - Classe II: técnicos médios, artistas e } \\
\text { atletas } \\
\text { - Classe III: administrativos e cargos de } \\
\text { apoio } \\
\text { - Classe IV: profissionais manuais } \\
\text { qualificados e semi-qualificados } \\
\text { - Classe V: profissionais manuais não }\end{array}$ & $\begin{array}{l}\text { Posição na ocupação, } \\
\text { tipo de ocupação, } \\
\text { propriedade }\end{array}$ \\
\hline
\end{tabular}




\begin{tabular}{|c|c|c|}
\hline & qualificados & \\
\hline $\begin{array}{l}\text { E27 } \\
\text { Starfield }\end{array}$ & $\begin{array}{l}\text { - Classe alta: dois empregos em tempo } \\
\text { integral e um ou ambos os pais com pós- } \\
\text { graduação, ou um emprego em tempo } \\
\text { integral e ambos os pais com curso } \\
\text { superior, ou dois empregos em tempo } \\
\text { integral e ambos os pais com curso } \\
\text { superior } \\
\text { - Classe média: um emprego em tempo } \\
\text { integral e um dos pais com curso superior, } \\
\text { ou um emprego em tempo integral e um } \\
\text { dos pais com curso superior ou dois } \\
\text { empregos em tempo integral e pais com } \\
\text { Ensino Médio completo ou menos } \\
\text { - Classe baixa: sem emprego em tempo } \\
\text { integral ou } 1 \text { trabalho em tempo integral } \\
\text { com Ensino Médio completo ou menos, } \\
\text { ou mãe solteira com trabalho em tempo } \\
\text { integral sem Ensino Médio }\end{array}$ & $\begin{array}{l}\text { Tipo de ocupação, } \\
\text { escolaridade }\end{array}$ \\
\hline $\begin{array}{l}\text { E28 } \\
\text { Starfield } \\
\text { adaptado } \\
\text { (Stevens) }\end{array}$ & $\begin{array}{l}\text { - Classe baixa: Ensino médio incompleto } \\
\text { ou menos e NPF }{ }^{13} \text { menor que } 100 \% \text {, ou } \\
\text { ensino médio incompleto ou menos e NPF } \\
\text { entre } 101-200 \% \text {, ou ensino médio } \\
\text { completo e NPF menor que } 100 \% \\
\text { - Classe média: Ensino médio completo e } \\
\text { NPF entre } 101-200 \% \text {, ou ensino médio } \\
\text { completo e NPF entre } 201-300 \% \text {, ou } \\
\text { ensino médio incompleto ou menos e NPF } \\
\text { entre } 201-300 \% \text {, ou ensino superior e SPF } \\
\text { menor que } 100 \% \text {, ou NPF menor que } \\
100 \% \text { e NPF entre } 101-200 \% \\
\text { - Classe alta: ensino superior e NPF entre } \\
\text { 201-300\%, ou ensino superior e } 301 \% \\
\text { mais NPF }\end{array}$ & $\begin{array}{l}\text { Combinação entre } \\
\text { educação e status de } \\
\text { pobreza familiar - } \\
\text { número de membros } \\
\text { da família e renda }\end{array}$ \\
\hline $\begin{array}{l}\text { E29 } \\
\text { Statistics } \\
\text { Finland }\end{array}$ & $\begin{array}{l}\text { - Classe I: Direção e cargos superiores } \\
\text { - Classe II: Profissionais, cargos não- } \\
\text { manuais } \\
\text { - Classe III: Semi-profissionais, técnicos, } \\
\text { cargos não-manuais } \\
\text { - Classe IV: Trabalhadores manuais }\end{array}$ & $\begin{array}{l}\text { Posição na ocupação, } \\
\text { tipo de ocupação, } \\
\text { propriedade }\end{array}$ \\
\hline $\begin{array}{l}\text { E30 } \\
\text { Swedish } \\
\text { socio- } \\
\text { economic } \\
\text { classification }\end{array}$ & $\begin{array}{l}\text { - Classe I: Trabalhadores não qualificados } \\
\text { - Classe II: Trabalhadores qualificados } \\
\text { - Classe III: Baixos assalariados } \\
\text { - Classe IV: Médios assalariados } \\
\text { - Classe V: Altos assalariados } \\
\text { - Classe VI: Agricultores e outros } \\
\text { autônomos }\end{array}$ & $\begin{array}{l}\text { Posição na ocupação, } \\
\text { renda }\end{array}$ \\
\hline
\end{tabular}

\footnotetext{
${ }^{13}$ Nível de pobreza federal é calculado de acordo com o número de membros da família e renda
} 


\begin{tabular}{|c|c|c|}
\hline & - Classe VII: Estudantes & \\
\hline $\begin{array}{l}\text { E31 } \\
\text { The European } \\
\text { socio- } \\
\text { economic } \\
\text { classification }^{14}\end{array}$ & $\begin{array}{l}\text { - Classe I: grandes assalariados, grandes } \\
\text { empresários, administradores e posições } \\
\text { de comando } \\
\text { - Classe II: médios assalariados, } \\
\text { empresários, ocupações administrativas e } \\
\text { gerenciais de alto grau técnico } \\
\text { - Classe III: ocupações intermediárias } \\
\text { (higher grade white-collar workers) } \\
\text { - Classe IV: pequenos empregadores } \\
\text { - Classe V: profissionais autônomos } \\
\text { - Classe VI: Ocupações técnicas } \\
\text { - Classe VII: Área de serviços, vendas e } \\
\text { clerical } \\
\text { - Classe VIII: Ocupações técnicas manuais } \\
\text { - Classe XI: Trabalhadores semi ou não } \\
\text { qualificados } \\
\text { - Classe X: Nunca trabalhou ou muito } \\
\text { tempo desempregado }\end{array}$ & $\begin{array}{l}\text { Posição na ocupação, } \\
\text { tipo de ocupação, } \\
\text { propriedade }\end{array}$ \\
\hline $\begin{array}{l}\text { E32 } \\
\text { The National } \\
\text { Statistics } \\
\text { Socio- } \\
\text { economic } \\
\text { classification }\end{array}$ & $\begin{array}{l}\text { - Classe 1: alta ocupação gerencial e } \\
\text { profissional (1A - Proprietários e } \\
\text { empregadores de grandes } \\
\text { estabelecimentos, 1B - altas ocupações } \\
\text { profissionais) } \\
\text { - Classe 2: baixa ocupação gerencial e } \\
\text { profissional } \\
\text { - Classe 3: ocupações intermediárias } \\
\text { - Classe 4: pequenos empregadores e } \\
\text { trabalhadores por conta própria } \\
\text { - Classe 5: ocupações de supervisão e } \\
\text { ocupações relacionadas } \\
\text { - Classe } 6 \text { profissões semi-rotineiras } \\
\text { - Classe } 7 \text { ocupações de rotina } \\
\text { - Classe } 8 \text { : nunca trabalhou e } \\
\text { desempregados de longa data }\end{array}$ & $\begin{array}{l}\text { Posição na ocupação, } \\
\text { tipo de ocupação, } \\
\text { propriedade do } \\
\text { processo de trabalho }\end{array}$ \\
\hline $\begin{array}{l}\text { E33 } \\
\text { Wright }\end{array}$ & $\begin{array}{l}\text { - gerentes e chefes em contradição com a } \\
\text { burguesia e o proletariado; } \\
\text { - pequenos empregadores em contradição } \\
\text { com a burguesia e pequena burguesia; } \\
\text { - assalariados semi-autônomos em } \\
\text { contradição com o proletariado e a } \\
\text { pequena burguesia. }\end{array}$ & $\begin{array}{l}\text { Posição na ocupação, } \\
\text { tipo de ocupação, } \\
\text { propriedade do } \\
\text { processo de trabalho }\end{array}$ \\
\hline
\end{tabular}

Em relação aos 28 estudos incluídos na primeira parte deste estudo, foram identificados 13 critérios que dividiram as classes sociais em cada modelo. Os dois mais recorrentes - posição na ocupação e tipo de ocupação - foram utilizados

\footnotetext{
${ }^{14}$ Disponível em: http://www.iser.essex.ac.uk/research/esec
} 
em quase $90 \%$ dos estudos (Tabela 7). Observa-se que nenhum estudo empregou um critério único para identificar as classes sociais.

Tabela 7 - Critérios isolados utilizados para identificar a divisão de classe nos modelos operacionais do conceito de classe social utilizados na epidemiologia. São Paulo, 2010.

\begin{tabular}{llc}
\hline Formas de trabalhar & N & \% \\
Posição na ocupação & 25 & 89,3 \\
Tipo de ocupação & 19 & 67,9 \\
Renda & 8 & 29,6 \\
Número de empregados & 4 & 14,8 \\
Registro formal no trabalho & 1 & 3,7 \\
Benefícios oriundos do trabalho & 1 & 3,7 \\
Uso de tecnologia & 1 & 3,7 \\
& & \\
Formas de viver & & \\
Nível de escolaridade & 10 & 35,7 \\
Agregação social & 2 & 7,4 \\
Localização da moradia no bairro & 2 & 7,4 \\
Status & 1 & 3,7 \\
Atividades de lazer & 1 & 3,7 \\
Propriedade de habitação & 1 & 3,7 \\
Tamanho da moradia & 1 & 3,7 \\
Número de membros da família & 1 & 3,7 \\
\hline
\end{tabular}

A Tabela 8 mostra os critérios classificados em formas de trabalhar e formas de viver, de acordo com a origem continental dos modelos. Tanto na América Latina, quanto nos outros continentes, a posição na ocupação e tipo de ocupação são critérios dominantes nos modelos de classe, assim como a escolaridade. Alguns critérios apareceram apenas nos modelos da América Latina (relacionados ao trabalho - benefícios, registro e uso de tecnologia; e à vida propriedade de habitação) e outros apenas nos outros modelos (status).

Tabela 8 - Critérios isolados utilizados para identificar a divisão de classe nos modelos operacionais do conceito de classe social utilizados na epidemiologia, de acordo com a origem do estudo. São Paulo, 2010. 


\begin{tabular}{|c|c|c|c|c|}
\hline & \multicolumn{2}{|c|}{ América Latina } & \multicolumn{2}{|c|}{$\begin{array}{c}\text { América do Norte } \\
\text { Europa }\end{array}$} \\
\hline & $\mathbf{N}$ & $\%$ & $\mathbf{N}$ & $\%$ \\
\hline \multicolumn{5}{|l|}{ Formas de trabalhar } \\
\hline Posição na ocupação & 8 & 88,9 & 17 & 89,5 \\
\hline Tipo de ocupação & 8 & 88,9 & 11 & 57,9 \\
\hline Renda & 4 & 50,0 & 4 & 21,0 \\
\hline Número de empregados & 3 & 37,5 & 1 & 5,3 \\
\hline Registro formal no trabalho & 1 & 12,5 & 0 & 0 \\
\hline Benefícios oriundos do trabalho & 1 & 12,5 & 0 & 0 \\
\hline Uso de tecnologia & 1 & 12,5 & 0 & 0 \\
\hline \multicolumn{5}{|l|}{ Formas de viver } \\
\hline Nível de escolaridade & 4 & 44,4 & 6 & 31,6 \\
\hline Atividades de lazer & 1 & 12,5 & 0 & 0 \\
\hline Número de membros da família & 1 & 12,5 & 1 & 5,3 \\
\hline Status & 0 & 0 & 1 & 5,3 \\
\hline Agregação social & 1 & 12,5 & 1 & 5,3 \\
\hline Propriedade de habitação & 1 & 12,5 & 0 & 0 \\
\hline Tamanho da moradia & 1 & 12,5 & & \\
\hline $\begin{array}{l}\text { Localização da moradia no } \\
\text { bairro }\end{array}$ & 1 & 12,5 & 1 & 5,3 \\
\hline
\end{tabular}

Quanto à combinação de critérios classificados em formas de trabalhar e de viver, a maioria utilizou critérios referentes somente às formas de trabalhar $(64,3 \%)$. Entretanto uma maior proporção de modelos latino-americanos agregou tanto as formas de trabalhar, quanto as formas de viver, para compor os modelos. Não foram encontrados modelos de classe que trabalham com as formas de viver isoladamente (Tabela 9).

Tabela 9 - Critérios isolados utilizados para identificar a divisão de classe nos modelos operacionais do conceito de classe social utilizados na epidemiologia.

São Paulo, 2010.

\begin{tabular}{|c|c|c|c|c|c|c|}
\hline & \multicolumn{2}{|c|}{ América Latina } & \multicolumn{2}{|c|}{$\begin{array}{c}\text { América do } \\
\text { Norte e Europa }\end{array}$} & \multicolumn{2}{|c|}{ Total } \\
\hline & $\mathbf{N}$ & $\%$ & $\mathbf{N}$ & $\%$ & $\mathbf{N}$ & $\%$ \\
\hline $\begin{array}{l}\text { Formas de trabalhar e de } \\
\text { viver }\end{array}$ & 5 & 55,6 & 5 & 26,3 & 10 & 35,7 \\
\hline Formas de trabalhar & 4 & 44,4 & 14 & 73,7 & 18 & 64,3 \\
\hline Formas de viver & 0 & 0 & 0 & 0 & 0 & 0 \\
\hline Total & 9 & 100 & 19 & 100 & 28 & 100 \\
\hline
\end{tabular}


Já em relação à quantidade de critérios para definir as classes sociais, observa-se que enquanto quase $90 \%$ dos modelos da América do Norte e Europa utilizam dois ou três critérios combinados, a maioria dos modelos da América Latina utiliza quatro a seis critérios (Tabela 10).

Tabela 10 - Número de critérios combinados utilizados para identificar as classes sociais de acordo com a origem dos modelos. São Paulo, 2010.

\begin{tabular}{ccccccc}
\hline $\begin{array}{l}\text { Número de } \\
\text { critérios }\end{array}$ & \multicolumn{2}{c}{ América Latina } & \multicolumn{2}{c}{$\begin{array}{c}\text { América do Norte e } \\
\text { Europa }\end{array}$} & \multicolumn{2}{c}{ Total } \\
& $\mathbf{N}$ & $\mathbf{\%}$ & $\mathbf{N}$ & $\mathbf{\%}$ & $\mathbf{N}$ & $\mathbf{\%}$ \\
2 & 0 & 0 & 8 & 42,1 & 8 & 28,6 \\
3 & 2 & 22,2 & 9 & 47,4 & 11 & 39,3 \\
4 & 4 & 44,4 & 1 & 5,3 & 5 & 17,9 \\
5 & 2 & 22,2 & 1 & 5,3 & 3 & 10,7 \\
6 & 1 & 11,1 & 0 & 0 & 1 & 3,6 \\
Total & $\mathbf{9}$ & $\mathbf{1 0 0}$ & $\mathbf{1 9}$ & $\mathbf{1 0 0}$ & $\mathbf{2 8}$ & $\mathbf{1 0 0}$ \\
\hline
\end{tabular}

A divisão em classes sociais de cada modelo também variou por número de classes, de acordo com os critérios acima descritos. O número de classes de cada modelo variou de 3 a 10 , sendo que 10 modelos $(35,7 \%)$ utilizaram cinco classes diferentes (Tabela 11).

Tabela 11 - Variação do número de modelos de classe social em relação ao número de frações de classes. São Paulo, 2010.

\begin{tabular}{cll}
\hline Número de classes sociais & $\mathbf{N}$ & $\%$ \\
\hline $\mathbf{3}$ & 5 & 17,9 \\
$\mathbf{4}$ & 5 & 17,9 \\
$\mathbf{5}$ & 10 & 35,7 \\
$\mathbf{6}$ & 3 & 10,7 \\
$\mathbf{7}$ & 3 & 10,7 \\
$\mathbf{8}$ & 1 & 3,6 \\
$\mathbf{1 0}$ & 1 & 3,6 \\
Total & $\mathbf{2 8}$ & $\mathbf{1 0 0}$ \\
\hline
\end{tabular}


Os estudos da América Latina partem dos seguintes referenciais teóricos: categoria reprodução social, Lenin (1957), Costa (1970), Singer (1981) e Bronfman (1983) (Tabela 12).

Tabela 12 - Estudos latino-americanos incluídos segundo referencial teórico. São Paulo, 2010.

\begin{tabular}{lcc}
\hline Referenciais teóricos & N & Estudo \\
\hline Reprodução social & 2 & E5, E12 \\
Lenin & 2 & E6, E10 \\
Singer & 2 & E3, E7 \\
Bronfman & 1 & E14 \\
Costa & 1 & E13 \\
Não descreve com clareza & 1 & E4 \\
\hline
\end{tabular}

Os demais estudos da América do Norte e Europa partem dos seguintes referenciais teóricos: Svalastoga (1959), Rose (2007), Goldthorpe (1979), Registrar (1980), Starfield (1989). Nove estudos não descrevem com clareza o referencial teórico utilizado (Tabela 13).

Tabela 13 - Estudos norte-americanos e europeus incluídos segundo referencial teórico. São Paulo, 2010.

\begin{tabular}{lll}
\hline Referenciais teóricos & N & Estudo \\
\hline Registrar & 6 & E15, E18, E25, E26, E29, E30 \\
Goldthorpe & 2 & E17, E32 \\
Rose & 1 & E31 \\
Starfield & 1 & E28 \\
Svalastoga & 1 & E19 \\
Não descreve com clareza & 8 & E16, E20, E21, E22, E23, E24, \\
& & E27, E33 \\
\hline
\end{tabular}




\subsection{PARTE 2 - ESTUDOS EPIDEMIOLÓGICOS QUE UTILIZARAM UM MODELO DO CONCEITO DE CLASSE SOCIAL}

Os 123 estudos epidemiológicos incluídos neste trabalho estão descritos no Quadro 16. Os Apêndices 4 e 5 apresentam as referências dos estudos incluídos e não localizados na íntegra, respectivamente. 
Quadro 16 - Caracterização dos estudos epidemiológicos incluídos quanto ao título, autor, ano de publicação e revista. São Paulo, 2010.

\begin{tabular}{|c|c|c|c|c|}
\hline Código & Título & Autor & Ano & Revista \\
\hline F1 & $\begin{array}{l}\text { A multi-group cross-lagged analyses of work stressors and } \\
\text { health using Canadian National sample }\end{array}$ & Ibrahim S & 2009 & $\begin{array}{l}\text { Social Science \& } \\
\text { Medicine }\end{array}$ \\
\hline $\mathrm{F} 2$ & $\begin{array}{l}\text { Abdominal obesity and respiratory function in men and } \\
\text { women in the EPIC-Norfolk study, United Kingdom }\end{array}$ & Canoy, D. & 2004 & $\begin{array}{l}\text { American Journal of } \\
\text { Epidemiology }\end{array}$ \\
\hline F3 & $\begin{array}{l}\text { Accumulation of factors influencing respiratory illness in } \\
\text { member of a national birth cohort and their offspring }\end{array}$ & Mann, S. L. & 1992 & $\begin{array}{l}\text { Journal of } \\
\text { Epidemiology and } \\
\text { Community Health }\end{array}$ \\
\hline F4 & $\begin{array}{l}\text { Adaptation to social adversity is associated with stroke } \\
\text { incidence - Evidence from the EPIC-Norfolk prospective } \\
\text { cohort study }\end{array}$ & Surtees, P. G. & 2007 & Stroke \\
\hline F5 & Adult coeliac disease and cigarette smoking & Snook, J. A. & 1996 & Gut \\
\hline F6 & Agressão física e classe social & Gianini RJ & 1999 & Rev. Saúde Pública \\
\hline F7 & $\begin{array}{l}\text { Alcohol Consumption Behaviours and Social Mobility in } \\
\text { Men and Women of the Midspan Family Study }\end{array}$ & Hart CL & 2009 & Alcohol \& Alcoholism \\
\hline F8 & $\begin{array}{l}\text { Appraisals of stressors and common mental disorder from } \\
\text { early to mid-adulthood in the } 1946 \text { British birth cohort }\end{array}$ & Hatch, S. L. & 2009 & $\begin{array}{l}\text { Journal of Affective } \\
\text { Disorders }\end{array}$ \\
\hline F9 & $\begin{array}{l}\text { Are inequalities in height narrowing? Comparing effects of } \\
\text { social class on height in two generations }\end{array}$ & Li, L. & 2004 & $\begin{array}{l}\text { Archives of Disease in } \\
\text { Childhood }\end{array}$ \\
\hline F10 & $\begin{array}{l}\text { Are inequalities in height underestimated by adult social } \\
\text { position? Effects of changing social structure and height } \\
\text { selection in a cohort study }\end{array}$ & Power, C. & 2002 & $\begin{array}{l}\text { British Medical } \\
\text { Journal }\end{array}$ \\
\hline F11 & $\begin{array}{l}\text { Area deprivation predicts lung function independently of } \\
\text { education and social class }\end{array}$ & Shohaimi, S. & 2004 & $\begin{array}{l}\text { European Respiratory } \\
\text { Journal }\end{array}$ \\
\hline
\end{tabular}




\begin{tabular}{|c|c|c|c|c|}
\hline F12 & $\begin{array}{l}\text { Association between central nervous system infections } \\
\text { during childhood and adult onset schizophrenia and other } \\
\text { psychoses: a 28-year follow-up }\end{array}$ & Rantakallo P & 1997 & $\begin{array}{l}\text { Internacional of } \\
\text { Epidemiology }\end{array}$ \\
\hline F13 & $\begin{array}{l}\text { Association between measures of morbidity and locomotor } \\
\text { disability: diagnosis alone is not enough }\end{array}$ & Adamson, J. & 2003 & Soc Sci Med \\
\hline F14 & $\begin{array}{l}\text { Association between schizophrenia and social inequality at } \\
\text { birth: case-control study }\end{array}$ & Harrison, G. & 2001 & $\begin{array}{l}\text { British Journal of } \\
\text { Psychiatry }\end{array}$ \\
\hline F15 & $\begin{array}{l}\text { Association between skin test diagnosed atopy and } \\
\text { professionally diagnosed depression: A Northern Finland } \\
1966 \text { Birth Cohort study }\end{array}$ & Timonen, $\mathrm{M}$. & 2002 & Biological Psychiatry \\
\hline F16 & $\begin{array}{l}\text { Association of cardiovascular disease risk factors with } \\
\text { socioeconomic position during childhood and during } \\
\text { adulthood }\end{array}$ & Blane, D. & 1996 & $\begin{array}{l}\text { British Medical } \\
\text { Journal }\end{array}$ \\
\hline F17 & $\begin{array}{l}\text { Asthma, enuresis, and chronic illness: Long term impact on } \\
\text { height }\end{array}$ & $\begin{array}{l}\text { Power, C., } \\
\text { Manor, O. }\end{array}$ & 1995 & $\begin{array}{l}\text { Archives of Disease in } \\
\text { Childhood }\end{array}$ \\
\hline F18 & $\begin{array}{l}\text { Birth weight does not predict blood pressure in a young } \\
\text { working population: A Sharp (Scottish Heart and Arterial } \\
\text { Disease Risk Prevention) study }\end{array}$ & Libby, G. & 2008 & $\begin{array}{l}\text { Annals of } \\
\text { Epidemiology }\end{array}$ \\
\hline F19 & $\begin{array}{l}\text { Birth weight, childhood growth and abdominal obesity in } \\
\text { adult life }\end{array}$ & Kuh, D & 2002 & $\begin{array}{l}\text { Internacional of } \\
\text { Obesity }\end{array}$ \\
\hline F20 & $\begin{array}{l}\text { Birth weight, childhood size, and muscle strength in adult } \\
\text { life: Evidence from a birth cohort study }\end{array}$ & Kuh, D. & 2002 & $\begin{array}{l}\text { American Journal of } \\
\text { Epidemiology }\end{array}$ \\
\hline F21 & $\begin{array}{l}\text { Birth weight, childhood socioeconomic environment, and } \\
\text { cognitive development in the } 1958 \text { British birth cohort } \\
\text { study }\end{array}$ & Jefferis, Bjmh & 2003 & $\begin{array}{l}\text { British Medical } \\
\text { Journal }\end{array}$ \\
\hline F22 & $\begin{array}{l}\text { Birthweight, childhood social class, and change in adult } \\
\text { blood pressure in the } 1946 \text { British birth cohort }\end{array}$ & Hardy, R. & 2003 & Lancet \\
\hline $\mathrm{F} 23$ & Blood transfusion, smoking, and obesity as risk factors for & Symmons, D. P. & 1997 & Arthritis Rheum \\
\hline
\end{tabular}




\begin{tabular}{|c|c|c|c|c|}
\hline & $\begin{array}{l}\text { the development of rheumatoid arthritis: results from a } \\
\text { primary care-based incident case-control study in Norfolk, } \\
\text { England }\end{array}$ & & & \\
\hline F24 & $\begin{array}{l}\text { Body height, birth cohort and social background in Finland } \\
\text { and Sweden }\end{array}$ & Silventoinen, K. & 2001 & Eur J Public Health \\
\hline $\mathrm{F} 25$ & $\begin{array}{l}\text { Cantabria first-episode schizophrenia study: three-year } \\
\text { follow-up }\end{array}$ & $\begin{array}{l}\text { Vazquez- } \\
\text { Barquero, J. L. }\end{array}$ & 1999 & Br J Psychiatry \\
\hline F26 & $\begin{array}{l}\text { Central and total obesity in middle aged men and women } \\
\text { in relation to lifetime socioeconomic status: evidence from } \\
\text { a national birth cohort }\end{array}$ & Langenberg, $\mathrm{C}$. & 2003 & $\begin{array}{l}\text { Journal of } \\
\text { Epidemiology and } \\
\text { Community Health }\end{array}$ \\
\hline $\mathrm{F} 27$ & $\begin{array}{l}\text { Changes in environmental tobacco smoke (ETS) exposure } \\
\text { over a } 20 \text {-year period: cross-sectional and longitudinal } \\
\text { analyses }\end{array}$ & Jefferis, B. J. & 2009 & Addiction \\
\hline F28 & $\begin{array}{l}\text { Characteristics of the low-energy reporters in a } \\
\text { longitudinal national dietary survey }\end{array}$ & Price, G. M. & 1997 & $\begin{array}{l}\text { British Journal of } \\
\text { Nutrition }\end{array}$ \\
\hline F29 & $\begin{array}{l}\text { Child to adult socioeconomic conditions and obesity in a } \\
\text { national cohort }\end{array}$ & Power, C. & 2003 & $\begin{array}{l}\text { Internacional of } \\
\text { Obesity }\end{array}$ \\
\hline F30 & $\begin{array}{l}\text { Childhood and adult dietary vitamin E intake and } \\
\text { cardiovascular risk factors in mid-life in the } 1946 \text { British } \\
\text { Birth Cohort }\end{array}$ & Mishra, G. D. & 2003 & Eur J Clin Nutr \\
\hline E31 & $\begin{array}{l}\text { Childhood and adulthood risk factors for socio-economic } \\
\text { differentials in psychological distress: evidence from the } \\
1958 \text { British birth cohort }\end{array}$ & Power, C. & 2002 & $\begin{array}{l}\text { Social Science \& } \\
\text { Medicine }\end{array}$ \\
\hline F32 & $\begin{array}{l}\text { Childhood and adulthood socio-economic position and } \\
\text { midlife depressive and anxiety disorders }\end{array}$ & Stansfeld, S. A. & 2008 & $\begin{array}{l}\text { British Journal of } \\
\text { Psychiatry }\end{array}$ \\
\hline F33 & $\begin{array}{l}\text { Childhood social class and adulthood obesity: findings } \\
\text { from the Glasgow Alumni Cohort }\end{array}$ & Okasha M & 2003 & $\begin{array}{l}\text { J Epidemiol } \\
\text { Community Health }\end{array}$ \\
\hline F34 & Cognitive ability in childhood and cognitive decline in & Richards, M. & 2004 & British Medical \\
\hline
\end{tabular}




\begin{tabular}{|c|c|c|c|c|}
\hline & mid-life: longitudinal birth cohort study & & & | Journal \\
\hline F35 & $\begin{array}{l}\text { Combination of low birth weight and high adult body mass } \\
\text { index: at what age is it established and what are its } \\
\text { determinants? }\end{array}$ & Power, C. & 2003 & $\begin{array}{l}\text { J Epidemiol } \\
\text { Community Health }\end{array}$ \\
\hline F36 & $\begin{array}{l}\text { Contextualizing smoking: Masculinity, femininity and } \\
\text { class differences in smoking in men and women from three } \\
\text { generations in the west of Scotland }\end{array}$ & Hunt, K. & 2004 & Health Educ Res \\
\hline F37 & $\begin{array}{l}\text { Co-occurrence of risk factors for cardiovascular disease by } \\
\text { social class: } 1958 \text { British birth cohort }\end{array}$ & Power, C. & 2008 & $\begin{array}{l}\text { Journal of } \\
\text { Epidemiology and } \\
\text { Community Health }\end{array}$ \\
\hline F38 & $\begin{array}{l}\text { Correlates of substance misuse in patients with first- } \\
\text { episode schizophrenia and schizoaffective disorder }\end{array}$ & Sevy, S. & 2001 & Acta Psychiatr Scand \\
\hline F39 & $\begin{array}{l}\text { Developmental origins of midlife physical performance: } \\
\text { Evidence from a British birth cohort }\end{array}$ & Kuh, D. & 2006 & $\begin{array}{l}\text { American Journal of } \\
\text { Epidemiology }\end{array}$ \\
\hline F40 & Do parental factors affect male and female fertility? & Joffe, M. & 2000 & Epidemiology \\
\hline F41 & Does area of residence affect body size and shape? & Ellaway, A. & 1997 & $\begin{array}{l}\text { Int J Obes Relat Metab } \\
\text { Disord }\end{array}$ \\
\hline $\mathrm{F} 42$ & $\begin{array}{l}\text { Does sarcopenia originate in early life? findings from the } \\
\text { Hertfordshire cohort study }\end{array}$ & Sayer, A. A. & 2004 & $\begin{array}{l}\text { Journals of } \\
\text { Gerontology }\end{array}$ \\
\hline F43 & $\begin{array}{l}\text { Duodenal ulcer and refined carbohydrate intake: a case- } \\
\text { control study assessing dietary fibre and refined sugar } \\
\text { intake }\end{array}$ & $\begin{array}{l}\text { Katschinski, B. } \\
\text { D. }\end{array}$ & 1990 & Gut \\
\hline F44 & $\begin{array}{l}\text { Early environment and child-to-adult growth trajectories in } \\
\text { the } 1958 \text { British birth cohort }\end{array}$ & Li, L. & 2004 & $\begin{array}{l}\text { American Journal of } \\
\text { Clinical Nutrition }\end{array}$ \\
\hline F45 & $\begin{array}{l}\text { Early growth and type } 2 \text { diabetes: evidence from the } 1946 \\
\text { British birth cohort }\end{array}$ & Wadsworth, M. & 2005 & Diabetologia \\
\hline F46 & $\begin{array}{l}\text { Early life and later determinants of adult disease: a } 50 \text { year } \\
\text { follow-up study of the Newcastle ThoUSAnd Families }\end{array}$ & Lamont, D. W. & 1998 & Public Health \\
\hline
\end{tabular}




\begin{tabular}{|c|c|c|c|c|}
\hline & cohort & & & \\
\hline F47 & $\begin{array}{l}\text { Effect of social class at birth on risk and presentation of } \\
\text { schizophrenia: case control study }\end{array}$ & Mulvany F & 2001 & $\begin{array}{l}\text { British Medical } \\
\text { Journal }\end{array}$ \\
\hline F48 & $\begin{array}{l}\text { Effect of tobacco smoking on survival of men and women } \\
\text { by social position: a } 28 \text { year cohort study }\end{array}$ & Gruer, L. & 2009 & $\begin{array}{l}\text { British Medical } \\
\text { Journal }\end{array}$ \\
\hline F49 & $\begin{array}{l}\text { Effects of socioeconomic position on inflammatory and } \\
\text { hemostatic markers: A life-course analysis in the } 1958 \\
\text { British birth cohort }\end{array}$ & Tabassum, F. & 2008 & $\begin{array}{l}\text { American Journal of } \\
\text { Epidemiology }\end{array}$ \\
\hline F50 & $\begin{array}{l}\text { Employment status, employment conditions, and limiting } \\
\text { illness: Prospective evidence from the British household } \\
\text { panel survey 1991-2001 }\end{array}$ & Bartley, M. & 2004 & $\begin{array}{l}\text { Journal of } \\
\text { Epidemiology and } \\
\text { Community Health }\end{array}$ \\
\hline F51 & $\begin{array}{l}\text { Energy intake at breakfast and weight change: Prospective } \\
\text { study of } 6,764 \text { middle-aged men and women }\end{array}$ & Purslow, L. R. & 2008 & $\begin{array}{l}\text { American Journal of } \\
\text { Epidemiology }\end{array}$ \\
\hline F52 & $\begin{array}{l}\text { Explaining social class differences in psychological health } \\
\text { among young-adults - a longitudinal perspective }\end{array}$ & Pov & 1992 & $\begin{array}{l}\text { Social Psychiatry and } \\
\text { Psychiatric } \\
\text { Epidemiology }\end{array}$ \\
\hline F53 & $\begin{array}{l}\text { Factors associated with change in pain and disability over } \\
\text { time: a community-based prospective observational study } \\
\text { of hip and knee osteoarthritis }\end{array}$ & Peters, T. J. & 2005 & $\begin{array}{l}\text { British Journal of } \\
\text { General Practice }\end{array}$ \\
\hline F54 & $\begin{array}{l}\text { Family and friends' influences on the uptake of regular } \\
\text { smoking from mid-adolescence to early adulthood }\end{array}$ & West, P. & 1999 & Addiction \\
\hline F55 & $\begin{array}{l}\text { Family social class, maternal body mass index, childhood } \\
\text { body mass index, and age at menarche as predictors of } \\
\text { adult obesity }\end{array}$ & Laitinen, J. & 2001 & $\begin{array}{l}\text { American Journal of } \\
\text { Clinical Nutrition }\end{array}$ \\
\hline F56 & Fibrinogen and other coronary risk factors & von Eyben, F. E. & 2005 & $\begin{array}{l}\text { Metabolism-Clinical } \\
\text { and Experimental }\end{array}$ \\
\hline F57 & $\begin{array}{l}\text { Grip strength, postural control, and functional leg power in } \\
\text { a representative cohort of British men and women: }\end{array}$ & Kuh, D. & 2005 & \begin{tabular}{|l} 
Journals of \\
Gerontology Series a-
\end{tabular} \\
\hline
\end{tabular}




\begin{tabular}{|c|c|}
\hline & $\begin{array}{l}\text { Associations with physical activity, health status, and } \\
\text { socioeconomic conditions }\end{array}$ \\
\hline F58 & $\begin{array}{l}\text { Health selection in a 14-year follow-up study - A question } \\
\text { of gendered discrimination? }\end{array}$ \\
\hline F59 & $\begin{array}{l}\text { Health selection: The role of inter- and intra-generational } \\
\text { mobility on social inequalities in health }\end{array}$ \\
\hline F60 & $\begin{array}{l}\text { Household wealth and the metabolic syndrome in the } \\
\text { whitehall II study }\end{array}$ \\
\hline F61 & $\begin{array}{l}\text { Inequalities in self rated health in the } 1958 \text { birth cohort: } \\
\text { Lifetime social circumstances or social mobility? }\end{array}$ \\
\hline F62 & $\begin{array}{l}\text { Inequalities in self-rated health: Explanations from } \\
\text { different stages of life }\end{array}$ \\
\hline F63 & $\begin{array}{l}\text { Is position in the occupational hierarchy a determinant of } \\
\text { decline in perceived health status? }\end{array}$ \\
\hline F64 & $\begin{array}{l}\text { Is the relation of social class to change in hearing threshold } \\
\text { levels from childhood to middle age explained by noise, } \\
\text { smoking, and drinking behaviour? }\end{array}$ \\
\hline F65 & $\begin{array}{l}\text { Labor market participation following onset of seizures and } \\
\text { early epilepsy: Findings from a UK cohort }\end{array}$ \\
\hline F66 & $\begin{array}{l}\text { Lateral epicondylitis in general practice: Course and } \\
\text { prognostic indicators of outcome }\end{array}$ \\
\hline F67 & $\begin{array}{l}\text { Leisure time physical activity and strenuousness of work as } \\
\text { predictors of physical functioning: a } 28 \text { year follow up of a } \\
\text { cohort of industrial employees }\end{array}$ \\
\hline F68 & $\begin{array}{l}\text { Life-course influences on health in British adults: effects of } \\
\text { socio-economic position in childhood and adulthood }\end{array}$ \\
\hline F69 & $\begin{array}{l}\text { Modifiable risk factors have an impact on socio-economic } \\
\text { differences in coronary heart disease events }\end{array}$ \\
\hline
\end{tabular}

\begin{tabular}{|c|c|c|}
\hline & & $\begin{array}{l}\text { Biological Sciences } \\
\text { and Medical Sciences }\end{array}$ \\
\hline $\begin{array}{l}\text { Hammarstrom, } \\
\text { A. }\end{array}$ & 2005 & $\begin{array}{l}\text { Social Science \& } \\
\text { Medicine }\end{array}$ \\
\hline Manor, O. & 2003 & $\begin{array}{l}\text { Social Science \& } \\
\text { Medicine }\end{array}$ \\
\hline Perel, P. & 2006 & Diabetes Care \\
\hline Power, C. & 1996 & $\begin{array}{l}\text { British Medical } \\
\text { Journal }\end{array}$ \\
\hline Power, C. & 1998 & Lancet \\
\hline Mustard, C. A. & 2003 & $\begin{array}{l}\text { Social Science \& } \\
\text { Medicine }\end{array}$ \\
\hline Ecob, R. & 2008 & $\begin{array}{l}\text { Internacional of } \\
\text { Audiology }\end{array}$ \\
\hline Holland, P. & 2009 & Epilepsia \\
\hline Smidt, N. & 2006 & $\begin{array}{l}\text { Journal of } \\
\text { Rheumatology }\end{array}$ \\
\hline Leino-Arjas, $\mathrm{P}$. & 2004 & Occup Environ Med \\
\hline Power, C. & 2007 & Int J Epidemiol \\
\hline Harald, K. & 2006 & $\begin{array}{l}\text { Scandinavian } \\
\text { Cardiovascular }\end{array}$ \\
\hline
\end{tabular}




\begin{tabular}{|c|c|c|c|c|}
\hline & & & & | Journal \\
\hline F70 & $\begin{array}{l}\text { Near work, education, family history, and myopia in Greek } \\
\text { conscripts }\end{array}$ & $\begin{array}{l}\text { Konstantopoulos, } \\
\text { A. }\end{array}$ & 2008 & Eye \\
\hline F71 & $\begin{array}{l}\text { Occupational exposure to hydrocarbons and chronic } \\
\text { pancreatitis - a case referent study }\end{array}$ & McNamee, R. & 1994 & $\begin{array}{l}\text { Occupational and } \\
\text { Environmental } \\
\text { Medicine }\end{array}$ \\
\hline F72 & $\begin{array}{l}\text { Origins of health inequalities in a national population } \\
\text { sample }\end{array}$ & Power, C. & 1997 & Lancet \\
\hline F73 & $\begin{array}{l}\text { Outcome and its predictors in schizophrenia within the } \\
\text { Northern Finland } 1966 \text { Birth Cohort }\end{array}$ & Lauronen, E. & 2007 & European Psychiatry \\
\hline F74 & $\begin{array}{l}\text { Outcomes of conduct problems in adolescence: } 40 \text { year } \\
\text { follow-up of national cohort }\end{array}$ & Colman, I. & 2009 & BMJ \\
\hline F75 & $\begin{array}{l}\text { Pathways between education and health: A caUSAl } \\
\text { modelling approach }\end{array}$ & Chandola, $\mathrm{T}$. & 2006 & $\begin{array}{l}\text { Journal of the Royal } \\
\text { Statistical Society } \\
\text { Series a-Statistics in } \\
\text { Society }\end{array}$ \\
\hline F76 & $\begin{array}{l}\text { Pertussis infection in childhood and subsequent Type } 1 \\
\text { diabetes mellitus }\end{array}$ & $\begin{array}{l}\text { Montgomery, S. } \\
\text { M. }\end{array}$ & 2002 & Diabetic Medicine \\
\hline F77 & $\begin{array}{l}\text { Physical activity and social status in adolescence as } \\
\text { predictors of physical inactivity in adulthood }\end{array}$ & Tammelin, $\mathrm{T}$. & 2003 & Preventive Medicine \\
\hline F78 & $\begin{array}{l}\text { Predictors of low back pain onset in a prospective British } \\
\text { study }\end{array}$ & Power, C. & 2001 & $\begin{array}{l}\text { American Journal of } \\
\text { Public Health }\end{array}$ \\
\hline F79 & $\begin{array}{l}\text { Prevalence of gastrointestinal diseases in two British } \\
\text { national birth cohorts }\end{array}$ & Ehlin, A. G. C. & 2003 & Gut \\
\hline F80 & $\begin{array}{l}\text { Prevalence of inflammatory bowel disease in British } 26 \\
\text { year olds: national longitudinal birth cohort }\end{array}$ & $\begin{array}{l}\text { Montgomery, S. } \\
\text { M. }\end{array}$ & 1998 & BMJ \\
\hline F81 & $\begin{array}{l}\text { Propensity to psychiatric and somatic ill-health: evidence } \\
\text { from a birth cohort }\end{array}$ & Neeleman, J. & 2002 & $\begin{array}{l}\text { Psychological } \\
\text { Medicine }\end{array}$ \\
\hline
\end{tabular}




\begin{tabular}{|c|c|c|c|c|}
\hline F82 & $\begin{array}{l}\text { Prospective association between emotional health and } \\
\text { clinical evidence of Parkinson's disease }\end{array}$ & Ishihara-Paul, L. & 2008 & $\begin{array}{l}\text { European Journal of } \\
\text { Neurology }\end{array}$ \\
\hline F83 & $\begin{array}{l}\text { Psychological distress and work and home roles: a focus on } \\
\text { socio-economic differences in distress }\end{array}$ & Matthews, S. & 2001 & $\begin{array}{l}\text { Psychological } \\
\text { Medicine }\end{array}$ \\
\hline F84 & $\begin{array}{l}\text { Psychological distress, major depressive disorder, and risk } \\
\text { of stroke }\end{array}$ & Surtees, P. G. & 2008 & Neurology \\
\hline F85 & $\begin{array}{l}\text { Rearing style and depressive disorder in adulthood: a } \\
\text { controlled study in a Spanish clinical sample }\end{array}$ & Rojo-Moreno, L. & 1999 & $\begin{array}{l}\text { Social Psychiatry and } \\
\text { Psychiatric } \\
\text { Epidemiology }\end{array}$ \\
\hline F86 & $\begin{array}{l}\text { Relation of Helicobacter pylori infection and } \\
\text { angiographically demonstrated coronary artery disease }\end{array}$ & Tsai, C. J. & 2000 & $\begin{array}{l}\text { Digestive Diseases } \\
\text { and Sciences }\end{array}$ \\
\hline F87 & $\begin{array}{l}\text { Relationship between serum ferritin, alcohol intake, and } \\
\text { social status in } 2235 \text { Danish men and women }\end{array}$ & Milman, $\mathrm{N}$. & 1996 & Ann Hematol \\
\hline F88 & $\begin{array}{l}\text { Relative contribution of early life and adult socioeconomic } \\
\text { factors to adult morbidity in the Whitehall II study }\end{array}$ & Marmot, M. & 2001 & $\begin{array}{l}\text { J Epidemiol } \\
\text { Community Health }\end{array}$ \\
\hline F89 & $\begin{array}{l}\text { Risk factors in the Midspan family study by social class in } \\
\text { childhood and adulthood }\end{array}$ & Hart, C. & 2008 & $\begin{array}{l}\text { Internacional of } \\
\text { Epidemiology }\end{array}$ \\
\hline F90 & $\begin{array}{l}\text { Social and geographical risk factors in Helicobacter pylori } \\
\text { infection }\end{array}$ & Whitaker, C. J. & 1993 & Epidemiol Infect \\
\hline F91 & $\begin{array}{l}\text { Social and regional differences in food and alcohol } \\
\text { consumption and their measurement in a national birth } \\
\text { cohort }\end{array}$ & Braddon & 1988 & N Z Méd J \\
\hline F92 & $\begin{array}{l}\text { Social circumstances and education: Life course origins of } \\
\text { social inequalities in metabolic risk in a prospective } \\
\text { national birth cohort }\end{array}$ & Langenberg, $\mathrm{C}$. & 2006 & $\begin{array}{l}\text { American Journal of } \\
\text { Public Health }\end{array}$ \\
\hline F93 & $\begin{array}{l}\text { Social class and self-rated health: can the gradient be } \\
\text { explained by differences in life style or work environment? }\end{array}$ & Bor & 2000 & $\begin{array}{l}\text { Social Science \& } \\
\text { Medicine }\end{array}$ \\
\hline F94 & Social class, risk factors, and stroke incidence in men and & McFadden E & 2009 & Stroke \\
\hline
\end{tabular}




\begin{tabular}{|l|l|} 
F95 & $\begin{array}{l}\text { women: a prospective study in the European prospective } \\
\text { investigation into cancer in Norfolk cohort }\end{array}$ \\
F96 & $\begin{array}{l}\text { Social differences in health: life-cycle effects between ages } \\
\text { S3 and } 33 \text { in the 1958 British birth cohort } \\
\text { Social inequalities in health by individual and household } \\
\text { measures of social position in a cohort of healthy people } \\
\text { Social inequalities in health: Are there gender differences? }\end{array}$ \\
F98 & $\begin{array}{l}\text { Social inequality in coronary heart disease: a comparison } \\
\text { of occupational classifications }\end{array}$ \\
F99 & $\begin{array}{l}\text { Social mobility: Evidence that it can widen health } \\
\text { inequalities }\end{array}$ \\
F100 & $\begin{array}{l}\text { Sociodemographic factors in chronic leg ulceration } \\
\text { Socio-demographic predictors of quitting smoking: how } \\
\text { important are household factors? }\end{array}$ \\
F101 & $\begin{array}{l}\text { Sociodemographic predictors of self-rated health in } \\
\text { patients with diabetes of short duration } \\
\text { Socioeconomic factors and disability retirement from back } \\
\text { pain. A 1983-1993 population-based prospective study in } \\
\text { Norway }\end{array}$ \\
F102 \\
F103
\end{tabular}

Power, C.

Chandola, T.

Matthews, S.

Chandola, T.

Boyle PJ

Moffatt, C. J.

Chandola, T.

Jonsson, P. M.

Hagen, K. B.

Purslow LR

Ellison-

Loschmann, L.

Li, C.
American Journal of

Public Health

$\mathrm{J}$ Epidemiol

2003 Community Health

Social Science \&

1999

1998

2009

2009 Medicine

British Journal of

2006

2004

Addiction

Scandinavian Journal

2001

of Public Health

Spine

2000

2008

BMC Public Health

2007

Eur Respir J

Stroke 


\begin{tabular}{|c|c|c|c|c|}
\hline F107 & Symptoms of stress predict musculoskeletal disorders & Leino, $\mathrm{P}$. & 1989 & \begin{tabular}{|l} 
J Epidemiol \\
Community Health
\end{tabular} \\
\hline F108 & $\begin{array}{l}\text { The association between childhood depression and } \\
\text { adulthood body mass index }\end{array}$ & Pine, D. S. & 2001 & Pediatrics \\
\hline F109 & $\begin{array}{l}\text { The association between father's social class and adult } \\
\text { obesity is not explained by educational attainment and an } \\
\text { unhealthy lifestyle in adulthood }\end{array}$ & Heraclides, A. & 2008 & $\begin{array}{l}\text { European Journal of } \\
\text { Epidemiology }\end{array}$ \\
\hline F110 & $\begin{array}{l}\text { The contribution of risk factors to stroke differentials, by } \\
\text { socioeconomic position in adulthood: the Renfrew/Paisley } \\
\text { Study }\end{array}$ & Hart, C. L. & 2000 & Am J Public Health \\
\hline F111 & $\begin{array}{l}\text { The duration and timing of exposure: Effects of } \\
\text { socioeconomic environment on adult health }\end{array}$ & Power, C. & 1999 & $\begin{array}{l}\text { American Journal of } \\
\text { Public Health }\end{array}$ \\
\hline F112 & $\begin{array}{l}\text { The effect of work environment and heavy smoking on the } \\
\text { social inequalities in smoking cessation }\end{array}$ & Albertsen, $\mathrm{K}$. & 2003 & Public Health \\
\hline F113 & $\begin{array}{l}\text { The health impact of smoking in manual and non-manual } \\
\text { social class men and women: a test of the Blaxter } \\
\text { hypothesis }\end{array}$ & $\begin{array}{l}\text { Marang-van de } \\
\text { Mheen, P. J. }\end{array}$ & 1999 & $\begin{array}{l}\text { Social Science \& } \\
\text { Medicine }\end{array}$ \\
\hline F114 & $\begin{array}{l}\text { The influence of childhood weight and socioeconomic } \\
\text { status on change in adult body mass index in a British } \\
\text { national birth cohort }\end{array}$ & Hardy, R. & 2000 & $\begin{array}{l}\text { Internacional of } \\
\text { Obesity }\end{array}$ \\
\hline F115 & $\begin{array}{l}\text { The influence of socioeconomic status on the reporting of } \\
\text { regional and widespread musculoskeletal pain: results from } \\
\text { the } 1958 \text { British Birth Cohort Study }\end{array}$ & Macfarlane, G. J. & 2009 & $\begin{array}{l}\text { Annals of the } \\
\text { Rheumatic Diseases }\end{array}$ \\
\hline F116 & $\begin{array}{l}\text { The irritable bowel syndrome has origins in the childhood } \\
\text { socioeconomic environment }\end{array}$ & Howell, S. & 2004 & $\begin{array}{l}\text { American Journal of } \\
\text { Gastroenterology }\end{array}$ \\
\hline F117 & $\begin{array}{l}\text { The prevalence and morbidity of chronic fatigue and } \\
\text { chronic fatigue syndrome: A prospective primary care } \\
\text { study }\end{array}$ & Wessely, S. & 1997 & $\begin{array}{l}\text { American Journal of } \\
\text { Public Health }\end{array}$ \\
\hline
\end{tabular}




\begin{tabular}{|l|l|} 
F118 & $\begin{array}{l}\text { The prevalence of PSE-CATEGO disorders in a Finnish } \\
\text { adult population cohort }\end{array}$ \\
F119 & $\begin{array}{l}\text { The relationship between prior psychiatric disorder and } \\
\text { chronic fatigue: evidence from a national birth cohort study } \\
\text { Well-being and health behaviour by parental } \\
\text { socioeconomic status - A follow-up study of adolescents } \\
\text { aged 16 until age 32 years }\end{array}$ \\
F121 & $\begin{array}{l}\text { What Mediates the Inverse Association between Education } \\
\text { and Occupational Disability from Back Pain? -- A } \\
\text { Prospective Cohort Study from the Nord-Trondelag Health } \\
\text { Study in Norway }\end{array}$ \\
F122 & $\begin{array}{l}\text { When does cardiovascular risk start? Past and present } \\
\text { socioeconomic circumstances and risk factors in adulthood }\end{array}$ \\
F123 & $\begin{array}{l}\text { Work environment and changes in self-rated health: A five } \\
\text { year follow-up study }\end{array}$
\end{tabular}

Lehtinen, V.
Harvey, S. B.
Huurre, T.
Hagen, Kare
Birger
Brunner, E.
Borg, V.

\begin{tabular}{c|l|}
1990 & $\begin{array}{l}\text { Soc Psychiatry } \\
\text { Psychiatr Epidemiol } \\
\text { Psychological } \\
\text { Medicine } \\
\text { Social Psychiatry and } \\
\text { Psychiatric } \\
\text { Epidemiology }\end{array}$ \\
2003 \\
2006 & $\begin{array}{l}\text { Social Science \& } \\
\text { Medicine }\end{array}$ \\
1999 & $\begin{array}{l}\text { J Epidemiol } \\
\text { Community Health }\end{array}$ \\
2000 & Stress Medicine
\end{tabular}


O ano de publicação variou de 1988 a 2009 e a distribuição por décadas revela um aumento de estudos a partir da década de 90, sendo que a maioria foi publicada a partir do ano de 2000 (74,0\%). Os estudos foram realizados majoritariamente na Europa (92,7\%), sendo a Grã-Bretanha o país que mais publicou estudos $(66,7 \%)$ (Tabela 14). A base Pubmed foi responsável pela localização de $100(97,5 \%)$ estudos incluídos e a SCOPUS localizou três estudos (E6, E75, e E23).

Tabela 14 - Caracterização dos estudos epidemiológicos incluídos de acordo com década e país de publicação. São Paulo, 2010.

\begin{tabular}{lcc}
\hline Década & $\mathbf{N}$ & $\mathbf{\%}$ \\
80 & 2 & 1,6 \\
90 & 30 & 24,4 \\
2000 & 91 & 74 \\
Total & $\mathbf{1 2 3}$ & $\mathbf{1 0 0}$ \\
& & \\
País & $\mathbf{N}$ & $\mathbf{\%}$ \\
Grã-Bretanha & 82 & 66,7 \\
Finlândia & 10 & 8,2 \\
Escócia & 6 & 4,9 \\
Dinamarca & 5 & 4,1 \\
Suécia & 3 & 2,4 \\
Vários & 3 & 2,4 \\
Canadá & 2 & 1,6 \\
Espanha & 2 & 1,6 \\
EUA & 2 & 1,6 \\
Noruega & 2 & 1,6 \\
Nova Zelândia & 2 & 1,6 \\
Brasil & 1 & 0,8 \\
Grécia & 1 & 0,8 \\
Irlanda & 1 & 0,8 \\
Taiwan & 1 & 0,8 \\
Total & $\mathbf{1 2 3}$ & $\mathbf{1 0 0}$ \\
\hline
\end{tabular}

No que se refere ao período de publicação dos estudos epidemiológicos e dos modelos de classe social, o Gráfico 2 mostra a evolução das publicações por década. Tanto os estudos epidemiológicos, quanto os estudos sobre modelos de classe começaram a aumentar na década de 80. Enquanto as publicações de 
modelos permaneceram estáveis nas décadas seguintes, as publicações epidemiológicas tiveram um forte aumento.

Gráfico 2 - Número de modelos operacionais de classe e número de estudos epidemiológicos por década de publicação. São Paulo, 2010.

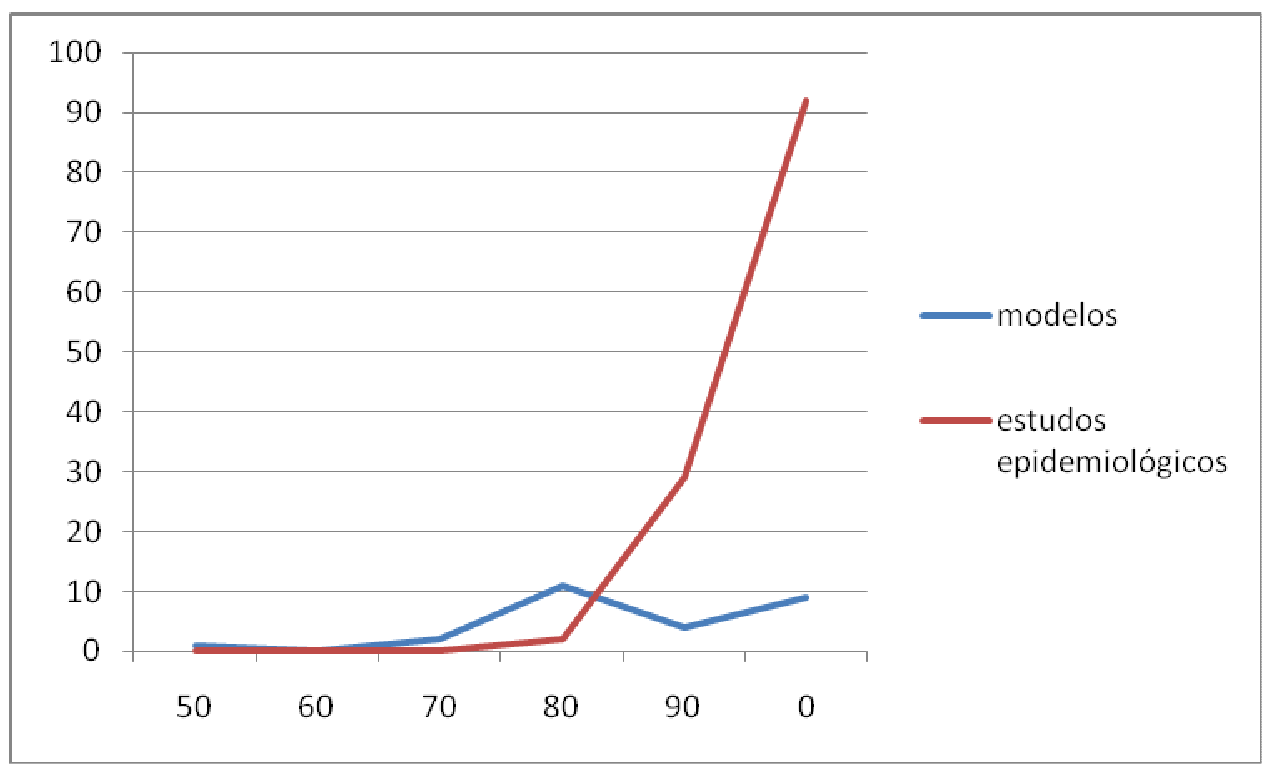

Em relação ao local de publicação, o Quadro 17 apresenta os 64 periódicos que publicaram os estudos epidemiológicos incluídos neste estudo. A origem dos periódicos foi consultada através do catálogo da base Pubmed. A maioria dos estudos foi publicada em 30 periódicos britânicos, seguido dos periódicos americanos $(\mathrm{N}=18)$ e alemães $(\mathrm{N}=3)$.

Quadro 17 - Estudos incluídos por periódico e origem do periódico. São Paulo, 2010.

\begin{tabular}{|l|l|c|c|}
\hline Periódico & Origem & N & \% \\
\hline Social Science \& Medicine & Grã-Bretanha & 12 & 9,8 \\
\hline Journal of Epidemiology and Community Health & Grã-Bretanha & 10 & 8,1 \\
\hline British Medical Journal & Grã-Bretanha & 9 & 7,3 \\
\hline American Journal of Public Health & EUA & 7 & 5,7 \\
\hline American Journal of Epidemiology & EUA & 5 & 4,1 \\
\hline Social Psychiatry and Psychiatric Epidemiology & Alemanha & 4 & 3,3 \\
\hline Addiction & Grã-Bretanha & 3 & 2,4 \\
\hline The British Journal of Psychiatry & Grã-Bretanha & 3 & 2,4 \\
\hline
\end{tabular}




\begin{tabular}{|c|c|c|c|}
\hline Gut & Grã-Bretanha & 3 & 2,4 \\
\hline International Journal of Epidemiology & Grã-Bretanha & 3 & 2,4 \\
\hline International Journal of Obesity & Grã-Bretanha & 3 & 2,4 \\
\hline Lancet & Grã-Bretanha & 3 & 2,4 \\
\hline Psychological Medicine & Grã-Bretanha & 3 & 2,4 \\
\hline Stroke & EUA & 3 & 2,4 \\
\hline American Journal of Clinical Nutrition & EUA & 2 & 1,6 \\
\hline Archives of Disease in Childhood & Grã-Bretanha & 2 & 1,6 \\
\hline European Respiratory Journal & Suíça & 2 & 1,6 \\
\hline Journal of Gerontology & EUA & 2 & 1,6 \\
\hline Occupational and Environmental Medicine & Grã-Bretanha & 2 & 1,6 \\
\hline Public Health & Grã-Bretanha & 1 & 0,8 \\
\hline Acta Psychiatrica Scandinavica & Dinamarca & 1 & 0,8 \\
\hline Alcohol \& Alcoholism & Grã-Bretanha & 1 & 0,8 \\
\hline American Journal of Gastroenterology & EUA & 1 & 0,8 \\
\hline Annals of Hematology & Alemanha & 1 & 0,8 \\
\hline Annals of Epidemiology & EUA & 1 & 0,8 \\
\hline Annals of the Rheumatic Diseases & Grã-Bretanha & 1 & 0,8 \\
\hline Arthritis and rheumatism & EUA & 1 & 0,8 \\
\hline Biological Psychiatry & EUA & 1 & 0,8 \\
\hline BMC Public Health & Grã-Bretanha & 1 & 0,8 \\
\hline British Journal of Dermatology & Grã-Bretanha & 1 & 0,8 \\
\hline British Journal of General Practice & Grã-Bretanha & 1 & 0,8 \\
\hline British Journal of Nutrition & Grã-Bretanha & 1 & 0,8 \\
\hline Diabetes Care & EUA & 1 & 0,8 \\
\hline Diabetic Medicine & Grã-Bretanha & 1 & 0,8 \\
\hline Diabetologia & Alemanha & 1 & 0,8 \\
\hline Digestive Diseases and Sciences & EUA & 1 & 0,8 \\
\hline Epidemiology and Infection & Grã-Bretanha & 1 & 0,8 \\
\hline Epidemiology & EUA & 1 & 0,8 \\
\hline Epilepsia & EUA & 1 & 0,8 \\
\hline European Journal of Clinical Nutrition & Grã-Bretanha & 1 & 0,8 \\
\hline European Journal of Public Health & Grã-Bretanha & 1 & 0,8 \\
\hline European Journal of Epidemiology & Holanda & 1 & 0,8 \\
\hline European Journal of Neurology & Grã-Bretanha & 1 & 0,8 \\
\hline European Psychiatry & França & 1 & 0,8 \\
\hline Eye & Grã-Bretanha & 1 & 0,8 \\
\hline Health Education Research & Grã-Bretanha & 1 & 0,8 \\
\hline $\begin{array}{l}\text { International Journal of Obesity and Related } \\
\text { metabolic disorders }\end{array}$ & Grã-Bretanha & 1 & 0,8 \\
\hline International Journal of Audiology & Grã-Bretanha & 1 & 0,8 \\
\hline Journal of Affective Disorders & Holanda & 1 & 0,8 \\
\hline Journal of Rheumatology & Canada & 1 & 0,8 \\
\hline Journal of the Royal Statistical Society & Grã-Bretanha & 1 & 0,8 \\
\hline Metabolism-Clinical and Experimental & EUA & 1 & 0,8 \\
\hline New Zealand Medical Association & $\begin{array}{l}\text { Nova } \\
\text { Zelândia }\end{array}$ & 1 & 0,8 \\
\hline Neurology & EUA & 1 & 0,8 \\
\hline
\end{tabular}




\begin{tabular}{|l|l|c|c|}
\hline Pediatrics & EUA & 1 & 0,8 \\
\hline Preventive Medicine & EUA & 1 & 0,8 \\
\hline Revista de Saúde Pública & Brasil & 1 & 0,8 \\
\hline Scandinavian Cardiovascular Journal & Suécia & 1 & 0,8 \\
\hline Scandinavian Journal of Public Health & Suécia & 1 & 0,8 \\
\hline Spine & EUA & 1 & 0,8 \\
\hline Stress Medicine & Grã-Bretanha & 1 & 0,8 \\
\hline
\end{tabular}

O Quadro 18 descreve o objeto de estudo, os modelos de classe utilizados, as divisões de classe, a população estudada, a associação da classe social com o objeto e em caso positivo, a identificação da classe com maior prevalência/incidência da doença. Os dados foram sintetizados na Tabela 15. 
Quadro 18- Caracterização dos estudos incluídos sobre a relação classe social e saúde, de acordo com o tipo de estudo, objeto de estudo, modelo do conceito de classe utilizado, divisão das classes empregada, população do estudo, associação entre o objeto e a classe social e classe que apresentava maior risco de apresentar o problema de saúde. São Paulo, 2010.

\begin{tabular}{|c|c|c|c|c|c|c|c|}
\hline Cód. & \begin{tabular}{|l|}
$\begin{array}{l}\text { Tipo de } \\
\text { estudo }\end{array}$ \\
\end{tabular} & Objeto de estudo & Modelo & Divisão & Populaçãa & Associação & $\begin{array}{l}\text { Risco } \\
\text { maior }\end{array}$ \\
\hline F1 & coorte & trabalho e saúde & Não referenciou & $\begin{array}{l}\text { Gerencial, qualificado, } \\
\text { não qualificado }\end{array}$ & 2556 & positiva & $\begin{array}{l}\text { Não } \\
\text { qualificado }\end{array}$ \\
\hline $\mathrm{F} 2$ & coorte & $\begin{array}{l}\text { obesidade abdominal e } \\
\text { função respiratória }\end{array}$ & $\begin{array}{l}\text { Standard } \\
\text { Occupational } \\
\text { Classification }\end{array}$ & 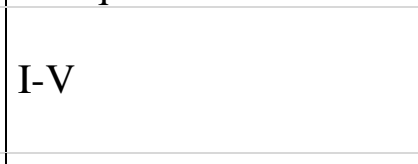 & 21.550 & positiva & IV-V \\
\hline F3 & coorte & $\begin{array}{l}\text { problemas } \\
\text { respiratórios }\end{array}$ & Não referenciou & Manual e não manual & 3322 & positiva & Manual \\
\hline $\mathrm{F} 4$ & coorte & $\begin{array}{l}\text { AVC e adversidade } \\
\text { social }\end{array}$ & $\begin{array}{l}\text { Registrar General's } \\
\text { classification }\end{array}$ & $\mathrm{I}-\mathrm{V}$ & 20629 & positiva & $\mathrm{V}$ \\
\hline F5 & $\left|\begin{array}{l}\text { caso- } \\
\text { controle }\end{array}\right|$ & $\begin{array}{l}\text { doença celíaca e } \\
\text { consumo de tabaco }\end{array}$ & Não referenciou & $\mathrm{I}-\mathrm{V}$ & 86 & negativa & \\
\hline F6 & $\begin{array}{l}\text { caso- } \\
\text { controle }\end{array}$ & $\begin{array}{l}\text { agressão física e classe } \\
\text { social }\end{array}$ & Bronfman e Tuíran & $\begin{array}{l}\text { Pequena burguesia, } \\
\text { proletariado não típico, } \\
\text { proletariado típico, } \\
\text { subproletariado }\end{array}$ & 413 & positiva & $\begin{array}{l}\text { Sub- } \\
\text { proletariado }\end{array}$ \\
\hline F7 & coorte & $\begin{array}{l}\text { consumo de álcool e } \\
\text { mobilidade social }\end{array}$ & $\begin{array}{l}\text { Registrar General's } \\
\text { classification }\end{array}$ & manual e não manual & 2338 & positiva & manual \\
\hline F8 & coorte & saúde mental & $\begin{array}{l}\text { Registrar General's } \\
\text { classification }\end{array}$ & manual e não manual & 2073 & negativa & \\
\hline F9 & coorte & estatura & Não referenciou & I +II, IIINM, IIIM, IV & 15826 & positiva & IV e V \\
\hline
\end{tabular}




\begin{tabular}{|c|c|c|c|c|c|c|c|}
\hline & & & & $+\mathrm{V}$ & & & \\
\hline F10 & coorte & estatura & Não referenciou & $\mathrm{I}-\mathrm{V}$ & 10176 & positiva & IV e V \\
\hline F11 & coorte & função pulmonar & $\begin{array}{l}\text { Registrar General's } \\
\text { classification }\end{array}$ & $\mathrm{I}-\mathrm{V}$ & 22675 & positiva & Manual \\
\hline F12 & coorte & $\begin{array}{l}\text { esquizofrenia e } \\
\text { infecção do sistema } \\
\text { nervoso central }\end{array}$ & Não referenciou & $\begin{array}{l}\text { I+II, III, IV e } \\
\text { agricultores }\end{array}$ & 10872 & positiva & III e IV \\
\hline F13 & coorte & $\begin{array}{l}\text { morbidade e } \\
\text { incapacidade de } \\
\text { locomoção }\end{array}$ & $\begin{array}{l}\text { Registrar General's } \\
\text { classification }\end{array}$ & $\mathrm{I}-\mathrm{V}$ & 858 & positiva & Manual \\
\hline F14 & \begin{tabular}{|l|} 
caso- \\
controle
\end{tabular} & esquizofrenia & $\begin{array}{l}\text { Registrar General's } \\
\text { classification }\end{array}$ & $\mathrm{I}-\mathrm{V}$ & 280 & positiva & IV e V \\
\hline F15 & coorte & $\begin{array}{l}\text { depressão e doença de } \\
\text { pele }\end{array}$ & Não referenciou & $\begin{array}{l}\text { I, II, III, IV, V e } \\
\text { agricultores }\end{array}$ & 5428 & positiva & $\mathrm{V}$ \\
\hline F16 & coorte & doença cardiovascular & $\begin{array}{l}\text { Registrar General's } \\
\text { classification }\end{array}$ & $\mathrm{I}-\mathrm{V}$ & 5645 & positiva & IV e V \\
\hline F17 & coorte & $\begin{array}{l}\text { asma, enurese, doença } \\
\text { crônica e altura na vida } \\
\text { adulta }\end{array}$ & $\begin{array}{l}\text { Registrar General's } \\
\text { classification }\end{array}$ & manual e não manual & 12537 & positiva & Manual \\
\hline F18 & coorte & $\begin{array}{l}\text { peso ao nascer e } \\
\text { pressão arterial }\end{array}$ & $\begin{array}{l}\text { Standard } \\
\text { occupation } \\
\text { classifications }\end{array}$ & $1,2,3 \mathrm{NM} 3 \mathrm{M}, 4$ e 5 & 1158 & positiva & IV e V \\
\hline F19 & coorte & $\begin{array}{l}\text { peso ao nascer, } \\
\text { crescimento e } \\
\text { obesidade abdominal }\end{array}$ & Não referenciou & manual & 3200 & positiva & Manual \\
\hline F20 & coorte & $\begin{array}{l}\text { peso ao nascer e força } \\
\text { muscular }\end{array}$ & Não referenciou & $\begin{array}{l}\text { profissional, } \\
\text { intermediários, } \\
\text { qualificados NM, }\end{array}$ & 2775 & \begin{tabular}{|l|} 
positiva, mas \\
diferença \\
insignificante
\end{tabular} & \\
\hline
\end{tabular}




\begin{tabular}{|c|c|c|c|c|c|c|c|}
\hline & & & & $\begin{array}{l}\text { qualificados M, } \\
\text { semiqualificados, não } \\
\text { qualificados }\end{array}$ & & & \\
\hline $\mathrm{F} 21$ & coorte & $\begin{array}{l}\text { peso ao nascer e } \\
\text { aspectos cognitivos }\end{array}$ & $\begin{array}{l}\text { Registrar General's } \\
\text { classification }\end{array}$ & I-II, IV-V & 10845 & positiva & IV e $\mathrm{V}$ \\
\hline F22 & coorte & $\begin{array}{l}\text { peso ao nascer e } \\
\text { pressão arterial }\end{array}$ & Não referenciou & Manual e não manual & 3634 & positiva & Manual \\
\hline $\mathrm{F} 23$ & \begin{tabular}{|l|} 
caso- \\
controle
\end{tabular} & $\begin{array}{l}\text { artrite reumatóide e } \\
\text { fatores associados }\end{array}$ & $\begin{array}{l}\text { Registrar General's } \\
\text { classification }\end{array}$ & $\mathrm{I}-\mathrm{V}$ & 165 & negativa & $\begin{array}{l}\text { Positiva, } \\
\text { mas bias }\end{array}$ \\
\hline $\mathrm{F} 24$ & coorte & $\begin{array}{l}\text { estatura e condição } \\
\text { social }\end{array}$ & não referenciou & $\begin{array}{l}\text { I, II, III, V e } \\
\text { agricultores }\end{array}$ & 11851 & positiva & Manual \\
\hline $\mathrm{F} 25$ & coorte & $\begin{array}{l}\text { esquizofrenia e } \\
\text { eventos clínicos }\end{array}$ & Não referenciou & Alta, média e baixa & 76 & positiva & Baixa \\
\hline F26 & coorte & $\begin{array}{l}\text { obesidade e condição } \\
\text { social }\end{array}$ & $\begin{array}{l}\text { Registrar General's } \\
\text { classification }\end{array}$ & $\mathrm{I}-\mathrm{V}$ & 3035 & positiva & V \\
\hline F27 & coorte & $\begin{array}{l}\text { exposição à fumaça do } \\
\text { tabaco }\end{array}$ & $\begin{array}{l}\text { Registrar General's } \\
\text { classification }\end{array}$ & $\mathrm{I}-\mathrm{V}$ & 1208 & positiva & Manual \\
\hline F28 & coorte & $\begin{array}{l}\text { dieta calórica e não } \\
\text { calórica e fatores } \\
\text { associados }\end{array}$ & $\begin{array}{l}\text { Registrar General's } \\
\text { classification }\end{array}$ & $\begin{array}{l}\text { I +II, IIINM, IIIM, IV } \\
+\mathrm{V}\end{array}$ & 1898 & positiva & Baixa \\
\hline F29 & coorte & $\begin{array}{l}\text { obesidade e condição } \\
\text { social }\end{array}$ & $\begin{array}{l}\text { Registrar General's } \\
\text { classification }\end{array}$ & $\mathrm{I}-\mathrm{V}$ & 11405 & positiva & IV e V \\
\hline F30 & coorte & $\begin{array}{l}\text { vitamina E e risco } \\
\text { cardiovascular }\end{array}$ & $\begin{array}{l}\text { Registrar General's } \\
\text { classification }\end{array}$ & manual e não manual & 2980 & positiva & Manual \\
\hline E31 & coorte & $\begin{array}{l}\text { sofrimento psíquico e } \\
\text { condições sociais }\end{array}$ & $\begin{array}{l}\text { Registrar General's } \\
\text { classification }\end{array}$ & $\begin{array}{l}\text { I +II, III NM, III M, e } \\
\text { IV +V }\end{array}$ & 11405 & positiva & IV e V \\
\hline F32 & coorte & \begin{tabular}{|l} 
posição social na \\
infância e transtornos
\end{tabular} & \begin{tabular}{|l|} 
Registrar General's \\
classification
\end{tabular} & manual e não manual & 9377 & positiva & Manual \\
\hline
\end{tabular}




\begin{tabular}{|c|c|c|c|c|c|c|c|}
\hline & & $\begin{array}{l}\text { de ansiedade na vida } \\
\text { adulta }\end{array}$ & & & & & \\
\hline F33 & coorte & $\begin{array}{l}\text { condição } \\
\text { socioeconômica na } \\
\text { infância e peso na vida } \\
\text { adulta }\end{array}$ & Não referenciou & I, II, III-V & 1070 & positiva & Baixa \\
\hline F34 & coorte & $\begin{array}{l}\text { capacidade cognitiva } \\
\text { na infância e declínio } \\
\text { cognitivo na vida } \\
\text { adulta }\end{array}$ & $\begin{array}{l}\text { Registrar General's } \\
\text { classification }\end{array}$ & $\mathrm{I}-\mathrm{V}$ & 2058 & negativa & \\
\hline F35 & coorte & $\begin{array}{l}\text { baixo peso ao nascer e } \\
\text { índice de massa } \\
\text { corporal }\end{array}$ & Não referenciou & manual e não manual & 7017 & positiva & Manual \\
\hline F36 & coorte & tabaco & Não referenciou & $\mathrm{I}-\mathrm{V}$ & 2153 & positiva & IIIM, IV, V \\
\hline F37 & coorte & $\begin{array}{l}\text { fatores de risco de } \\
\text { doenças } \\
\text { cardiovasculares e } \\
\text { classe social }\end{array}$ & $\begin{array}{l}\text { Registrar General's } \\
\text { classification }\end{array}$ & manual e não manual & 7174 & positiva & Manual \\
\hline F38 & $\begin{array}{l}\text { caso- } \\
\text { controle }\end{array}$ & $\begin{array}{l}\text { esquizofrenia e abuso } \\
\text { de substâncias }\end{array}$ & Hollingshead & $\begin{array}{l}\text { superior, médio } \\
\text { superior, médio, média } \\
\text { baixa, inferior }\end{array}$ & 119 & positiva & Alta \\
\hline F39 & coorte & $\begin{array}{l}\text { desempenho físico e } \\
\text { fatores associados }\end{array}$ & $\begin{array}{l}\text { Registrar General's } \\
\text { classification }\end{array}$ & manual e não manual & 1784 & positiva & Manual \\
\hline $\mathrm{F} 40$ & coorte & $\begin{array}{l}\text { fatores durante a } \\
\text { gravidez e fertilidade }\end{array}$ & $\begin{array}{l}\text { Registrar General's } \\
\text { classification }\end{array}$ & manual e não manual & 4304 & negativa & \\
\hline F41 & coorte & $\begin{array}{l}\text { área de residência e } \\
\text { tamanho corporal }\end{array}$ & $\begin{array}{l}\text { Registrar General's } \\
\text { classification }\end{array}$ & $\mathrm{I}-\mathrm{V}$ & 691 & positiva & IV e V \\
\hline F42 & coorte & sarcopenia e & Não referenciou & manual e não manual & 1403 & positiva & Manual \\
\hline
\end{tabular}




\begin{tabular}{|c|c|c|c|c|c|c|c|}
\hline & & crescimento infantil & & & & & \\
\hline F43 & $\begin{array}{l}\text { caso- } \\
\text { controle }\end{array}$ & $\begin{array}{l}\text { ingestão de alimentos e } \\
\text { risco de úlcera } \\
\text { duodenal }\end{array}$ & $\begin{array}{l}\text { Registrar General's } \\
\text { classification }\end{array}$ & $\mathrm{I}-\mathrm{V}$ & 254 & positiva & IV e V \\
\hline F44 & coorte & $\begin{array}{l}\text { altura e fatores } \\
\text { relacionados }\end{array}$ & Não referenciou & manual e não manual & 7430 & positiva & Manual \\
\hline F45 & coorte & $\begin{array}{l}\text { baixo peso ao nascer e } \\
\text { diabetes tipo } 2\end{array}$ & Não referenciou & manual e não manual & 3934 & positiva & Manual \\
\hline F46 & coorte & $\begin{array}{l}\text { condição } \\
\text { socioeconômica na } \\
\text { infância e doenças na } \\
\text { vida adulta }\end{array}$ & $\begin{array}{l}\text { Registrar General's } \\
\text { classification }\end{array}$ & $\mathrm{I}-\mathrm{V}$ & 763 & positiva & V \\
\hline F47 & $\begin{array}{l}\text { caso- } \\
\text { controle }\end{array}$ & $\begin{array}{l}\text { esquizofrenia e } \\
\text { condições sociais }\end{array}$ & Não referenciou & I-VI & 352 & positiva & I-II \\
\hline $\mathrm{F} 48$ & coorte & tabaco e sobrevivência & $\begin{array}{l}\text { Registrar General's } \\
\text { classification }\end{array}$ & $\begin{array}{l}\text { I +II, III NM, III M, e } \\
\text { IV +V }\end{array}$ & 15402 & positiva & I e II \\
\hline F49 & coorte & $\begin{array}{l}\text { marcadores de risco } \\
\text { inflamatório e } \\
\text { condição social }\end{array}$ & $\begin{array}{l}\text { Registrar General's } \\
\text { classification }\end{array}$ & $\mathrm{I}-\mathrm{V}$ & 8795 & positiva & IV $-\mathrm{V}$ \\
\hline F50 & coorte & $\begin{array}{l}\text { doenças e condições de } \\
\text { trabalho }\end{array}$ & $\begin{array}{l}\text { Registrar General's } \\
\text { classification }\end{array}$ & I-VII & 4631 & positiva & IV-VII \\
\hline F51 & coorte & $\begin{array}{l}\text { consumo energético e } \\
\text { peso }\end{array}$ & $\begin{array}{l}\text { Registrar General's } \\
\text { classification }\end{array}$ & I - IV & 6764 & negativa & \\
\hline F52 & coorte & $\begin{array}{l}\text { saúde mental e classe } \\
\text { social }\end{array}$ & $\begin{array}{l}\text { Registrar General's } \\
\text { classification }\end{array}$ & $\begin{array}{l}\text { I +II, III NM, III M, e } \\
\text { IV +V }\end{array}$ & 12537 & positiva & IV e V \\
\hline F53 & coorte & $\begin{array}{l}\text { dor e incapacidade e } \\
\text { fatores associados }\end{array}$ & Não referenciou & I-V & 587 & positiva & $\mathrm{V}$ \\
\hline F54 & coorte & tabaco e influência da & Não referenciou & manual e não manual & 676 & positiva & Manual \\
\hline
\end{tabular}




\begin{tabular}{|c|c|c|c|c|c|c|c|}
\hline & & família e amigos & & & & & \\
\hline F55 & coorte & $\begin{array}{l}\text { obesidade, índice de } \\
\text { massa corporal } \\
\text { materno e na infância e } \\
\text { idade da menarca }\end{array}$ & Não referenciou & $\begin{array}{l}\text { I+II, III, IV e } \\
\text { agricultores }\end{array}$ & 6280 & positiva & IV \\
\hline F56 & $\begin{array}{l}\text { caso- } \\
\text { controle }\end{array} \mid$ & $\begin{array}{l}\text { risco cardiovascular e } \\
\text { fibrinogênio }\end{array}$ & Hansen & $\mathrm{I}-\mathrm{V}$ & 48 & positiva & II a V \\
\hline F57 & coorte & $\begin{array}{l}\text { atividade física e } \\
\text { condições sociais }\end{array}$ & $\begin{array}{l}\text { Registrar General's } \\
\text { classification }\end{array}$ & manual e não manual & 2984 & negativa & \\
\hline F58 & coorte & gênero e saúde & \begin{tabular}{|l} 
Swedish \\
socioeconomic \\
classification
\end{tabular} & $\begin{array}{l}\text { Colarinho azul e } \\
\text { colarinho branco }\end{array}$ & 1046 & positiva & $\begin{array}{l}\text { Colarinho } \\
\text { azul }\end{array}$ \\
\hline F59 & coorte & saúde e classe social & $\begin{array}{l}\text { Registrar General's } \\
\text { classification }\end{array}$ & I-II, IIINM, IIIM, IV-V & 11405 & positiva & IV-V \\
\hline F60 & coorte & $\begin{array}{l}\text { síndrome metabólica e } \\
\text { condições sociais }\end{array}$ & $\begin{array}{l}\text { Registrar General's } \\
\text { classification }\end{array}$ & I-II, IIINM, IIIM, IV-V & 5599 & positiva & IV-V \\
\hline F61 & coorte & $\begin{array}{l}\text { auto-avaliação da } \\
\text { saúde e condições } \\
\text { sociais }\end{array}$ & $\begin{array}{l}\text { Registrar General's } \\
\text { classification }\end{array}$ & I-II, IIINM, IIIM, IV-V & 11407 & positiva & IV-V \\
\hline F62 & coorte & $\begin{array}{l}\text { fatores de risco e } \\
\text { desigualdade em saúde }\end{array}$ & $\begin{array}{l}\text { Registrar General's } \\
\text { classification }\end{array}$ & I-II, IIINM, IIIM, IV-V & 11405 & positiva & IV-V \\
\hline F63 & coorte & $\begin{array}{l}\text { ocupação e percepção } \\
\text { da saúde }\end{array}$ & Não referenciou & I - IV & 6007 & positiva & III-IV \\
\hline F64 & coorte & $\begin{array}{l}\text { audição na infância e } \\
\text { ruído, consumo de } \\
\text { álcool e tabaco }\end{array}$ & $\begin{array}{l}\text { Registrar General's } \\
\text { classification }\end{array}$ & manual e não manual & 8894 & positiva & Manual \\
\hline F65 & coorte & $\begin{array}{l}\text { convulsão e epilepsia e } \\
\text { participação no }\end{array}$ & $\begin{array}{l}\text { Registrar General's } \\
\text { classification }\end{array}$ & $\begin{array}{l}\text { Empregadores, NM, } \\
\text { qualificados manuais, }\end{array}$ & 350 & positiva & Baixa \\
\hline
\end{tabular}




\begin{tabular}{|c|c|c|c|c|c|c|c|}
\hline & & mercado de trabalho & & $\begin{array}{l}\text { semi qualificados e não } \\
\text { qualificados }\end{array}$ & & & \\
\hline F66 & coorte & $\begin{array}{l}\text { epicondilie lateral e } \\
\text { fatores associados }\end{array}$ & Não referenciou & $\begin{array}{l}\text { Alta, média, baixa e } \\
\text { desempregados }\end{array}$ & 349 & positiva & Baixa \\
\hline F67 & coorte & $\begin{array}{l}\text { atividade física e } \\
\text { trabalho }\end{array}$ & Não referenciou & $\begin{array}{l}\text { Colarinho azul e } \\
\text { colarinho branco }\end{array}$ & 529 & positiva & $\begin{array}{l}\text { Colarinho } \\
\text { azul }\end{array}$ \\
\hline F68 & coorte & $\begin{array}{l}\text { posição } \\
\text { socioeconômica e risco } \\
\text { de doenças }\end{array}$ & $\begin{array}{l}\text { Registrar General's } \\
\text { classification }\end{array}$ & $\mathrm{I}-\mathrm{V}$ & 9377 & positiva & $\mathrm{V}$ \\
\hline F69 & coorte & $\begin{array}{l}\text { doença cardíaca e } \\
\text { fatores de risco }\end{array}$ & Não referenciou & $\begin{array}{l}\text { Empresários, } \\
\text { funcionários de nível } \\
\text { superior, de nível } \\
\text { inferior, empregados } \\
\text { manuais, agricultores, } \\
\text { outros }\end{array}$ & 19272 & positiva & Manual \\
\hline F70 & $\begin{array}{l}\text { caso- } \\
\text { controle }\end{array}$ & $\begin{array}{l}\text { miopia e fatores } \\
\text { associados }\end{array}$ & $\begin{array}{l}\text { Registrar General's } \\
\text { classification }\end{array}$ & $\begin{array}{l}\text { Alta (I,II,IIINM) e baixa } \\
\text { (IIIM,IV,V) }\end{array}$ & 200 & positiva & Alta \\
\hline F71 & $\begin{array}{l}\text { caso- } \\
\text { controle }\end{array}$ & $\begin{array}{l}\text { exposição ocupacional } \\
\text { a hidrocarbonetos e } \\
\text { pancreatite crônica }\end{array}$ & OPCS & 3 classes & 306 & positiva & Manual \\
\hline F72 & coorte & saúde e classe social & $\begin{array}{l}\text { Registrar General's } \\
\text { classification }\end{array}$ & I-II, IIINM, IIIM, IV-V & 11407 & positiva & IV-V \\
\hline F73 & coorte & $\begin{array}{l}\text { esquizofrenia e } \\
\text { eventos associados }\end{array}$ & Não referenciou & $\begin{array}{l}\text { high (I,II) and low (III- } \\
\text { V) }\end{array}$ & 59 & positiva & Alta \\
\hline F74 & coorte & $\begin{array}{l}\text { resultados dos } \\
\text { problemas na } \\
\text { adolescência e fatores } \\
\text { relacionados }\end{array}$ & $\begin{array}{l}\text { Registrar General's } \\
\text { classification }\end{array}$ & manual e não manual & 3652 & positiva & Manual \\
\hline
\end{tabular}




\begin{tabular}{|c|c|c|c|c|c|c|c|}
\hline F75 & coorte & educação e saúde & $\begin{array}{l}\text { Registrar General's } \\
\text { classification }\end{array}$ & $\begin{array}{l}\text { Empregadores, NM, } \\
\text { qualificados manuais, } \\
\text { semi qualificados e não } \\
\text { qualificados }\end{array}$ & 17416 & positiva & Manual \\
\hline F76 & coorte & $\begin{array}{l}\text { coqueluche e diabetes } \\
\text { tipo } 1\end{array}$ & $\begin{array}{l}\text { Registrar General's } \\
\text { classification }\end{array}$ & $\mathrm{I}-\mathrm{V}$ & 16820 & negativa & \\
\hline F77 & coorte & $\begin{array}{l}\text { atividade física na } \\
\text { adolescência e } \\
\text { sedentarismo na vida } \\
\text { adulta }\end{array}$ & Não referenciou & $\begin{array}{l}\text { I+II, III, IV e } \\
\text { agricultores }\end{array}$ & 7794 & negativa & \\
\hline F78 & coorte & $\begin{array}{l}\text { dor lombar e fatores } \\
\text { relacionados }\end{array}$ & $\begin{array}{l}\text { Registrar General's } \\
\text { classification }\end{array}$ & $\mathrm{I}-\mathrm{V}$ & 5791 & positiva & IV e V \\
\hline F79 & coorte & $\begin{array}{l}\text { doença gastrointestinal } \\
\text { e fatores relacionados }\end{array}$ & $\begin{array}{l}\text { Registrar General's } \\
\text { classification }\end{array}$ & $\mathrm{I}-\mathrm{V}$ & 11261 & positiva & Baixa \\
\hline F80 & coorte & $\begin{array}{l}\text { doença inflamatória } \\
\text { intestinal e fatores } \\
\text { relacionados }\end{array}$ & $\begin{array}{l}\text { Registrar General's } \\
\text { classification }\end{array}$ & Manual e não manual & 9803 & negativa & \\
\hline F81 & coorte & $\begin{array}{l}\text { problemas } \\
\text { psiquiátricos e de } \\
\text { saúde e fatores } \\
\text { relacionados }\end{array}$ & Não referenciou & 5 classes & 5362 & $\begin{array}{l}\text { positiva, mas } \\
\text { não } \\
\text { diretamente }\end{array}$ & Baixa \\
\hline F82 & coorte & $\begin{array}{l}\text { saúde emocional e } \\
\text { doença de Parkinson }\end{array}$ & $\begin{array}{l}\text { Registrar General's } \\
\text { classification }\end{array}$ & $\mathrm{I}-\mathrm{V}$ & 20855 & negativa & \\
\hline F83 & coorte & $\begin{array}{l}\text { sofrimento psíquico e } \\
\text { condições sociais }\end{array}$ & $\begin{array}{l}\text { Registrar General's } \\
\text { classification }\end{array}$ & $\begin{array}{l}\text { I +II, III NM, III M e } \\
\text { IV +V }\end{array}$ & 11405 & positiva & IV e V \\
\hline F84 & coorte & $\begin{array}{l}\text { Sofrimento psíquico, } \\
\text { transtorno depressivo } \\
\text { maior e risco de AVC }\end{array}$ & $\begin{array}{l}\text { Registrar General's } \\
\text { classification }\end{array}$ & $\mathrm{I}-\mathrm{V}$ & 20627 & positiva & V \\
\hline
\end{tabular}




\begin{tabular}{|c|c|c|c|c|c|c|c|}
\hline F85 & $\begin{array}{l}\text { caso- } \\
\text { controle }\end{array}$ & $\begin{array}{l}\text { transtorno depressivo e } \\
\text { fatores associados }\end{array}$ & Goldthorpe & $\begin{array}{l}\text { Media alta e media } \\
\text { baixa }\end{array}$ & 100 & positiva & Média baixa \\
\hline F86 & $\begin{array}{l}\text { caso- } \\
\text { controle }\end{array}$ & $\begin{array}{l}\text { doença cardíaca e } \\
\text { infecção por HP }\end{array}$ & $\begin{array}{l}\text { Registrar General's } \\
\text { classification }\end{array}$ & Manual e não manual & 292 & negativa & \\
\hline F87 & coorte & $\begin{array}{l}\text { consumo de álcool, } \\
\text { ferritina e condições } \\
\text { sociais }\end{array}$ & Não referenciou & $\mathrm{I}-\mathrm{V}$ & 2235 & positiva & I-III \\
\hline F88 & coorte & $\begin{array}{l}\text { morbidade e condições } \\
\text { sociais }\end{array}$ & $\begin{array}{l}\text { Registrar General's } \\
\text { classification }\end{array}$ & $\begin{array}{l}\text { I +II, III NM, III M,e } \\
\text { IV +V }\end{array}$ & 10308 & positiva & I e II \\
\hline F89 & coorte & saúde e classe social & Não referenciou & Manual e não manual & 2338 & positiva & Manual \\
\hline F90 & coorte & $\begin{array}{l}\text { infecção por HP e } \\
\text { condições sociais }\end{array}$ & OPCS & Manual e não manual & 985 & positiva & Manual \\
\hline F91 & coorte & $\begin{array}{l}\text { consumo de alimentos } \\
\text { e álcool e condições } \\
\text { sociais }\end{array}$ & $\begin{array}{l}\text { Registrar General's } \\
\text { classification }\end{array}$ & $\begin{array}{l}\text { I +II, III non-manual, III } \\
\text { manual, e IV +V }\end{array}$ & 3322 & positiva & Manual \\
\hline F92 & coorte & $\begin{array}{l}\text { risco metabólico e } \\
\text { condições sociais }\end{array}$ & $\begin{array}{l}\text { Registrar General's } \\
\text { classification }\end{array}$ & $\begin{array}{l}\text { Empregadores, NM, } \\
\text { qualificados manuais, } \\
\text { semi qualificados e não } \\
\text { qualificados }\end{array}$ & 2629 & positiva & Baixa \\
\hline F93 & coorte & saúde e classe social & Não referenciou & $\mathrm{I}-\mathrm{V}$ & 5001 & positiva & Baixa \\
\hline F94 & coorte & $\begin{array}{l}\text { AVC, fatores } \\
\text { associados e classe } \\
\text { social }\end{array}$ & $\begin{array}{l}\text { Registrar General's } \\
\text { classification }\end{array}$ & $\begin{array}{l}\text { Empregadores, NM, } \\
\text { qualificados manuais, } \\
\text { semi qualificados e não } \\
\text { qualificados }\end{array}$ & 22488 & positiva & Baixa \\
\hline F95 & coorte & saúde e classe social & $\begin{array}{l}\text { Registrar General's } \\
\text { classification }\end{array}$ & I-II, IIINM, IIIM, IV-V & 11407 & positiva & IV-V \\
\hline F96 & coorte & saúde e classe social & $\begin{array}{l}\text { Registrar General's } \\
\text { classification }\end{array}$ & $\begin{array}{l}\text { Empregadores gerencial } \\
\text { e profissional, }\end{array}$ & 10264 & positiva & $\begin{array}{l}\text { Classe } \\
\text { trabalhadora }\end{array}$ \\
\hline
\end{tabular}




\begin{tabular}{|c|c|c|c|c|c|c|c|}
\hline & & & & $\begin{array}{l}\text { intermediários, } \\
\text { pequenos empregadores } \\
\text { e supervisores, classe } \\
\text { trabalhadora }\end{array}$ & & & \\
\hline F97 & coorte & saúde e classe social & $\begin{array}{l}\text { Registrar General's } \\
\text { classification }\end{array}$ & $\mathrm{I}-\mathrm{V}$ & 11405 & positiva & IV-V \\
\hline F98 & coorte & $\begin{array}{l}\text { doença cardiovascular } \\
\text { e condições sociais }\end{array}$ & $\begin{array}{l}\text { Registrar General's } \\
\text { classification E } \\
\text { Cambridge scale }\end{array}$ & vários & 5401 & positiva & Baixa \\
\hline F99 & coorte & $\begin{array}{l}\text { mobilidade social e } \\
\text { desigualdade em saúde }\end{array}$ & $\begin{array}{l}\text { Registrar General's } \\
\text { classification }\end{array}$ & I-V & 247,52 & positiva & IIIM, IV, V \\
\hline F100 & $\begin{array}{l}\text { caso- } \\
\text { controle }\end{array}$ & $\begin{array}{l}\text { úlcera crônica de perna } \\
\text { e condições sociais }\end{array}$ & $\begin{array}{l}\text { Registrar General's } \\
\text { classification }\end{array}$ & I+II, III, IV, V & 226 & positiva & IV-V \\
\hline F101 & coorte & $\begin{array}{l}\text { cessação do tabaco e } \\
\text { condições sociais }\end{array}$ & $\begin{array}{l}\text { Registrar General's } \\
\text { classification }\end{array}$ & $\begin{array}{l}\text { Empregadores gerencial } \\
\text { e profissional, } \\
\text { intermediários, } \\
\text { pequenos empregadores } \\
\text { e supervisores, classe } \\
\text { trabalhadora }\end{array}$ & 10264 & positiva & Baixa \\
\hline F102 & coorte & diabetes e saúde & Não referenciou & $\begin{array}{l}\text { Alta, media e classe } \\
\text { trabalhadora }\end{array}$ & 1583 & positiva & $\begin{array}{l}\text { Classe } \\
\text { trabalhadora }\end{array}$ \\
\hline F103 & coorte & $\begin{array}{l}\text { aposentadoria por } \\
\text { dores na costa e } \\
\text { desigualdade social }\end{array}$ & Não referenciou & I-VI & 1333556 & positiva & VI \\
\hline F104 & coorte & $\begin{array}{l}\text { ganho de peso em } \\
\text { curto prazo e } \\
\text { condições sociais }\end{array}$ & $\begin{array}{l}\text { Registrar General's } \\
\text { classification }\end{array}$ & $\mathrm{I}-\mathrm{V}$ & 14619 & positiva & IV-V \\
\hline
\end{tabular}




\begin{tabular}{|c|c|c|c|c|c|c|c|}
\hline F105 & coorte & $\begin{array}{l}\text { asma, bronquite e } \\
\text { condições sociais }\end{array}$ & Não referenciou & I-VI & 9023 & positiva & Baixa \\
\hline F106 & coorte & $\begin{array}{l}\text { AVC e fatores } \\
\text { relacionados }\end{array}$ & Statistics Sweden & 7 classes & 69625 & positiva & $\begin{array}{l}\text { Qualificados } \\
\text { manuais }\end{array}$ \\
\hline F107 & coorte & $\begin{array}{l}\text { stress e distúrbios } \\
\text { osteomusculares }\end{array}$ & Não referenciou & $\begin{array}{l}\text { Colarinho branco e } \\
\text { colarinho azul }\end{array}$ & 902 & positiva & $\begin{array}{l}\text { Colarinho } \\
\text { azul }\end{array}$ \\
\hline F108 & \begin{tabular}{|l|} 
caso- \\
controle
\end{tabular} & $\begin{array}{l}\text { depressão e índice de } \\
\text { massa corporal }\end{array}$ & Hollingshead & I-II, III, IV-V & 375 & positiva & Não refere \\
\hline F109 & coorte & $\begin{array}{l}\text { classe social e } \\
\text { obesidade }\end{array}$ & $\begin{array}{l}\text { Registrar General's } \\
\text { classification }\end{array}$ & I, II, IIINM, IIIM, IV-V & 4598 & positiva & Baixa \\
\hline F110 & coorte & $\begin{array}{l}\text { AVC e fatores } \\
\text { relacionados }\end{array}$ & $\begin{array}{l}\text { Registrar General's } \\
\text { classification }\end{array}$ & $\mathrm{I}-\mathrm{V}$ & 14947 & positiva & Baixa \\
\hline F111 & coorte & $\begin{array}{l}\text { saúde e condições } \\
\text { sociais }\end{array}$ & $\begin{array}{l}\text { Registrar General's } \\
\text { classification }\end{array}$ & $\mathrm{I}-\mathrm{V}$ & 11405 & positiva & Baixa \\
\hline F112 & coorte & $\begin{array}{l}\text { cessação do tabaco e } \\
\text { condições sociais }\end{array}$ & Não referenciou & $\mathrm{I}-\mathrm{V}$ & 3606 & positiva & Baixa \\
\hline F113 & coorte & $\begin{array}{l}\text { tabagismo e condições } \\
\text { sociais }\end{array}$ & $\begin{array}{l}\text { Registrar General's } \\
\text { classification }\end{array}$ & Manual e não manual & 14824 & positiva & Manual \\
\hline F114 & coorte & $\begin{array}{l}\text { peso na infância e } \\
\text { índice de massa } \\
\text { corporal no adulto }\end{array}$ & Não referenciou & Manual e não manual & 2659 & positiva & Manual \\
\hline F115 & coorte & $\begin{array}{l}\text { dor músculo } \\
\text { esquelética } \\
\text { generalizada e } \\
\text { condições sociais }\end{array}$ & $\begin{array}{l}\text { Registrar General's } \\
\text { classification }\end{array}$ & $\mathrm{I}-\mathrm{V}$ & 9377 & positiva & Baixa \\
\hline F116 & coorte & $\begin{array}{l}\text { síndrome do intestino } \\
\text { irritável e variáveis } \\
\text { associadas }\end{array}$ & Não referenciou & $\begin{array}{l}\text { Alta, média alta, média } \\
\text { baixa e baixa }\end{array}$ & 980 & positiva & Baixa \\
\hline
\end{tabular}




\begin{tabular}{|c|c|c|c|c|c|c|c|}
\hline F117 & $\begin{array}{l}\text { caso- } \\
\text { controle }\end{array} \mid$ & $\begin{array}{l}\text { fadiga crônica e } \\
\text { síndrome da fadiga } \\
\text { cônica }\end{array}$ & $\begin{array}{l}\text { Registrar General's } \\
\text { classification }\end{array}$ & $\mathrm{I}-\mathrm{V}$ & 378 & negativa & \\
\hline F118 & coorte & $\begin{array}{l}\text { distúrbios PSE e } \\
\text { fatores relacionados }\end{array}$ & Não referenciou & I-IV & 742 & positiva & IV \\
\hline F119 & coorte & $\begin{array}{l}\text { transtorno psiquiátrico } \\
\text { e fadiga }\end{array}$ & $\begin{array}{l}\text { Registrar General's } \\
\text { classification }\end{array}$ & Manual e não manual & 5362 & negativa & \\
\hline F120 & coorte & saúde e classe social & $\begin{array}{l}\text { Registrar General's } \\
\text { classification }\end{array}$ & Manual e não manual & 1457 & positiva & Manual \\
\hline F121 & coorte & $\begin{array}{l}\text { educação e } \\
\text { incapacidade } \\
\text { profissional por dor } \\
\text { nas costas }\end{array}$ & Não referenciou & $\begin{array}{l}\text { Profissionais, } \\
\text { trabalhadores não } \\
\text { manuais e trabalhadores } \\
\text { manuais }\end{array}$ & 38,426 & positiva & Manual \\
\hline F122 & coorte & $\begin{array}{l}\text { risco cardiovascular e } \\
\text { condição social }\end{array}$ & $\begin{array}{l}\text { Registrar General's } \\
\text { classification }\end{array}$ & I-II, IIINM, IIIM, IV-V & 6980 & positiva & IV e V \\
\hline F123 & coorte & $\begin{array}{l}\text { ambiente de trabalho e } \\
\text { saúde }\end{array}$ & Não referenciou & $\mathrm{I}-\mathrm{V}$ & 5001 & positiva & IV e $\mathrm{V}$ \\
\hline
\end{tabular}


Quanto à amostra, houve predomínio dos estudos de coorte que acompanharam mais de 1000 pessoas $(86,1 \%)$ e dos estudos caso-controle que investigaram as associações em até 500 pessoas (100\%). Com relação à associação entre o objeto e a classe social, os desfechos foram associados estatisticamente $(\mathrm{p}<5 \%)$ em 88,6\% dos estudos, sendo que os estudos de coorte apresentaram uma porcentagem ligeiramente maior $(90,7 \%)$. Já em relação ao desfecho relacionado a uma específica classe, 91,9\% dos estudos mostraram que as classes com menor acesso à riqueza social apresentaram maiores prevalências ou incidências dos problemas de saúde em relação às outras classes (Tabela 15).

Tabela 15 - Descrição dos estudos de coorte e caso-controle segundo população estudada, associação entre o objeto e classe social e maior risco de problemas de saúde por classe. São Paulo, 2010.

\begin{tabular}{|c|c|c|c|c|c|c|}
\hline & \multicolumn{2}{|c|}{ Coorte } & \multicolumn{2}{|c|}{ Caso-controle } & \multicolumn{2}{|c|}{ Total } \\
\hline & $\mathbf{N}$ & $\%$ & $\mathbf{N}$ & $\%$ & $\mathbf{N}$ & $\%$ \\
\hline \multicolumn{7}{|l|}{ População estudada } \\
\hline Até 50 & 1 & 0,9 & 1 & 6,7 & 2 & 1,6 \\
\hline $50-100$ & 1 & 0,9 & 2 & 13,3 & 3 & 2,4 \\
\hline $101-500$ & 3 & 2,8 & 12 & 80,0 & 15 & 12,2 \\
\hline $501-1000$ & 10 & 9,3 & 0 & 0 & 10 & 8,1 \\
\hline $1000-5000$ & 32 & 29,6 & 0 & 0 & 32 & 26,0 \\
\hline $5001-10000$ & 24 & 22,2 & 0 & 0 & 24 & 19,5 \\
\hline Mais de 10000 & 37 & 34,3 & 0 & 0 & 37 & 30,1 \\
\hline Total & 108 & 100 & 15 & 100 & 123 & 100 \\
\hline \multicolumn{7}{|l|}{ Associação } \\
\hline Positiva & 98 & 90,7 & 11 & 73,3 & 109 & 88,6 \\
\hline Negativa & 10 & 9,3 & 4 & 26,7 & 14 & 11,4 \\
\hline Total & 108 & 100 & 15 & 100 & 123 & 100 \\
\hline \multicolumn{7}{|l|}{ Risco maior - Classe } \\
\hline $\begin{array}{l}\text { Com menor acesso } \\
\text { à riqueza social }\end{array}$ & 101 & 93,6 & 12 & 80,0 & 113 & 91,9 \\
\hline $\begin{array}{l}\text { Com maior acesso à } \\
\text { riqueza social }\end{array}$ & 7 & 6,4 & 3 & 20,0 & 10 & 8,1 \\
\hline Total & 108 & 100 & 15 & 100 & 123 & 100 \\
\hline
\end{tabular}

Em relação à associação positiva do objeto com a categoria classe social, nove estudos apresentaram diferenças nos resultados entre homens e mulheres. 
Quatro estudos (F7, F63, F106 e F118) concluíram que a classe social é uma categoria significativa apenas para os homens e cinco estudos (F28, F52, F58, F92 e F109) apenas para as mulheres. Estes estudos evidenciam que a categoria gênero também é importante para a análise da distribuição desigual das doenças na população.

Sobre o objeto estudado, 44 estudos relacionaram diretamente um problema de saúde à condição social e os outros 79 relacionaram dois problemas de saúde, analisando a categoria classe social como um fator associado (Tabela 16).

Tabela 16 - Estudos epidemiológicos incluídos segundo a análise da categoria classe social. São Paulo, 2010.

\begin{tabular}{llll}
\hline & $\mathbf{N}$ & \% & Código \\
Classe social como determinante & $44 \quad 35,8$ & (F4, F6, F7, F24, F26, F29, F31, F33, \\
& & F37, F41, F46, F47, F49, F57, F59, F60, \\
& & F61, F62, F72, F83, F87, F88, F89, F90, \\
& & F91, F92, F93, F94, F95, F96, F97, F98, \\
& & F99, F111, F112, F113, F115, F120, \\
Classe social como fator associado & 79 & F122) \\
\hline
\end{tabular}

Ao classificar os estudos em dois grupos (classe social como determinante e classe social como fator associado) e verificar novamente a associação entre a classe e o desfecho, observam-se resultados positivos maiores. Dos 44 estudos que utilizaram a categoria classe social como determinante, 43 apontaram diferenças significativas $(97,7 \%)$ entre as classes sociais e os problemas de saúde estudados. 


\section{DISCUSSÃO}

O estudo identificou 28 modelos de operacionalização do conceito de classe utilizados na epidemiologia, com destaque para a América Latina, com nove modelos propostos.

A análise temporal revela que a maioria dos estudos na América Latina foi publicada na década de 80 , o que coincide com o processo de mobilização de vários setores sociais, em virtude do aprofundamento dos problemas sociais e políticos, decorrentes da crise mundial do capitalismo nos anos 70 (Breilh e Granda, 1989; Kliksberg, 2002).

Os dados latino-americanos sobre a pobreza, desemprego e informalidade são alarmantes e revelam a enorme desigualdade social da região que se tornou um problema extremamente relevante na contemporaneidade. Superar a pobreza e melhorar as condições de vida e saúde são tarefas que devem ser tratadas como prioridades de políticas públicas sociais (Kliksberg, 2002).

Através destes 28 modelos e dos quatro excluídos, duas formas de operacionalização foram identificadas: uma relacionada ao âmbito do consumo que utiliza variáveis majoritariamente econômicas e outra relacionada ao âmbito da produção. Dois modelos foram sugeridos por associações brasileiras de mercado com o objetivo de medir o poder de consumo das famílias. Ressalta-se que a utilização do conceito de classe social nas pesquisas empíricas perdeu espaço em contraposição aos estudos tradicionais de estratificação econômica.

As classificações econômicas surgiram na área de marketing para que as agências de propaganda soubessem o perfil dos consumidores de diferentes classes sociais. Diversos autores criticam o uso inadequado do conceito de classe social nesta classificação, já que o conceito de classe não está restrito ao poder econômico familiar (Mattar, 1995).

As classificações econômicas não identificam as relações da ocupação do individuo no sistema de produção e não necessariamente refletem diferenças sociais que determinam o processo saúde-doença. Estas classificações estão restritas à identificação do poder de consumo e se revelam ultrapassadas, pois nem ao menos identificam os padrões dinâmicos das formas sociais e temporais do consumo (Mattar, 1995). 
Observa-se através da busca bibliográfica que diversos estudos epidemiológicos brasileiros utilizaram estas classificações e estabeleceram relações entre classe social e o objeto do estudo. A grande maioria dos estudos epidemiológicos publicados no século XXI classificou os sujeitos de suas pesquisas com base nesses modelos de classificação como no caso dos estudos sobre o uso de substâncias psicoativas entre estudantes (Teixeira et al, 2009), prevalência de hipertensão arterial sistêmica (Piccini, Victora, 1994) e epilepsia (Noronha et al, 2007). Os resultados detalhados serão posteriormente divulgados.

Dois estudos consideraram, para classificar as famílias, outras variáveis como número de membros da família, condição de moradia, renda familiar, escolaridade e principal fonte de renda familiar. Também foram estabelecidos pontos de corte e instrumentos padronizados para a coleta de dados.

Stavenhagen (1977) considera que os critérios de estratificação podem ser classificados em quantitativos, relacionados a variáveis passíveis de corte como a renda e escolaridade, e qualitativos, diferenciados em objetivos (como posse de bens) e subjetivos (como etnia e prestígio de certas ocupações). É possível elaborar inúmeros esquemas de estratificação, sejam dicotômicos ou quintutômicos, que ressaltam fundamentalmente três classes: uma alta ou superior, uma média e uma baixa (Stavenhagen, 1977).

Possas (1989) salienta que há a necessidade de distinguir os conceitos de classe social e estratificação social. O conceito marxista de classe social não está relacionado com critérios e valores diferentes que determinam o agrupamento de pessoas, ao contrário da utilização da estratificação social. Este último possibilita vários recortes da população a depender do recorte metodológico empregado. Entretanto ressalta que "a utilização de critérios de estratificação não é incompatível com o conceito marxista de classe social", a depender da metodologia empregada para classificar a população (Possas, 1989, p.161).

Outro critério utilizado para a classificação é baseado na inserção do indivíduo no modo de produção capitalista. Ao se considerar as diferentes inserções no processo produtivo, para além dos diferenciados níveis de consumo, pode-se superar a prática de discriminar classes sociais segundo critérios arbitrariamente selecionados pelos investigadores (Barros, 1986). 
É possível verificar semelhanças em relação aos critérios de diferenciação de classes e frações de classes. Em relação aos 15 estudos europeus e quatro norte-americanos, os modelos também utilizaram prioritariamente a posição na ocupação no modo de produção capitalista para definir as classes sociais.

As duas grandes classes, burguesia e proletariado, foram fracionadas de acordo com diversos critérios: renda, número de empregados, inserção, qualificação, vínculo com a produção, escolaridade e uso de tecnologia.

Considera-se que as relações de produção determinam a divisão, direção e organização do trabalho em uma sociedade capitalista, na qual provem a luta de classes entre exploradores e explorados (Althusser, 1999).

A burguesia é definida como a classe detentora dos meios de produção e pode haver uma subdivisão, segundo o número de empregados e/ou a renda mensal. Assim, há as seguintes frações de classe: burguesia empresarial, burguesia gerencial, pequena burguesia tradicional, nova pequena burguesia.

O proletariado é aquele que vende sua força de trabalho e de acordo com os estudos é fracionado em típico e atípico, de acordo com o lugar na produção capitalista. Antunes (1995) chama a totalidade dos assalariados que vivem da venda de sua força de trabalho de "classe que vive do trabalho". Este conceito amplia o conceito marxista de proletariado tentando caracterizar o amplo leque de trabalhadores, em nossos dias.

O subproletariado é a classe constituída por trabalhadores que não possuem qualificação, escolaridade e estabilidade. Dois estudos utilizam o termo “força de trabalho livre" para denominar esta classe (Bronfman e Tuirán, 1984; Solla, 1992). Solla (1992) designa que o subproletariado é o "exército industrial de reserva", ou seja, são os trabalhadores que não estão inseridos economicamente, sendo uma força de trabalho excedente capaz de garantir a reprodução e acumulação do capital.

O Registrar General's Social Classes (RGSC) classifica a população britânica através da ocupação desde 1851. Durante o século XX, o esquema sofreu diversas modificações com a inclusão de frações de classe e realocação de algumas ocupações como, por exemplo, os carteiros que estavam classificados na classe II e em 1961 passaram para a classe IV (Social Report Update, 1995). 
Já Wright (1985) desenvolveu um esquema de classes que considera a inserção na produção e as contradições entre os trabalhadores como pontos essenciais na identificação das classes sociais. $\mathrm{O}$ autor identifica três posições relacionadas ao trabalho que estão em situações contraditórias na relação de classes, considerando a apropriação da força de trabalho, posição de mando, nível de qualificação e apropriação da força de trabalho (Wright, 1985):

Hollingshead, após 13 anos de sua proposta de modelo de classe social na área de saúde mental (Hollingshead e Redlich, 1958), propôs o Índice de dois fatores de posição social, de acordo com a ocupação e escolaridade do indivíduo. A atribuição de valores e pesos a cada variável gera um número que correspondia a uma determinada classe (a escala apresentava sete pontos, sendo o um relacionado à baixa ocupação e escolaridade e sete relacionado à alta ocupação e escolaridade). Cada variável apresentava pesos diferentes no modelo, sendo que era multiplicada por sete, se relacionada à ocupação, ou quatro, se relacionada à escolaridade. Este índice foi utilizado com predomínio na área da psicologia americana (Haug e Sussmas, 1971; Hollingshead, 1971; Oakes, 2003).

O esquema de Goldthorpe (Erikson e Goldthorpe, 1979) é o modelo mais influente da categoria weberiana, além de ser muito utilizado nos estudos sociológicos (Marks, [s.d]).

Embora haja grandes diferenças teóricas entre a teoria de Marx e Weber, Marks [s.d] afirma que nos modelos operacionais estas diferenças teóricas diminuem, já que em ambas as teorias diferenciam os empregadores dos empregados.

Antunes (1995) assinala que o capitalismo contemporâneo, sustentado pelo projeto ideológico neoliberal, imprimiu ao mundo do trabalho a característica de uma mercadoria, em um valor de troca, o que tem conduzido mudanças na estrutura produtiva que levam à precarização do trabalho, alienação do ser social, redução de suas necessidades sociais e um aumento da exploração da força de trabalho.

O valor de troca é a propriedade que a mercadoria possui de servir como objeto de troca.

Althusser (1999) sustenta que a divisão de classes e a consequente divisão do trabalho impossibilita a mudança da realidade social da maioria dos 
trabalhadores ou "elevar-se acima de sua classe". Cita o exemplo do operário que dificilmente chegará a se tornar engenheiro.

As transformações do trabalho no capitalismo contemporâneo dificultam a análise das classes sociais de uma sociedade, já que as classes trabalhadoras estão mais complexas, fragmentadas e heterogêneas. Por um lado há uma maior qualificação e intelectualização do trabalhador e por outro uma desqualificação e precarização que contribui para o desemprego estrutural (Antunes, 1995).

Cattani (2007) afirma que

Nos últimos anos, houve uma tentativa de se diluírem as elaborações críticas clássicas alegando-se que as classes perderam qualquer alcance explicativo. O domínio do neoliberalismo e do realismo da "verdade de mercado" parecia indicar o fim dos "inimigos da sociedade aberta" e com isso, dos conflitos e as desigualdades (...). A retomada do debate em termos de classes sociais e a elaboração de novos conceitos tornam-se necessárias para que a Sociologia possa apreender as consequiências do processo em curso sobre o conjunto da sociedade (Catani, 2007, p. 91).

Antunes (1995) enfatiza o surgimento do "trabalhador polivalente e multifuncional”, capaz de atuar em vários setores da produção e Kliksberg (2002) destaca a classe dos "novos pobres" na América Latina, composta por famílias de classe média que mais sofreram os impactos das recessões econômicas.

No mundo contemporâneo há certa dificuldade de estabelecer critérios para classificar os trabalhadores e articular as relações de produção principalmente em países do capitalismo periférico e semiperiférico ${ }^{15}$.

Combater as desigualdades e suas raízes profundas nas estruturas sociais requer novas abordagens para a compreensão do contexto em estudos populacionais de intervenção em saúde. Sem essas novas abordagens, não conseguiremos avançar de forma adequada neste campo de pesquisa. A fim de integrar com sucesso a nossa crescente compreensão dos contextos históricos, dinâmico e global em estudos populacionais em saúde, muitas estratégias são necessárias (Edwards, 2011:47).

Santos (1998, [s.p.]) considera a abordagem das classes sociais "centradas em empregos" problemática, pois "importantes situações ou processos que não se

\footnotetext{
${ }^{15}$ Pochmann (2001) trabalha com a seguinte divisão da economia mundial: centro, semiperiferia e periferia. Exemplos de países: do centro capitalista: Áustria, Bélgica, Canadá, Dinamarca, Finlândia, França, Alemanha, Itália, Japão, Holanda, Noruega, Suécia, Suíça, Inglaterra, Espanha e Estados Unidos da América; semiperiféricos: Austrália, Nova Zelândia, Grécia, Portugal, Turquia, Bulgária, Checoslováquia, Hungria, Polônia, Romênia, Rússia, Iugoslávia, Argentina, Brasil, Chile, México, Venezuela, China, Índia, Irlanda, Coréia, Taiwan, Egito e África do Sul; e periféricos: Zaire, Tanzânia, Nigéria, Marrocos, Quênia, Gana, Etiópia, Peru, Colômbia, Paraguai, Bolívia, Equador e Serra Leoa.
} 
manifestam adequadamente em termos da estrutura de emprego escapam à análise".

Possas (1989) destaca a heterogeneidade estrutural relacionada com a população trabalhadora e condições de trabalho e o CNDSS (2008) enfatiza que as condições de saúde estão associadas às condições de trabalho.

O caráter econômico do capitalismo periférico não se explica por sua especificidade econômica ao nível da estrutura produtiva ou por restrições decorrentes de um suposto atraso tecnológico. Decorre, ao contrário, das condições históricas que impediriam a integração social através do desenvolvimento econômico, uma vez que este por si só não foi capaz de completá-la (Possas, 1989: 155)

Os problemas de saúde estão relacionados com o grau de desenvolvimento alcançado por um país ou região. Os avanços tecnológicos e as mudanças industriais redefiniram o cenário do trabalho no Brasil, com a passagem de uma economia primariamente agrária e de mineração para uma economia industrial com ênfase nas atividades de comércio e serviço. As características desse processo de transição tiveram por consequência importantes problemas sociais e econômicos, por exemplo, crescimento constante do trabalho informal, salários baixos, maior insegurança no emprego e grandes diferenças sociais e regionais no que se refere a desemprego e trabalho infantil (CNDSS, 2008:63).

Solla (1992) ressalta a necessidade de superação de problemas na utilização do conceito de classe social, como considerar as peculiaridades de cada sociedade e os processos dinâmicos que nela ocorrem; a consideração que nem todos os conceitos podem ser reduzidos a variáveis na investigação empírica; e o aprofundamento de questões teórico-conceituais, como o ponto de corte de variáveis quantitativas, a quantidade de variáveis necessárias para compor um indicador, a inclusão da população não diretamente inserida na dimensão econômica como os estudantes e a classificação de indivíduos com mais de uma inserção na produção.

Pochmann (2004) relata que as mudanças no mundo trabalho advindas dos ajustes do capitalismo contemporâneo mudaram as configurações da relação trabalho e educação. Embora as exigências educacionais tenham aumentado, assim como o acesso à escola nas classes sociais mais baixas, não se observou o potencial transformador da educação, já que mesmo com uma escolaridade alta, a população mais pobre não consegue melhorar a inserção no mercado de trabalho. O desemprego também acompanhou a tendência perversa de aumentar à medida 
que se eleva a escolaridade. Este fato é observado não só nas classes mais baixas, mas também em trabalhadores com ensino superior (Pochmann, 2004).

Ao utilizar variáveis de escolaridade nos modelos de classe, é importante considerar a realidade de trabalhadores com ocupações incompatíveis com o nível de escolaridade. Dessa forma, os estudos devem qualificar essas mudanças no mundo do trabalho e na inserção na produção.

Hollingshead (1971) diz que é importante considerar a escolaridade do sujeito em um modelo de classe, já que diferencia o estilo de vida, tendo efeito em sua posição de classe.

Em relação à renda, Cattani (2007) relata que os ricos tendem a esconder suas riquezas, além de haver uma dificuldade de obtenção de dados fidedignos, devido à inviolabilidade do segredo bancário e das declarações de renda. Essa dificuldade de acesso a informações sobre os mais ricos dificulta a apreensão da estrutura social envolvida.

Barata (2009) assinala que o uso da variável local de moradia é importante para analisar os problemas de saúde, já que tem a capacidade de considerar os espaços geográficos.

A categoria espaço permite reconhecer a heterogeneidade urbana, uma vez que incorpora a estrutura e a dinâmica social - onde e como vivem as pessoas; o que determina a produção e a circulação dos bens e serviços (Barcellos, Bastos, 1996).

Todos os modelos encontrados nesta revisão utilizaram uma combinação de variáveis para definir as classes sociais. Gianini (1995) diz que há vantagens e desvantagens, já que a associação de variáveis aumenta o poder discriminante entre as classes sociais, mas também aumenta a dificuldade para aplicação nos estudos epidemiológicos. Estudos que associaram escolaridade materna ou paterna e ocupação paterna apresentaram alto poder discriminante entre as classes sociais (Gianini, 1995).

É necessário analisar e adaptar as formas de operacionalização do conceito de classe de forma que não seja anulada a potencialidade da utilização dessa categoria em estudos empíricos epidemiológicos. Para melhor compreender as desigualdades sociais é válido incorporar variáveis que reflitam diferentes ângulos da reprodução social. 
Possas (1989) considera que em países capitalistas periféricos as condições de vida e estilos de vida adquirem grande importância na análise da desigualdade social, sendo dimensões fundamentais das condições de existência. A mesma autora destaca que no Brasil há um enorme contingente populacional não inserido ou afastado do mercado de trabalho, além de setores produtivos dinâmicos que submetem os trabalhadores a condições precárias, o que diversifica o perfil epidemiológico desta população.

\begin{abstract}
A alta mobilidade do mercado de trabalho em economias periféricas como a brasileira impede, pela intensa rotatividade da mão-de-obra, que a exposição a processos de trabalho específicos se dê de forma contínua, prevalecendo a múltipla exposição de um mesmo trabalhador a processos de trabalho diferenciados (Possas, 1989, p. 195).
\end{abstract}

Possas (1989) argumenta que o conceito de classe social, quando tomado a partir do referencial do materialismo histórico, não pode ser operacionalizado. Ela critica a tentativa de operacionalização a partir da construção do conceito de perfil epidemiológico e propõe um esquema de determinação múltipla por hierarquia causal referida. Este esquema identifica condições de risco (variáveis) de acordo com as condições de trabalho, de vida e estilos de vida. Nas suas palavras:

\begin{abstract}
Assumir o conceito de classe social como um conceito teórico relevante para dar conta do real não implica tentar, no plano empírico, reduzir, através de procedimentos operacionais, o real a este conceito, identificando-o com atributos como renda, escolaridade, profissão, local de moradia ou qualquer outro critério" (Possas, 1989, p.175).

Uma característica importante do referencial apresentado é a possibilidade de expressar a concepção de causalidade hierarquizada aqui proposta segundo os distintos níveis de generalidade das variáveis consideradas e pelo cruzamento, em indivíduos concretos, de determinantes de risco associados às condições de vida e trabalho da população (Possas, 1989, p.216).
\end{abstract}

Krieger e outros pesquisadores (2010) sugerem vários pontos em relação aos estudos das desigualdades na saúde, com ênfase na "importância da teoria na formação de análise das desigualdades em saúde".

Enquadramentos teóricos explícitos são necessários que se dedicam, intelectual e epistemologicamente, com a forma como as sociedades produzem e reproduzem a desigualdade social, dominação política, relações trabalhistas, modos de vida e contexto ecológico, afetando ambos os níveis e as distribuições das desigualdades em saúde e saúde (Krieger et al, 2010:1). 
As limitações e dificuldades de operacionalização do conceito de classe não excluem a possibilidade da utilização dos modelos na pesquisa empírica epidemiológica, haja vista o enorme potencial que este conceito possui na área da saúde.

Entretanto, Breilh (1991) ressalta que a utilização do conceito de classe social pode esbarrar em problemas com a obtenção de dados através de registros secundários. Os registros de informação geralmente não possuem informações sobre variáveis "estruturais" e “ informações de acordo com uma racionalidade histórica que permita ponderar a ocorrência de risco nas diferentes classes sociais" (Breilh, 1991. P.150).

Uma pesquisa sobre qualidade de dados de um sistema de informação revelou que nas últimas décadas os dados individuais não apresentaram problemas de preenchimento. Por outro lado dados sobre ocupação e escolaridade ainda apresentam problemas expressivos relacionados à falta de informação ou deficiência no preenchimento, apesar da melhora da qualidade a partir da década de 90 (Mathias, Jorge, 2001).

Em relação aos estudos epidemiológicos, a distribuição desigual dos problemas de saúde mostra a relevância da utilização de um modelo de classe para identificar as desigualdades sociais. Apesar dos dados terem sido obtidos apenas tomando em consideração estudos epidemiológicos de coorte e caso-controle, o que pode ser considerado uma limitação do estudo, a relação classe social e saúde foi fortemente evidenciada.

Os estudos foram realizados principalmente na Grã-Bretanha, pela sua tradição histórica em pesquisas epidemiológicas de coorte. Devido ao recorte do tipo de estudo (coorte e caso-controle) e a não inclusão dos estudos transversais, descritivos ou de prevalência, não foi possível realizar uma análise espacial adequada da utilização dos modelos operacionais na epidemiologia, já que não houve uma amostra da totalidade dos estudos epidemiológicos.

A associação positiva entre classe social e um problema de saúde foi evidenciada na maioria dos estudos epidemiológicos que utilizaram um modelo de classe social para analisar os dados. Entretanto a maioria considerou a classe social um fator de risco para o desenvolvimento do problema de saúde, através de análises estatísticas. 
Barata e Barreto (1996) ressaltam os problemas que a epidemiologia hegemônica vem enfrentando em relação à sua teoria e prática.

\begin{abstract}
Há sinais evidentes do esgotamento do modelo de risco, tanto no que se refere às suas ineficiências teóricas quanto à sua relativa ineficiência prática, isto é, à incapacidade de produzir um discurso coerente e facilmente assimilável pelas pessoas, em termos de prevenção das doenças (Barata, Barreto, 1996, p.77).
\end{abstract}

Almeida Filho (2000) propõe a superação da "epidemiologia dos riscos" através do debate e reformulação da base conceitual.

Resta à Epidemiologia a alternativa de abandonar o conceito clássico de risco e construir um novo objeto-modelo (...). Nossa disciplina terá que realizar um imenso investimento de formação teórica (...). Será necessário produzir esquemas explicativos ancorados na realidade concreta de saúde, nos diversos planos de emergência dos fenômenos da vida e da saúde (Almeida-Filho, 2000, p.234).

Gianini (1995) refere que problemas metodológicos alteram a consistência da relação classe social e saúde. No caso dos estudos epidemiológicos, a inclusão de variáveis sem relação imediata com o problema de saúde pode interferir na interpretação dos resultados.

Harper et al (2010) relatam que a mensuração da desigualdade social não é um processo neutro, já que há valores implícitos na escolha da estratégia de mensuração utilizada nos estudos empíricos. O processo metodológico, incluindo a inclusão e exclusão de variáveis, as formas de análise dos dados e a obtenção de resultados, está vinculada a estes valores dos pesquisadores. Os autores sugerem que os pesquisadores descrevam explicitamente os juízos normativos relacionados às formas de mensuração da desigualdade social, já que os mesmos dados empíricos podem levar a interpretações radicalmente diferentes. A caracterização e magnitude da desigualdade social fundamentam as políticas públicas, ou seja, formas adequadas de mensuração da desigugualdade são fundamentais para a melhoria das condições sociais e de saúde (Harper et al, 2010).

Silva et al (1992) realizaram um estudo sobre a relação entre baixo peso ao nascer e hábito de fumar materno, utilizando o modelo proposto por Barros (1986). Verificaram relações positivas entre os fatores ao analisarem os dados de forma geral. Entretanto ao incluir a categoria classe social na análise, averiguaram que mães fumantes das classes burguesas tiveram menor proporção de recémnascidos de baixo peso em relação às mães não fumantes das classes 
trabalhadoras. Concluíram que o baixo peso ao nascer foi cerca de duas vezes mais frequente no proletariado e quase três vezes maior no subproletariado do que na burguesia, evidenciando a importância de se considerar a classe social em estudos epidemiológicos.

Uma revisão da literatura sobre a utilização de SES na área da saúde revelou um aumento no número de publicações principalmente a partir da década de 90. A média de artigos publicados com SES no título foi de 175,6 por ano, em um total de 3544 artigos entre 1990 e 1999 (Oakes e Rossi, 2003). Esta revisão mostrou também que poucos estudos têm se concentrado na definição e operacionalização de SES, além de avaliações sobre as propriedades dos modelos.

Já uma revisão sistemática identificou através de outras revisões sistemáticas os efeitos de intervenções sobre os determinantes da saúde (Bambra et al, 2010). Os autores concluíram que certas intervenções como incentivar o uso de transporte público, incentivar a participação do trabalhador no ambiente de trabalho e melhorar o acesso aos serviços de saúde são capazes de reduzir as desigualdades sociais, em particular na ocupação e habitação. Novos estudos são necessários para verificar o efeito destas intervenções na saúde (Bambra et al, 2010). 


\section{CONSIDERAÇÕES FINAIS}




\section{CONSIDERAÇÕES FINAIS}

A pesquisa evidenciou diversos modelos do conceito de classe social e a sua aplicabilidade nos estudos epidemiológicos. Os resultados contribuem para o debate sobre a utilização do conceito de classe social na área da saúde. As potencialidades e os problemas dos modelos de classe social foram evidenciados, assim como a utilização destes modelos nos estudos epidemiológicos.

Discutiu-se também a opinião de epidemiólogos que reconhecem a importância do conceito teórico de classe na nossa realidade, porém não o consideram operacionalizável, propondo outras formas de leitura dos determinantes do processo saúde-doença.

A utilização do conceito de classe social em estudos epidemiológicos críticos é adequada para o estudo da desigualdade social e de saúde. A operacionalização do conceito de classe social é utilizada em todo mundo com destaque para a América Latina.

Há a necessidade de operacionalizar o conceito de classes considerando as modificações contemporâneas no mundo do trabalho e suas especificidades, superando as dificuldades desse referencial teórico-metodológico.

Considerando as dificuldades na identificação das desigualdades sociais na contemporaneidade, os modelos de classe social devem contemplar as características socioeconômicas e demográficas nacionais e regionais de cada país.

Esta revisão também identificou 123 estudos epidemiológicos que utilizaram um modelo de classe social. Em relação a estes estudos, a incorporação da categoria classe social revelou diferenças importantes na distribuição dos problemas de saúde. Os estudos empíricos demonstraram que não é possível dissociar o aspecto social do biológico e que as condições de classe são determinantes do processo saúde-doença.

Assim, os estudos epidemiológicos devem considerar a utilização da categoria classe social para identificação das desigualdades sociais em saúde e assim dar respostas adequadas às necessidades de saúde, compreendidas, a partir das considerações teóricas da Saúde Coletiva, como necessidades sociais mais amplas. 
Reitera-se neste trabalho a consideração, há muito discutida em âmbito mundial e particularmente na América Latina, por aqueles estudiosos que vêm tentando dar conta da complexa tarefa de operacionalizar o conceito de classe, de que a Epidemiologia Crítica, ao tentar superar a compartimentalização das diferenças sociais em variáveis que as diluem ou até mesmo as desqualificam, constitui instrumento potente da Saúde Coletiva, para comprovar cientificamente a relação entre classes sociais e desfechos no âmbito do processo saúde-doença. 


\section{REFERÊNCIAS BIBLIOGRÁFICAS}




\section{REFERÊNCIAS BIBLIOGRÁFICAS}

Almeida Filho N, Rouquayrol MZ. Introdução à Epidemiologia Moderna. Rio de Janeiro: Abrasco; 1990.

Almeida Filho N. A ciência da saúde. São Paulo: Hucitec; 2000.

Althusser L. Sobre a reprodução. Petrópolis: Vozes;1999.

Antunes R.. Adeus ao trabalho? Ensaio sobre as metamorfoses e a centralidade do mundo do trabalho. São Paulo: Cortez; 1995.

Arana GAC. Use of theories and models on papers of a Latin-American journal in public health, 2000 to 2004. Rev Saúde Pública. 2007; 41(6):963-69.

Bambra C, Gibson M, Sowden A, Wright K, Whitehead M, Petticrew M. Tackling the wider social determinants of health and health inequalities: evidence from systematic reviews. J Epidemiol Community Health. 2010; 64(4):284-91.

Barata RB, Barreto ML. Algumas questões sobre o desenvolvimento da epidemiologia na América Latina. Cienc Saúde Coletiva. 1996; 1(1): 71-79.

Barata RB. Como e por que as desigualdades sociais fazem mal à saúde. Rio de Janeiro: Fiocruz; 2009.

Barcellos C, Bastos FI. Geoprocessamento, ambiente e saúde: uma união possível? Cad Saúde Pública. 1996; 12(3):389-97.

Bardin L. Análise de conteúdo. Lisboa: Edições 70; 1977.

Barros MBA. Saúde e classe social: um estudo sobre morbidade e consumo de medicamentos [tese de doutorado]. Ribeirão Preto: Faculdade de Medicina de Ribeirão Preto, Universidade de São Paulo; 1983.

Berlinck MT. Marginalidade social e relações de classes em São Paulo. Rio de Janeiro: Vozes; 1975.

Booth A. Cochrane or cock-eyed? How should we conduct systematic reviews of qualitative research? Qualitative Evidence-based Practice Conferences. Conventry University; 2001.

Bourdieu P. O poder simbólico. Rio de Janeiro: Bertrand Brasil; 1998.

Breilh J. Epidemiologia crítica. Rio de Janeiro: Fiocruz; 2006.

Breilh J. Epidemiologia. Economia, política e saúde. São Paulo: Hucitec; 1991.

Breilh J, Granda E. Investigação da Saúde na Sociedade: guia pedagógico sobre um novo enfoque do método epidemiológico. São Paulo: Cortez; 1989. 
Breilh J. Nuevos conceptos y técnicas de investigación: guia pedagógica para un taller de metodologia. Quito: CEAS; 1994.

Brito F. Transição demográfica e desigualdades sociais no Brasil. Rev. bras. Estud. Popul. 2008; 25(1):5-26.

Campos et al. Atlas da exclusão social no Brasil, volume 2: dinâmica e manifestação territorial. São Paulo: Cortez; 2004.

Castellanos PL. Epidemiologia y organización de los servicios: La formacion en epidemiología para el desarrollo de los servicios de salud. Apresentado em: Conferencia de la Asociación Latinoamericana y del Caribe de Educación en Salud Pública ALAESP, 14, Taxco, 15-19 nov; 1987.

Cattani AD. Desigualdades socioeconômicas: conceitos e problemas de pesquisa. Sociologias. 2007; 9(18):74-99.

Comissão Nacional sobre Determinantes Sociais da Saúde (CNSDSD). As causas sociais das iniqüidades em saúde no Brasil. Rio de Janeiro: Fiocruz; 2008.

Crompton R. Class and stratification: an introduction to current debates. Polity Press: Cambridge; 1998.

Davies et al. A systematic review of the use of theory in the design of guideline dissemination and implementation strategies and interpretation of the results of rigorous evaluations. Implement Sci. 2010;5:14.1.

Edwards N, Ruggiero E. Exploring which context in the study of health inequities and their mitigation. Scand J Public Health. 2011; 39(suppl 6):43-49.

Erikson R, Goldthorpe JH. Intergenerational Class Mobility in Three Western European Societies: England, France and Sweden. Br J Sociol. 1979; 30(4):415441.

Ferreira FHG. Os determinantes da desigualdade de renda no Brasil: luta de classes ou heterogeneidade educacional. In: Seminário sobre desigualdade e pobreza no Brasil; 1999 ago. 12-14; Rio de Janeiro.

Galobardes B, Lynch J, Smith GD. Measuring socioeconomic position in health research. British Medical Bulletin. 2007; 81 and 82(1):21-37.

Gianini RJ. Desigualdade social e saúde na América Latina. São Paulo: Annablume; 1995.

Granda E, Breilh J. Saúde na sociedade. São Paulo: Cortez: Instituto de Saúde; 1989. 
Grusky D. The past, present and future of social inequality. In: Grusky D, Ku MC, Szelenyi S. Social Stratification: Class, gender and race in sociological perspective. Boulder: Westview Press; 2000. p. 3-51.

Harper S, King NB, Meersman SC, Reichman ME, Breen N, Lynch J. Implicit value judgments in the measurement of health inequalities. Milbank Q. 2010; 88(1):4-29.

Haug MR, Sussmas MB. The Indiscriminate State of Social Class Measurement. Social Forces. 1971; 49(4):549-563.

Hirano S. Castas, estamentos e classes sociais. Introdução ao pensamento sociológico de Marx e Weber. Campinas: Unicamp; 2006.

Hollingshead AB. Commentary on "The Indiscriminate State of Social Class Measurement". Social Forces. 1971; 49(4):563-567.

Hollingshead AB, Redlich FC. Social class and mental illness: a community study. New York: John Wiley \& Sons; 1958.

Ianni O. Teorias de estratificação social. São Paulo: Editora Nacional; 1972.

Joanna Briggs Institute (JBI). Joanna Briggs Institute Reviewers’ Manual: 2008 edition. Adelaide: The Joanna Briggs Institute; 2008.

Kliksberg B. América Latina: uma região de risco - pobreza, desigualdade e institucionalidade social. Brasília: UNESCO; 2002.

Krieger N, Williams DR, Moss NE. Measuring social class in US public health research: concepts, methodologies, and guidelines. Annu. Rev. Public Health. 1997;18:341-378.

Krieger N, Alegria M, Almeida-Filho N, Silva JB, Barreto ML, Beckfield J et al. Who, and what, causes health inequities? Reflections on emerging debates from an exploratory Latin American/North American workshop. J Epidemiol Community Health. 2010;1-3.

Laurell AC. A saúde-doença como processo social. In: Duarte, E. (org). Medicina social - aspectos históricos e sociais. São Paulo: Global; 1983.

Lombardi C, Bronfman M, Facchini LA, Victora CG, Barros FC, Béria JU. Operacionalização do conceito de classe social em estudos epidemiológicos. Rev Saúde Pública. 1988; 22(4):253-265.

Lopes JRB. Brasil,1989: um estudo sócio-econômico da indigência e da pobreza urbana. Rio de Janeiro: Centro Edelstein de Pesquisas Sociais; 2008.

Lucas RM, McMichael JA. Association or causation: evaluating links between "environment and disease". Bulletin of the World Health Organization. 2005; 83(10):792-795. 
Marks G. The measurement of socioeconomic status and social class in the LSAY project. Technical Paper Number 14; [s.d]

Marx K. O Capital: crítica da economia política. São Paulo: Nova Cultural; 1985. p. 151-213.

Marx K. 18 Brumário de Luis Bonaparte. São Paulo: Martin Claret; 2008.

Mathias TAF, Jorge MHPM. Sistema de informações sobre mortalidade: análise da qualidade dos dados para o município de Maringá, Estado do Paraná, Brasil. Acta Scientiarum. 2001; 23(3):759-765.

Mattar FN. Análise crítica dos estudos de estratificação sócio-econômica de ABAAbipeme. Rev de Administração. 1995; 30(1):57-74.

McFadden E, Luben R, Khaw KT. Different measures of social class in women and mortality. Eur J Epidemiol. 2009; 24(5):231-6.

Minayo MCS, Assis DG, Deslandes SF, Souza ER. Possibilidades e dificuldades nas relações entre ciências sociais e epidemiologia. Cien Saúde Colet. 2003; 8(1):97-107.

Netto JP. Capitalismo monopolista e serviço social. São Paulo: Cortez; 1992.

Noronha AL, Borges MA, Marques LH, Zanetta DM, Fernandes PT, de Boer H, Espíndola J, Miranda CT, Prilipko L, Bell GS, Sander JW, Li LM. Prevalence and pattern of epilepsy treatment in different socioeconomic classes in Brazil. Epilepsia. 2007; 48(5):880-5.

Nunes ED. Ciências sociais em saúde: um panorama geral. In: Goldenberg P, Marsiglia RMG, Gomes MHA. O clássico e o novo: tendências, objetos e abordagens em ciências sociais e saúde. Rio de Janeiro: Fiocruz; 2003.

Oakes JM, Rossi P. The measurement of SES in health research: current practice and steps toward a new approach. Soc Sci Med 2003; 56:769-84.

Paim JS, Almeida Filho N. Saúde coletiva: uma "nova saúde pública" ou campo aberto a novos paradigmas? Rev Saúde Pública 1998; 32(4): 299-316.

Pearson A, Wiechula R, Court A, Lockwood C. The JBI model of evidence-based healthcare. Int J Evid Based Healthc. 2005; 3:207-215.

Piccini RX, Victora CG. Hipertensão arterial sistêmica em área urbana no sul do Brasil: prevalência e fatores de risco. Rev Saúde Pública. 1994; 28(4): 261-267.

Pochmann M. O emprego na globalização. São Paulo: Boitempo; 2001.

Pochmann M. Educação e trabalho: como desenvolver uma relação virtuosa? Educ Soc. 2004; 25(87):383-99 
Possas C. Epidemiologia e sociedade. Heterogeneidade estrutural e saúde no Brasil. São Paulo: Hucitec, 1989.

Poulantzas N. As classes sociais no capitalismo de hoje. Rio de Janeiro: Zahar; 1975.

Prata PR. Desenvolvimento econômico, desigualdade e saúde. Cad Saúde Pública. 1994;10(3): 387-391.

Rouquayrol MZ. Epidemiologia, História Natural e Prevenção de Doenças. In: Rouquayrol MZ. Epidemiologia \& Saúde. Rio de Janeiro: Medsi; 1993. p. 7-22.

Rose D. Official Social Classifications in the UK. Social Research Update. 1995; Issue 9.

Rosen G. Uma história da saúde pública. São Paulo: Hucitec: Editora da Universidade Estadual Paulista; Rio de Janeiro: Associação Brasileira de PósGraduação em Saúde Coletiva; 1994.

Sabroza PC, Toledo LM, Osanai CH. A organização do espaço e os processos endêmico-epidêmicos. In: Leal MC, Sabroza PC, Rodrigues RH, Buss PM. Saúde, ambiente e desenvolvimento. São Paulo: Hucitec; 1992.

Santos M. Pobreza urbana. São Paulo: Hucitec; 1978.

Santos JAF. A teoria e a tipologia de classe neomarxista de Erik Olin Wright. Dados. 1998; 41(2):377-410.

Silva AAM, Gomes UA, Bettiol H, Bo CMRD, Mucillo G, Barbieri MA. Associação entre idade, classe social e hábito de fumar maternos com peso ao nascer. Rev Saúde Pública. 1992; 26(3):150-154.

Silva JB. Barros MBA. Epidemiologia e desigualdade: notas sobre a teoria e a história. Rev Panam Salud Publica. 2002;12(6):375-386.

Singer P. Dominação e desigualdade: estrutura de classes e repartição de renda no Brasil. Rio de Janeiro: Paz e Terra; 1981.

Soares CB. Consumo contemporâneo de drogas e juventude: a construção do objeto da perspectiva da saúde coletiva [tese livre-docência]. São Paulo: Escola de Enfermagem da Universidade de São Paulo; 2007.

Social Report Update. Official Social Classifications in the UK. Guildford: University of Surrey; 1995.

Solla JSP. Classe social e saúde: um estudo sobre a utilização deste conceito na investigação epidemiológica [dissertação de mestrado]. Bahia: Universidade Federal da Bahia; 1992. 
Stavenhagen R. Classes sociais e estratificação social. Sociologia e sociedade: leituras de introdução à sociologia. Rio de Janeiro: Livros Técnicos e Científicos Editora; 1977.

Stotz EN. Enfoque sobre educação popular e saúde. Cad de educação popular e saúde. Serie B. Textos básicos de saúde. Brasília; 2007.

Teixeira AF, Aliane PP, Ribeiro LC, Ronzani TM. Uso de substâncias psicoativas entre estudantes de Goianá, MG. Estud. Psicol. 2009; 14(1):51-57.

Trivinos ANS. Introdução à pesquisa em ciências sociais: a pesquisa qualitativa em educação. São Paulo: Atlas; 1992.

Viana MLW. A questão social e os recursos sociais. In: Mínimos sociais, questões, conceitos e opções estratégicas. Brasília: MPAS/SAS; 1999.

Weber M. A distribuição do poder dentro da comunidade. Classes, estamentos, partidos. In: Economia e sociedade. Fundamentos da Sociologia compreensiva. Brasília: Universidade de Brasília; 1999. p. 175-186.

Weber M. O conceito de casta. In: Teorias de estratificação social. São Paulo: Companhia Editora Nacional; 1972.

Wright EO. Classes. London: Verso; 1985. 
9 ANEXOS 
ANEXO I

\section{JBI Critical Appraisal Checklist for Text/Opinion}

Reviewer

Date

Author

Year

Record Number

Yes No Unclear

\section{Criteria}

1) Is the source of the opinion clearly identified?

2) Does the source of the opinion have standing in the field of expertise?

3) Are the interests of patients/clients the central focus of the opinion?

4) Is the opinion's basis in logic/experience clearly argued?

5) Is the argument developed analytical?

6) Is there reference to the extant literature/evidence and any incongruency with it logically defended?

7) Is the opinion supported by peers?

Overall appraisal: Include Exclude Seek further info

Comments (Including reason for exclusion) 


\begin{abstract}
ANEXO II
Checklist for Cohort/Case Control appraisal

Reviewer

Date

Author

Year

Record Number

Yes No Unclear

\section{Criteria}

1) Is sample representative of patiens in the population as a whole?

2) Are the patients at a similar point in the course os their condition/illness?

3) Has bias been minimised in relation to selection of cases and of controls?

4) Are confounding factors identified and strategies to deal with them stated?

5) Are outcomes assessed using objective criteria?

6) Was follow up carried out over a sufficient time period?

7) Were the outcomes of people who withdrew described and included in the analysis?

8) Were outcomes measured in a reliable way?

9) Was appropriate statistical analysis used? 


\section{ANEXO III}

\section{Data extraction Form}

Reviewer

Author
Date

Year
Record Number

Extraction Details: Institute, J. B. - Best Practice (2003)

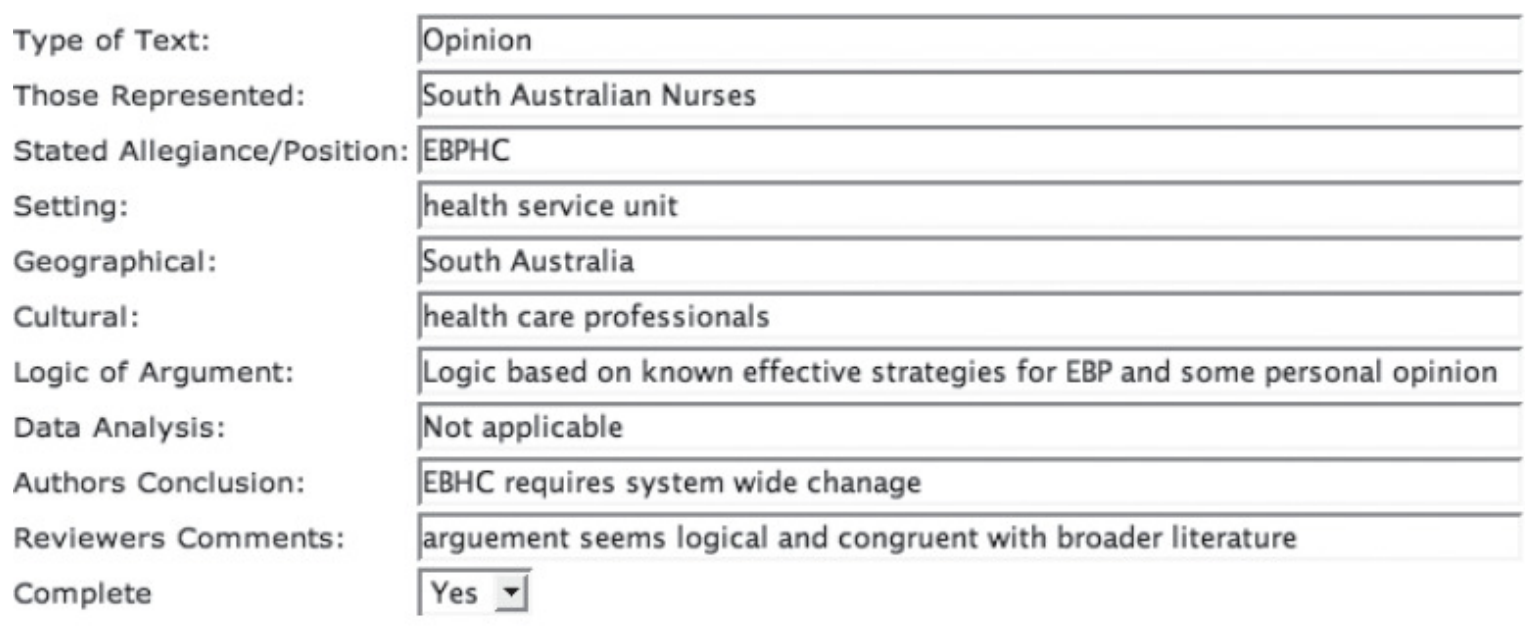




\section{ANEXO IV}

\section{Data extraction Form}

Reviewer

Author
Date

Year

Record Number

\begin{tabular}{|c|c|}
\hline Method & Cohort \\
\hline Setting & hospital \\
\hline Participants & adults \\
\hline \# Participants & Group A: $\sqrt{123} \quad$ Group B: 321 \\
\hline \multirow[t]{4}{*}{ Interventions } & Interventions A: \\
\hline & music \\
\hline & Interventions B: \\
\hline & talk back radio \\
\hline \multicolumn{2}{|l|}{$\begin{array}{l}\text { Authors } \\
\text { Conclusion }\end{array}$} \\
\hline $\begin{array}{l}\text { Reviewers } \\
\text { Comments }\end{array}$ & $\begin{array}{l}\text { relaxation demonstrated. Effect of music on other clinical outcomes not } \\
\text { established. }\end{array}$ \\
\hline Complete & Yes \pm \\
\hline
\end{tabular}




\section{APÊNDICE}




\section{APÊNDICE I}

Instrumento para avaliação inicial dos critérios de inclusão. Adaptado de Joanna Briggs Institute

\section{Avaliação inicial dos critérios de inclusão}

\begin{tabular}{|c|c|c|c|}
\hline & \multicolumn{3}{|c|}{ Código do estudo_. } \\
\hline \multicolumn{4}{|l|}{$\begin{array}{l}\text { Título } \\
\text { Autor (es) }\end{array}$} \\
\hline \multirow{2}{*}{\multicolumn{4}{|c|}{$\begin{array}{l}\text { Revisor_____ } \\
\text { Data_______ }\end{array}$}} \\
\hline & & & \\
\hline Critérios & Sim & Não & Indeterminado \\
\hline \multicolumn{4}{|l|}{$\begin{array}{l}\text { O estudo se encontra no âmbito da revisão } \\
\text { selecionada? }\end{array}$} \\
\hline $\begin{array}{l}\text { A teoria ou o modelo teórico foi descrito no } \\
\text { estudo? }\end{array}$ & & & \\
\hline
\end{tabular}

Decisão inicial: $\square$ Incluído

$\square$ Indeterminado

$\square$ Excluído 


\section{APÊNDICE II \\ Referências dos estudos incluídos nesta revisão sobre a operacionalização do conceito de classe social na América Latina}

Barros MBA. A utilização do conceito de classe social nos estudos dos perfis epidemiológicos: uma proposta. Rev Saúde Pública. 1986; 20(4):269-273.

Behm H. Economic and social determinants of mortality in Latin America. Rev Cuhana Adm Salud. 1980; 6(1):1-30.

Breilh J, Granda E, Campaña A, Betancourt OF. Clase social y desigualdad ante la muerte en Quito. In: Breilh J, Granda E, Campaña A, Betancourt O. Ciudad y muerte infantil. Quito: CEAS; 1983.

Bronfman M, Tuirán R. La desigualdad ante la muerte: clases sociales y mortalidad en la niñez. Cuad. méd. soc. 1984; 29/30:53-75.

Carvalheiro JR. Processo migratório e disseminação de doenças. In: Textos de apoio. Rio de Janeiro: ABRASCO; 1986.

Lombardi C, Bronfman M, Facchini LA, Victora CG, Barros FC, Béria JU ET al. The operationalization of the concept of social class in epidemiological studies. Rev Saúde Pública. 1988; 22(4):253-265.

Queiroz VM, Salum MJL. A construção de perfis epidemiológicos e a responsabilidade da universidade pública na luta pela saúde como direito social. Congresso de Medicina Social; 2000.

Silva GB. Critérios de estratificação social. Rev Saúde Pública.1981; 15(1):38-45

Solla JJSP. Classe Social e Saúde: um Estudo sobre a Utilização deste Conceito na Investigação Epidemiológica [dissertação]. Salvador: Universidade Federal da Bahia; 1992. 


\section{APÊNDICE III}

\section{Referências dos estudos incluídos nesta revisão sobre a operacionalização do conceito de classe social na América do Norte e Europa}

Alonso J, Pérez P, Sáez M, Murillo C. Validez de la ocupación como un indicador de la clase social, según la clasificación del British Registrar General. Gac Sanit. 1997; 11(5): 205-13.

Central Statistics Office. Census 2006 - Principal socio-economic results. [homepage na Internet]. Cork; 2007. [citado 2010 jun. 5]. Disponível em: http://www.cso.ie/default.htm

Corcoran C, Perrin M, Harlap S, Deutsch L, Fennig S, Manor O, et al. Effect of socioeconomic status and parents' education at birth on risk of schizophrenia in offspring. Soc Psychiatry Psychiatr Epidemiol. 2009 Apr;44(4):265-71

Erikson R, Goldthorpe JH. Intergenerational Class Mobility in Three Western European Societies: England, France and Sweden. Br J Sociol. 1979; 30(4):415-441.

French national job classification. National Institute of Statistics and Economic Studies. [homepage na Internet]. France; 2002. [citado 2010 jun. 5]. Disponível em: http://www.insee.fr/en/default.asp

Hansen EJ. Social groups in Denmark. Copenhagen: The. Danish National Centre for Social Research; 1984. Disponível em:

http://www.sfi.dk/Default.aspx?ID=2631

Hollingshead AB, Redlich FC. Social class and mental illness: a community study. New York: John Wiley \& Sons. 1958.

Navarro V, Benach J. Desigualdades sociales en salud en España. Madrid: The Johns Hopkins University; 1996.

Regidor E, Gutiérrez-Fisac JL, Banegas JR, López-García E, Rodríguez-Artalejo F. Obesity and socioeconomic position measured at three stages of the life course in the elderly. Eur J Clin Nutr. 2004; 58(3):488-94.

Registrar General's Classification. Office of Population Censuses and Surveys. London: HMSO; 1980. Disponível em: http://www.ons.gov.uk/aboutstatistics/classifications/current/ns-sec/index.html

Salvany AD, Marcos J. Propuesta de un indicador de la "clase social" basado en la ocupación. Gac Sanit. 1989; 3:320-6.

Spanish Society of Epidemiology. Una propuesta de medida de la clase social. Atención Primaria. 2000; 25:350-63.

Starfield B, Robertson J, Riley AW. Social class gradients and health in childhood. Ambul Pediatr. 2002; 2(4):238-46. 
Stevens GD. Gradients in the health status and developmental risks of young children: the combined influences of multiple social risk factors. Matern Child Health J. 2006; 10(2):187-99.

Statistics Finland. Socio-economic classification. Finland: Handbooks; 1989. Disponível em: http://tilastokeskus.fi/index en.html

Statistics Sweden. Swedish socio-economic classification. The Swedish Trade Union Confederation. Sweden; 1995. Disponível em:

http://www.scb.se/Grupp/Hitta_statistik/Forsta_Statistik/Klassifikationer/_Dokument/ $\underline{\text { SEI-AGG_Eng.pdf }}$

The European socio-economic classification. European Socio-economic Classification (ESeC). Institute for social \& economic research; 2004. Disponível em: http://www.iser.essex.ac.uk/research/esec

The National Statistics Socio-economic classification. The National Statistics Socioeconomic Classification User Manual. England: National Statistics; 2008. Disponível em:

http://www.statistics.gov.uk/methods_quality/ns_sec/downloads/NS-

$\underline{\text { SEC_User_2005.pdf }}$

Wright EO. Class, Crisis and the State. London: New Left Books; 1978. 


\section{APÊNDICE IV}

\section{Referências dos estudos epidemiológicos incluídos nesta revisão (ordenado de acordo com o título).}

Ibrahim S, Smith P, Muntaner C. A multi-group cross-lagged analyses of work stressors and health using Canadian National sample. Soc Sci Med. 2009;68(1):49-59.

Canoy D, Luben R, Welch A, Bingham S, Wareham N, Day N, Khaw KT. Abdominal obesity and respiratory function in men and women in the EPIC-Norfolk Study, United Kingdom. Am J Epidemiol. 2004 Jun 15;159(12):1140-9.

Mann SL, Wadsworth ME, Colley JR. Accumulation of factors influencing respiratory illness in members of a national birth cohort and their offspring. $\mathrm{J}$ Epidemiol Community Health. 1992 Jun;46(3):286-92.

Surtees PG, Wainwright NW, Luben RL, Wareham NJ, Bingham SA, Khaw KT. Adaptation to social adversity is associated with stroke incidence: evidence from the EPIC-Norfolk prospective cohort study. Stroke. 2007 May;38(5):1447-53.

Snook JA, Dwyer L, Lee-Elliott C, Khan S, Wheeler DW, Nicholas DS. Adult coeliac disease and cigarette smoking. Gut. 1996 Jul;39(1):60-2.

Gianini RJ; Litvoc J, Eluf Neto J. Agressão física e classe social. Rev. Saúde Pública. 1999; 33(2):180-6.

Hart CL, Smith GD, Upton MN, Watt GC. Alcohol consumption behaviours and social mobility in men and women of the Midspan Family study. Alcohol Alcohol. 2009 May-Jun;44(3):332-6.

Hatch SL, Mishra G, Hotopf M, Jones PB, Kuh D. Appraisals of stressors and common mental disorder from early to mid-adulthood in the 1946 British birth cohort. J Affect Disord. 2009 Dec;119(1-3):66-75.

Li L, Manor O, Power C. Are inequalities in height narrowing? Comparing effects of social class on height in two generations. Arch Dis Child. 2004 Nov;89(11):1018-23.

Power C, Manor O, Li L. Are inequalities in height underestimated by adult social position? Effects of changing social structure and height selection in a cohort study. BMJ. 2002 Jul 20;325(7356):131-4.

Shohaimi S, Welch A, Bingham S, Luben R, Day N, Wareham N, et al. Area deprivation predicts lung function independently of education and social class. Respir J. 2004 Jul;24(1):157-61.

Rantakallio P, Jones P, Moring J, Von Wendt L. Association between central nervous system infections during childhood and adult onset schizophrenia and other psychoses: a 28-year follow-up. Int J Epidemiol. 1997 Aug;26(4):837-43. 
Adamson J, Hunt K, Ebrahim S. Association between measures of morbidity and locomotor disability: diagnosis alone is not enough. Soc Sci Med. 2003 Oct;57(8):1355-60.

Harrison G, Gunnell D, Glazebrook C, Page K, Kwiecinski R. Association between schizophrenia and social inequality at birth: case-control study. Br J Psychiatry. 2001 Oct; 179:346-50.

Timonen M, Jokelainen J, Silvennoinen-Kassinen S, Herva A, Zitting P, Xu B, Peltola $\mathrm{O}$, et al. Association between skin test diagnosed atopy and professionally diagnosed depression: a Northern Finland 1966 Birth Cohort study. Biol Psychiatry. 2002 Aug 15;52(4):349-55.

Blane D, Hart CL, Smith GD, Gillis CR, Hole DJ, Hawthorne VM. Association of cardiovascular disease risk factors with socioeconomic position during childhood and during adulthood. BMJ. 1996 Dec 7;313(7070):1434-8.

Power C, Manor O. Asthma, enuresis, and chronic illness: long term impact on height. Arch Dis Child. 1995 Oct;73(4):298-304.

Libby G, McEwan SR, Belch JJ, Morris AD. Birth weight does not predict blood pressure in a young working population: a sharp (Scottish Heart and Arterial Disease Risk Prevention) study. Ann Epidemiol. 2008 Apr;18(4):298-301.

Kuh D, Hardy R, Chaturvedi N, Wadsworth ME. Birth weight, childhood growth and abdominal obesity in adult life. Int J Obes Relat Metab Disord. 2002 Jan;26(1):40-7.

Kuh D, Bassey J, Hardy R, Aihie Sayer A, Wadsworth M, Cooper C. Birth weight, childhood size, and muscle strength in adult life: evidence from a birth cohort study. Am J Epidemiol. 2002 Oct 1;156(7):627-33.

Jefferis BJ, Power C, Hertzman C. Birth weight, childhood socioeconomic environment, and cognitive development in the 1958 British birth cohort study. BMJ. 2002 Aug 10;325(7359):305.

Hardy R, Kuh D, Langenberg C, Wadsworth ME. Birthweight, childhood social class, and change in adult blood pressure in the 1946 British birth cohort. Lancet. 2003 Oct 11;362(9391):1178-83.

Symmons DP, Bankhead CR, Harrison BJ, Brennan P, Barrett EM, Scott DG, et al. Blood transfusion, smoking, and obesity as risk factors for the development of rheumatoid arthritis: results from a primary care-based incident case-control study in Norfolk, England. Arthritis Rheum. 1997 Nov;40(11):1955-61.

Silventoinen K, Lahelma E, Lundberg O, Rahkonen O. Body height, birth cohort and social background in Finland and Sweden. Eur J Public Health. 2001 Jun;11(2):124-9.

Vázquez-Barquero JL, Cuesta MJ, Herrera Castanedo S, Lastra I, Herrán A, Dunn G. Cantabria first-episode schizophrenia study: three-year follow-up. Br J Psychiatry. 1999 Feb;174:141-9. 
Langenberg C, Hardy R, Kuh D, Brunner E, Wadsworth M. Central and total obesity in middle aged men and women in relation to lifetime socioeconomic status: evidence from a national birth cohort. J Epidemiol Community Health. 2003 Oct;57(10):81622.

Jefferis BJ, Thomson AG, Lennon LT, Feyerabend C, Doig M, McMeekin L, et al. Changes in environmental tobacco smoke (ETS) exposure over a 20-year period: cross-sectional and longitudinal analyses. Addiction. 2009 Mar;104(3):496-503.

Price GM, Paul AA, Cole TJ, Wadsworth ME. Characteristics of the low-energy reporters in a longitudinal national dietary survey. Br J Nutr. 1997 Jun;77(6):833-51.

Power C, Manor O, Matthews S. Child to adult socioeconomic conditions and obesity in a national cohort. Int J Obes Relat Metab Disord. 2003 Sep;27(9):1081-6.

Mishra GD, Malik NS, Paul AA, Wadsworth ME, Bolton-Smith C. Childhood and adult dietary vitamin $\mathrm{E}$ intake and cardiovascular risk factors in mid-life in the 1946 British Birth Cohort. Eur J Clin Nutr. 2003 Nov;57(11):1418-25.

Power C, Stansfeld SA, Matthews S, Manor O, Hope S. Childhood and adulthood risk factors for socio-economic differentials in psychological distress: evidence from the 1958 British birth cohort. Soc Sci Med. 2002 Dec;55(11):1989-2004.

Stansfeld SA, Clark C, Rodgers B, Caldwell T, Power C. Childhood and adulthood socio-economic position and midlife depressive and anxiety disorders. $\mathrm{Br} \mathrm{J}$ Psychiatry. 2008 Feb;192(2):152-3.

Okasha M, McCarron P, McEwen J, Durnin J, Smith GD. Childhood social class and adulthood obesity: findings from the Glasgow Alumni Cohort. J Epidemiol Community Health. 2003 Jul;57(7):508-9.

Richards M, Shipley B, Fuhrer R, Wadsworth ME. Cognitive ability in childhood and cognitive decline in mid-life: longitudinal birth cohort study. BMJ. 2004 Mar 6;328(7439):552.

Power C, Li L, Manor O, Smith GD. Combination of low birth weight and high adult body mass index: at what age is it established and what are its determinants? J Epidemiol Community Health. 2003 Dec;57(12):969-73.

Hunt K, Hannah MK, West P. Contextualizing smoking: masculinity, femininity and class differences in smoking in men and women from three generations in the west of Scotland. Health Educ Res. 2004 Jun;19(3):239-49.

Power C, Atherton K, Manor O. Co-occurrence of risk factors for cardiovascular disease by social class: 1958 British birth cohort. J Epidemiol Community Health. 2008 Dec;62(12):1030-5.

Sevy S, Robinson DG, Holloway S, Alvir JM, Woerner MG, Bilder R, Goldman R, Lieberman J, Kane J. Correlates of substance misuse in patients with first-episode schizophrenia and schizoaffective disorder. Acta Psychiatr Scand. 2001 Nov;104(5):367-74. 
Kuh D, Hardy R, Butterworth S, Okell L, Richards M, Wadsworth M, et al. Developmental origins of midlife physical performance: evidence from a British birth cohort. Am J Epidemiol. 2006 Jul 15;164(2):110-21.

Joffe M, Barnes I. Do parental factors affect male and female fertility? Epidemiology. 2000 Nov;11(6):700-5.

Ellaway A, Anderson A, Macintyre S. Does area of residence affect body size and shape? Int J Obes Relat Metab Disord. 1997 Apr;21(4):304-8.

Sayer AA, Syddall HE, Gilbody HJ, Dennison EM, Cooper C. Does sarcopenia originate in early life? Findings from the Hertfordshire cohort study. J Gerontol A Biol Sci Med Sci. 2004 Sep;59(9):M930-4.

Katschinski BD, Logan RF, Edmond M, Langman MJ. Duodenal ulcer and refined carbohydrate intake: a case-control study assessing dietary fibre and refined sugar intake. Gut. 1990 Sep;31(9):993-6.

Li L, Manor O, Power C. Early environment and child-to-adult growth trajectories in the 1958 British birth cohort. Am J Clin Nutr. 2004 Jul;80(1):185-92.

Wadsworth M, Butterworth S, Marmot M, Ecob R, Hardy R. Early growth and type 2 diabetes: evidence from the 1946 British birth cohort. Diabetologia. 2005 Dec;48(12):2505-10.

Lamont DW, Parker L, Cohen MA, White M, Bennett SM, Unwin NC, Craft AW, Alberti KG. Early life and later determinants of adult disease: a 50 year follow-up study of the Newcastle Thousand Families cohort. Public Health. 1998 Mar;112(2):85-93.

Mulvany F, O'Callaghan E, Takei N, Byrne M, Fearon P, Larkin C. Effect of social class at birth on risk and presentation of schizophrenia: case-control study.

BMJ. 2001 Dec 15;323(7326):1398-401.

Gruer L, Hart CL, Gordon DS, Watt GC. Effect of tobacco smoking on survival of men and women by social position: a 28 year cohort study. BMJ 2009; 338:b480.

Tabassum F, Kumari M, Rumley A, Lowe G, Power C, Strachan DP. Effects of socioeconomic position on inflammatory and hemostatic markers: a life-course analysis in the 1958 British birth cohort. Am J Epidemiol. 2008 Jun 1;167(11):133241.

Bartley M, Sacker A, Clarke P. Employment status, employment conditions, and limiting illness: prospective evidence from the British household panel survey 19912001. J Epidemiol Community Health. 2004 Jun;58(6):501-6.

Purslow LR, Sandhu MS, Forouhi N, Young EH, Luben RN, Welch AA, et al. Energy intake at breakfast and weight change: prospective study of 6,764 middleaged men and women. Am J Epidemiol. 2008 Jan 15;167(2):188-92. 
Power C, Manor O. Explaining social class differences in psychological health among young adults: a longitudinal perspective. Soc Psychiatry Psychiatr Epidemiol. 1992 Nov;27(6):284-91.

Peters TJ, Sanders C, Dieppe P, Donovan J. Factors associated with change in pain and disability over time: a community-based prospective observational study of hip and knee osteoarthritis. Br J Gen Pract. 2005 Mar;55(512):205-11.

West P, Sweeting H, Ecob R. Family and friends' influences on the uptake of regular smoking from mid-adolescence to early adulthood. Addiction. 1999 Sep;94(9):1397411.

Laitinen J, Power C, Järvelin MR. Family social class, maternal body mass index, childhood body mass index, and age at menarche as predictors of adult obesity. Am J Clin Nutr. 2001 Sep;74(3):287-94.

Von Eyben FE, Mouritsen EA, Holm J, Montvilas P, Dimcevski G, Rasmussen IH, Kristensen LL, Suciu G, Von Eyben R. Fibrinogen and other coronary risk factors. Metabolism. 2005 Feb;54(2):165-70.

Kuh D, Bassey EJ, Butterworth S, Hardy R, Wadsworth ME; Musculoskeletal Study Team. Grip strength, postural control, and functional leg power in a representative cohort of British men and women: associations with physical activity, health status, and socioeconomic conditions. J Gerontol A Biol Sci Med Sci. 2005 Feb;60(2):22431.

Hammarström A, Janlert U. Health selection in a 14-year follow-up study--a question of gendered discrimination? Soc Sci Med. 2005 Nov;61(10):2221-32.

Manor O, Matthews S, Power C. Health selection: the role of inter- and intragenerational mobility on social inequalities in health. Soc Sci Med. 2003 Dec;57(11):2217-27.

Perel P, Langenberg C, Ferrie J, Moser K, Brunner E, Marmot M. Household wealth and the metabolic syndrome in the Whitehall II study. Diabetes Care. 2006 Dec;29(12):2694-700.

Power C, Matthews S, Manor O. Inequalities in self rated health in the 1958 birth cohort: lifetime social circumstances or social mobility? BMJ. 1996 Aug 24;313(7055):449-53.

Power C, Matthews S, Manor O. Inequalities in self-rated health: explanations from different stages of life. Lancet. 1998 Apr 4;351(9108):1009-14.

Mustard CA, Vermeulen M, Lavis JN. Is position in the occupational hierarchy a determinant of decline in perceived health status? Soc Sci Med. 2003 Dec;57(12):2291-303.

Ecob R, Sutton G, Rudnicka A, Smith P, Power C, Strachan D, Davis A. Is the relation of social class to change in hearing threshold levels from childhood to middle age explained by noise, smoking, and drinking behaviour? Int J Audiol. 2008 Mar;47(3):100-8. 
Holland P, Lane S, Whitehead M, Marson AG, Jacoby A. Labor market participation following onset of seizures and early epilepsy: Findings from a UK cohort. Epilepsia. 2009 May;50(5):1030-9.

Smidt N, Lewis M, Van der Windt DA, Hay EM, Bouter LM, Croft P. Lateral epicondylitis in general practice: course and prognostic indicators of outcome. J Rheumatol. 2006 Oct;33(10):2053-59.

Leino-Arjas P, Solovieva S, Riihimäki H, Kirjonen J, Telama R. Leisure time physical activity and strenuousness of work as predictors of physical functioning: a 28 year follow up of a cohort of industrial employees. Occup Environ Med. 2004 Dec;61(12):1032-8.

Power C, Atherton K, Strachan DP, Shepherd P, Fuller E, Davis A, Gibb I, Kumari M, Lowe G, Macfarlane GJ, Rahi J, Rodgers B, Stansfeld S. Life-course influences on health in British adults: effects of socio-economic position in childhood and adulthood. Int J Epidemiol. 2007 Jun;36(3):532-9.

Harald K, Pajunen P, Jousilahti P, Koskinen S, Vartiainen E, Salomaa V. Modifiable risk factors have an impact on socio-economic differences in coronary heart disease events. Scand Cardiovasc J. 2006 Apr;40(2):87-95.

Konstantopoulos A, Yadegarfar G, Elgohary M. Near work, education, family history, and myopia in Greek conscripts. Eye (Lond). 2008 Apr;22(4):542-6.

McNamee R, Braganza JM, Hogg J, Leck I, Rose P, Cherry NM. Occupational exposure to hydrocarbons and chronic pancreatitis: a case-referent study. Occup Environ Med. 1994 Sep;51(9):631-7.

Power C, Matthews S. Origins of health inequalities in a national population sample. Lancet. 1997 Nov 29;350(9091):1584-9.

Lauronen E, Miettunen J, Veijola J, Karhu M, Jones PB, Isohanni M. Outcome and its predictors in schizophrenia within the Northern Finland 1966 Birth Cohort. Eur Psychiatry. 2007 Mar;22(2):129-36.

Colman I, Murray J, Abbott RA, Maughan B, Kuh D, Croudace TJ, Jones PB. Outcomes of conduct problems in adolescence: 40 year follow-up of national cohort. BMJ. 2009 Jan 8;338:a2981.

Chandola, T and Clarke, P and Morris, JN and Blane, D. Pathways between education and health: a causal modelling approach. J Roy Stat Soc A Sta. 2006; 169: 337-359.

Montgomery SM, Ehlin AG, Ekbom A, Wakefield AJ. Pertussis infection in childhood and subsequent type 1 diabetes mellitus. Diabet Med. 2002 Dec;19(12):986-93.

Tammelin T, Näyhä S, Laitinen J, Rintamäki H, Järvelin MR. Physical activity and social status in adolescence as predictors of physical inactivity in adulthood. Prev Med. 2003 Oct;37(4):375-81. 
Power C, Frank J, Hertzman C, Schierhout G, Li L. Predictors of low back pain onset in a prospective British study. Am J Public Health. 2001 Oct;91(10):1671-8.

Ehlin AG, Montgomery SM, Ekbom A, Pounder RE, Wakefield AJ. Prevalence of gastrointestinal diseases in two British national birth cohorts. Gut. 2003 Aug;52(8):1117-21.

Montgomery SM, Morris DL, Thompson NP, Subhani J, Pounder RE, Wakefield AJ. Prevalence of inflammatory bowel disease in British 26 year olds: national longitudinal birth cohort. BMJ. 1998 Apr 4;316(7137):1058-9.

Neeleman J, Sytema S, Wadsworth M. Propensity to psychiatric and somatic illhealth: evidence from a birth cohort. Psychol Med. 2002 Jul;32(5):793-803.

Ishihara-Paul L, Wainwright NW, Khaw KT, Luben RN, Welch AA, Day NE, Brayne C, Surtees PG. Prospective association between emotional health and clinical evidence of Parkinson's disease. Eur J Neurol. 2008 Nov;15(11):1148-54.

Matthews S, Power C, Stansfeld SA. Psychological distress and work and home roles: a focus on socio-economic differences in distress. Psychol Med. 2001 May;31(4):725-36.

Surtees PG, Wainwright NW, Luben RN, Wareham NJ, Bingham SA, Khaw KT. Psychological distress, major depressive disorder, and risk of stroke. Neurology. 2008 Mar 4;70(10):788-94.

Rojo-Moreno L, Livianos-Aldana L, Cervera-Martínez G, Dominguez-Carabantes JA. Rearing style and depressive disorder in adulthood: a controlled study in a Spanish clinical sample. Soc Psychiatry Psychiatr Epidemiol. 1999 Oct;34(10):54854.

Tsai CJ, Huang TY. Relation of Helicobacter pylori infection and angiographically demonstrated coronary artery disease. Dig Dis Sci. 2000 Jun;45(6):1227-32.

Milman N, Kirchhoff M. Relationship between serum ferritin, alcohol intake, and social status in 2235 Danish men and women. Ann Hematol. 1996 Mar;72(3):145-51.

Marmot M, Shipley M, Brunner E, Hemingway H. Relative contribution of early life and adult socioeconomic factors to adult morbidity in the Whitehall II study. J Epidemiol Community Health. 2001 May;55(5):301-7.

Hart C, McConnachie A, Upton M, Watt G. Risk factors in the Midspan family study by social class in childhood and adulthood. Int J Epidemiol. 2008 Jun;37(3):604-14.

Whitaker CJ, Dubiel AJ, Galpin OP. Social and geographical risk factors in Helicobacter pylori infection. Epidemiol Infect. 1993 Aug;111(1):63-70.

Braddon FE, Wadsworth ME, Davies JM, Cripps HA. Social and regional differences in food and alcohol consumption and their measurement in a national birth cohort. $\mathrm{J}$ Epidemiol Community Health. 1988 Dec;42(4):341-9. 
Langenberg C, Kuh D, Wadsworth ME, Brunner E, Hardy R. Social circumstances and education: life course origins of social inequalities in metabolic risk in a prospective national birth cohort. Am J Public Health. 2006 Dec;96(12):2216-21.

Borg V, Kristensen TS. Social class and self-rated health: can the gradient be explained by differences in life style or work environment? Soc Sci Med. 2000 Oct;51(7):1019-30.

McFadden E, Luben R, Wareham N, Bingham S, Khaw KT. Social class, risk factors, and stroke incidence in men and women: a prospective study in the European prospective investigation into cancer in Norfolk cohort. Stroke. 2009 Apr;40(4):10707.

Power C, Hertzman C, Matthews S, Manor O. Social differences in health: life-cycle effects between ages 23 and 33 in the 1958 British birth cohort. Am J Public Health. 1997 Sep;87(9):1499-503.

Chandola T, Bartley M, Wiggins R, Schofield P. Social inequalities in health by individual and household measures of social position in a cohort of healthy people. $\mathrm{J}$ Epidemiol Community Health. 2003 Jan;57(1):56-62.

Matthews S, Manor O, Power C. Social inequalities in health: are there gender differences? Soc Sci Med. 1999 Jan;48(1):49-60.

Chandola T. Social inequality in coronary heart disease: a comparison of occupational classifications. Soc Sci Med. 1998 Aug;47(4):525-33.

Boyle PJ, Norman P, Popham F. Social mobility: evidence that it can widen health inequalities. Soc Sci Med. 2009 May;68(10):1835-42.

Moffatt CJ, Franks PJ, Doherty DC, Smithdale R, Martin R. Sociodemographic factors in chronic leg ulceration. Br J Dermatol. 2006 Aug;155(2):307-12.

Chandola T, Head J, Bartley M. Socio-demographic predictors of quitting smoking: how important are household factors? Addiction. 2004 Jun;99(6):770-7.

Jonsson PM, Nyström L, Sterky G, Wall S. Sociodemographic predictors of self-rated health in patients with diabetes of short duration. Scand J Public Health. 2001 Dec;29(4):263-70.

Hagen KB, Holte HH, Tambs K, Bjerkedal T. Socioeconomic factors and disability retirement from back pain: a 1983-1993 population-based prospective study in Norway. Spine (Phila Pa 1976). 2000 Oct 1;25(19):2480-7.

Purslow LR, Young EH, Wareham NJ, Forouhi N, Brunner EJ, Luben RN, Welch AA, Khaw KT, Bingham SA, Sandhu MS. Socioeconomic position and risk of shortterm weight gain: prospective study of 14,619 middle-aged men and women. BMC Public Health. 2008 Apr 9;8:112.

Ellison-Loschmann L, Sunyer J, Plana E, Pearce N, Zock JP, Jarvis D, et al. Socioeconomic status, asthma and chronic bronchitis in a large community-based study. Eur Respir J. 2007 May;29(5):897-905. 
Li C, Hedblad B, Rosvall M, Buchwald F, Khan FA, Engström G. Stroke incidence, recurrence, and case-fatality in relation to socioeconomic position: a population-based study of middle-aged Swedish men and women. Stroke. 2008 Aug;39(8):2191-6.

Leino P. Symptoms of stress predict musculoskeletal disorders. J Epidemiol Community Health. 1989 Sep;43(3):293-300.

Pine DS, Goldstein RB, Wolk S, Weissman MM. The association between childhood depression and adulthood body mass index. Pediatrics. 2001 May;107(5):1049-56.

Heraclides A, Witte D, Brunner EJ. The association between father's social class and adult obesity is not explained by educational attainment and an unhealthy lifestyle in adulthood. Eur J Epidemiol. 2008;23(8):573-9.

Hart CL, Hole DJ, Smith GD. The contribution of risk factors to stroke differentials, by socioeconomic position in adulthood: the Renfrew/Paisley Study. Am J Public Health. 2000 Nov;90(11):1788-91.

Power C, Manor O, Matthews S. The duration and timing of exposure: effects of socioeconomic environment on adult health. Am J Public Health. 1999 Jul;89(7):1059-65.

Albertsen K, Hannerz H, Borg V, Burr H. The effect of work environment and heavy smoking on the social inequalities in smoking cessation. Public Health. 2003 Nov;117(6):383-8.

Marang-van de Mheen PJ, Smith GD, Hart CL. The health impact of smoking in manual and non-manual social class men and women: a test of the Blaxter hypothesis. Soc Sci Med. 1999 Jun;48(12):1851-6.

Hardy R, Wadsworth M, Kuh D. The influence of childhood weight and socioeconomic status on change in adult body mass index in a British national birth cohort. Int J Obes Relat Metab Disord. 2000 Jun;24(6):725-34.

Macfarlane GJ, Norrie G, Atherton K, Power C, Jones GT. The influence of socioeconomic status on the reporting of regional and widespread musculoskeletal pain: results from the 1958 British Birth Cohort Study. Ann Rheum Dis. 2009 Oct;68(10):1591-5.

Howell S, Talley NJ, Quine S, Poulton R. The irritable bowel syndrome has origins in the childhood socioeconomic environment. Am J Gastroenterol. 2004 Aug;99(8):1572-8.

Wessely S, Chalder T, Hirsch S, Wallace P, Wright D. The prevalence and morbidity of chronic fatigue and chronic fatigue syndrome: a prospective primary care study. Am J Public Health. 1997 Sep;87(9):1449-55.

Lehtinen V, Lindholm T, Veijola J, Väisänen E. The prevalence of PSE-CATEGO disorders in a Finnish adult population cohort. Soc Psychiatry Psychiatr Epidemiol. $1990 \mathrm{Jul} ; 25(4): 187-92$. 
Harvey SB, Wadsworth M, Wessely S, Hotopf M. The relationship between prior psychiatric disorder and chronic fatigue: evidence from a national birth cohort study. Psychol Med. 2008 Jul;38(7):933-40.

Huurre $\mathrm{T}$, Aro $\mathrm{H}$, Rahkonen $\mathrm{O}$. Well-being and health behaviour by parental socioeconomic status: a follow-up study of adolescents aged 16 until age 32 years. Soc Psychiatry Psychiatr Epidemiol. 2003 May;38(5):249-55.

Hagen KB, Tambs K, Bjerkedal T. What mediates the inverse association between education and occupational disability from back pain?--A prospective cohort study from the Nord-Trøndelag health study in Norway. Soc Sci Med. 2006 Sep;63(5):1267-75.

Brunner E, Shipley MJ, Blane D, Smith GD, Marmot MG. When does cardiovascular risk start? Past and present socioeconomic circumstances and risk factors in adulthood. J Epidemiol Community Health. 1999 Dec;53(12):757-64.

Borg V, Kristensen TS, Burr H. Work environment and changes in self-rated health : A five year follow-up study. Stress medicine. 2000; 16(1):37-47. 


\section{APÊNDICE V \\ Referências não localizadas na íntegra (ordenado de acordo com o título)}

Sacker A, Wiggins RD. Age-period-cohort effects on inequalities in psychological distress, 1981-2000. Psychol Med. 2002 Aug;32(6):977-90.

Nilsson P, Ostergren PO, Lindholm L, Scherstén B. Can social class differentials in hypertension be explained by the general susceptibility hypothesis? Soc Sci Med. 1994 May;38(9):1235-42.

Charney E, Goodman HC, McBride M, Lyon B, Pratt R. Childhood antecedents of adult obesity. Do chubby infants become obese adults? N Engl J Med. 1976 Jul 1;295(1):6-9.

Thomsen JL. Chronic alcoholism in a forensic material. 1. Social parameters in alcoholics. Med Sci Law. 1996 Jul;36(3):199-208.

Kiernan KE, Colley JR, Douglas JW, Reid DD. Chronic cough in young adults in relation to smoking habits, childhood environment and chest illness. Respiration. 1976;33(3):236-44.

Ekesbo R, Nilsson PM, Lindholm LH, Persson K, Wadström T. Combined seropositivity for $\mathrm{H}$. pylori and C. pneumoniae is associated with age, obesity and social factors. J Cardiovasc Risk. 2000 Jun;7(3):191-5.

Woodward M, Bolton-Smith C, Tunstall-Pedoe H. Deficient health knowledge, diet, and other lifestyles in smokers: is a multifactorial approach required? Prev Med. 1994 May;23(3):354-61.

Shaar KH, McCarthy M, Meshefedjian G. Disadvantage in physically disabled adults: an assessment of the causation and selection hypotheses. Soc Sci Med. 1994 Aug;39(3):407-13.

Sweeting HN, West PB. Drug use over the youth-adult transition in a west of Scotland cohort: Prevalence, pathways and socio-demographic correlates. Addiction Research \& Theory. 2008; 16(5):474-494.

Kolacek S, Kapetanović T, Luzar V. Early determinants of cardiovascular risk factors in adults . Blood pressure. Acta Paediatr. 1993 Apr;82(4):377-82.

Lloyd CE, Robinson N, Fuller JH. Education and employment experiences in young adults with type 1 diabetes mellitus. Diabet Med. 1992 Aug-Sep;9(7):661-6.

Badr II, Farghaly AG, Koura MR, Mohamed HF, Hassan EM, Kotkat AM. Health status assessment of drug addicts in Alexandria. J Egypt Public Health Assoc. 1998;73(3-4):275-96. 
Agréus L, Engstrand L, Svärdsudd K, Nyrén O, Tibblin G. Helicobacter pylori seropositivity among Swedish adults with and without abdominal symptoms. A population-based epidemiologic study. Scand J Gastroenterol. 1995 Aug;30(8):752-7.

Frery N, Chavance M, Valette I, Schaffar L, Neisson-Vernant C, Jouannelle J, Monplaisir N. HTLV-I infection in French West Indies: a case-control study. Eur J Epidemiol. 1991 Mar;7(2):175-82.

Jørgensen LM, Sørensen TI, Schroll M, Larsen S. Influence of dietary factors on weight change assessed by multivariate graphical models. Int J Obes Relat Metab Disord. 1995 Dec;19(12):909-15.

Suarez L, Barrett-Connor E. Is an educated wife hazardous to your health? Am J Epidemiol. 1984 Feb;119(2):244-9.

Shedlack K, Lee G, Sakuma M, Xie SH, Kushner M, Pepple J, Finer DL, Hoff AL, DeLisi LE. Language processing and memory in ill and well siblings from multiplex families affected with schizophrenia. Schizophr Res. 1997 May 3;25(1):43-52.

Holland P, Berney L, Blane D, Smith GD, Gunnell DJ, Montgomery SM. Life course accumulation of disadvantage: childhood health and hazard exposure during adulthood. Soc Sci Med. 2000 May;50(9):1285-95.

Rastogi SK, Gupta BN, Husain T, Pangtey BS, Srivastava S, Garg N. Long-term effects of soldering fumes upon respiratory symptoms and pulmonary function. Ann Occup Hyg. 1991 Jun;35(3):299-307.

Bauer MS, Calabrese J, Dunner DL, Post R, Whybrow PC, Gyulai L, Tay LK, Younkin SR, Bynum D, Lavori P, et al. Multisite data reanalysis of the validity of rapid cycling as a course modifier for bipolar disorder in DSM-IV. Am J Psychiatry. 1994 Apr;151(4):506-15.

Aro S, Hasan J. Occupational class, psychosocial stress and morbidity. Ann Clin Res. 1987;19(2):62-8.

Montgomery SM, Morris DL, Pounder RE, Wakefield AJ. Paramyxovirus infections in childhood and subsequent inflammatory bowel disease. Gastroenterology. 1999 Apr;116(4):796-803.

Breuer-Katschinski BD, Bracht J, Tietjen-Harms S, Goebell H. Physical activity at work and the risk of chronic pancreatitis. Eur J Gastroenterol Hepatol. 1996 Apr;8(4):399-402.

Kanner RE, Renzetti AD Jr, Stanish WM, Barkman HW Jr, Klauber MR. Predictors of survival in subjects with chronic airflow limitation. Am J Med. 1983 Feb;74(2):249-55.

Cordray SM, Polk KR, Britton BM. Premilitary antecedents of post-traumatic stress disorder in an Oregon cohort. J Clin Psychol. 1992 May;48(3):271-80. 
Yaqoob M, Bell GM, Percy DF, Finn R. Primary glomerulonephritis and hydrocarbon exposure: a case-control study and literature review. Q J Med. 1992 May;83(301):409-18.

Kuh DL, Power C, Rodgers B. Secular trends in social class and sex differences in adult height. Int J Epidemiol. 1991 Dec;20(4):1001-9.

Heliövaara M, Aho K, Aromaa A, Knekt P, Reunanen A. Smoking and risk of rheumatoid arthritis. J Rheumatol. 1993 Nov;20(11):1830-5.

Logan RF, Edmond M, Somerville KW, Langman MJ. Smoking and ulcerative colitis. Br Med J. 1984; 288:751-753.

Power C. Social and economic background and class inequalities in health among young adults. Soc Sci Med. 1991;32(4):411-7.

Robinson N, Edouard L, Diehl A, Fuller JH. Social class and risk factors for vascular disease in diabetes. Diabete Metab. 1984 Oct;10(4):245-9.

Wiersma D, Giel R, De Jong A, Slooff CJ. Social class and schizophrenia in a Dutch cohort. Psychol Med. 1983 Feb;13(1):141-50.

Fabrega H Jr, Ulrich R, Cornelius J. Sociocultural and clinical characteristics of patients with comorbid depressions: a comparison of substance abuse and nonsubstance abuse diagnoses. Compr Psychiatry. 1993 Sep-Oct;34(5):312-21.

Plouvier S, Leclerc A, Chastang JF, Bonenfant S, Goldberg M. Socioeconomic position and low-back pain--the role of biomechanical strains and psychosocial work factors in the GAZEL cohort. Scand J Work Environ Health. 2009 Dec;35(6):429-36.

Wessely SC, Castle D, Douglas AJ, Taylor PJ. The criminal careers of incident cases of schizophrenia. Psychol Med. 1994 May;24(2):483-502.

Egan VG, Crawford JR, Brettle RP, Goodwin GM. The Edinburgh cohort of HIVpositive drug users: current intellectual function is impaired, but not due to early AIDS dementia complex. AIDS. 1990 Jul;4(7):651-6.

Reister G, Tress W, Schepank H, Manz R, Sollors-Mossler B. The epidemiology of psychogenic disorders and consequences for prevention. Psychother Psychosom. 1989;52(1-3):10-20.

Vanderpump MP, Tunbridge WM, French JM, Appleton D, Bates D, Clark F, et al. The incidence of thyroid disorders in the community: a twenty-year follow-up of the Whickham Survey. Clin Endocrinol (Oxf). 1995 Jul;43(1):55-68.

Freeman JV, Power C, Rodgers B. Weight-for-height indices of adiposity: relationships with height in childhood and early adult life. Int J Epidemiol. 1995 Oct;24(5):970-6.

Hogh A, Borg V, Mikkelsen KL. Work-related violence as a predictor of fatigue: A 5-year follow-up of the Danish Work Environment Cohort Study. Work \& Stress. 2003;17(2): 182-194. 